\title{
DEVELOPMENT OF UAV DERIVATIVE MDO METHODOLOGY FOR FLIGHT SIMULATION
}

\author{
By \\ Ohyun Kwon \\ Ryerson University, 2012 \\ A thesis \\ Presented to Ryerson University \\ in partial fulfillment of the \\ requirements for the degree of \\ Master Applied Science \\ in the Program of \\ Aerospace Engineering
}

Bachelor of Engineering, Department of Aerospace Engineering

Toronto, Ontario, Canada, 2016

C O Ohyun Kwon 2016 


\section{Author's Declaration}

I hereby declare that I am the sole author of this thesis. This is a true copy of the thesis, including any required final revisions, as accepted by my examiners.

I authorize Ryerson University to lend this thesis to other institutions or individuals for the purpose of scholarly research.

I further authorize Ryerson University to reproduce this thesis by photocopying or by other means, in total or in part, at the request of other institutions or individuals for the purpose of scholarly research.

I understand that my thesis may be made electronically available to the public. 


\title{
Abstract
}

\section{DEVELOPMENT OF UAV DERIVATIVE MDO METHODOLOGY FOR FLIGHT SIMULATION}

\author{
Ohyun Kwon \\ Master of Applied Science \\ Department of Aerospace Engineering \\ Ryerson University \\ 2016
}

An integrated methodology for the design of an Unmanned Aerial Vehicle (UAV) derivative has been developed. The proposed methodology utilized the Multidisciplinary Design Optimization (MDO) for the derivative optimization and utilized flight simulation for virtual flight tests. Derivative design reduced the development time and the use of flight simulator allowed quick verification of the results. In this research, Found Aircraft Expedition E350 aircraft was selected as the baseline for the UAV derivative. Empirical equations were used for the optimization process where the results were organized for easy transformation into a flight simulation model. An in house program was developed to convert raw simulation data for flight-data analysis. The optimization result yielded an improvement on the endurance of the aircraft. The flight simulation result for the original aircraft demonstrated agreement with the chosen aircraft. The application of the process demonstrated that using MDO and flight simulation was a viable method for developing a UAV derivative. 


\section{Acknowledgments}

I thank my advisor, Dr. Joon Chung for his patience and guidance.

I also thank my family and friends for their support, especially my colleagues in the MIMS facility. 


\section{Table of Contents}

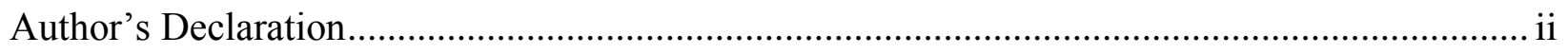

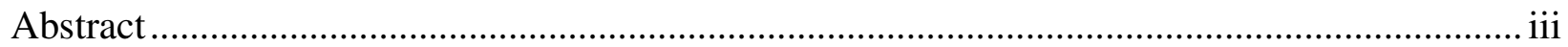

Acknowledgments............................................................................................................... iv

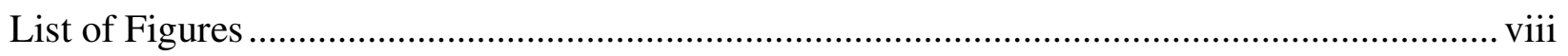

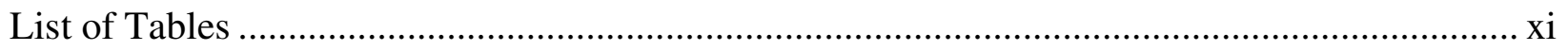

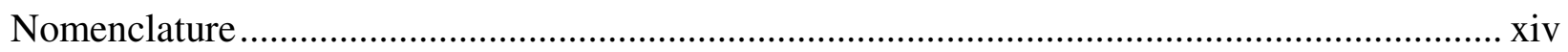

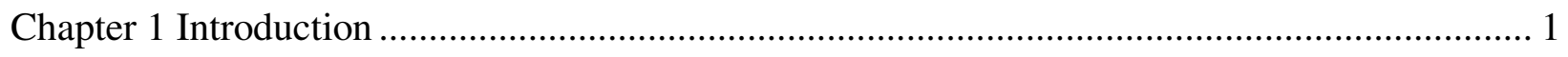

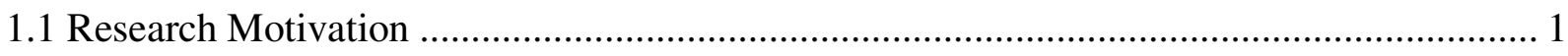

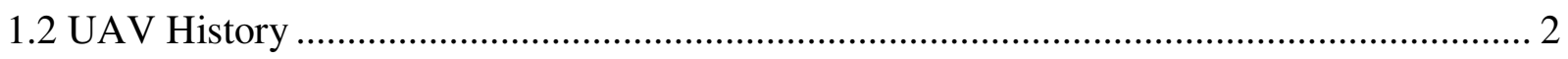

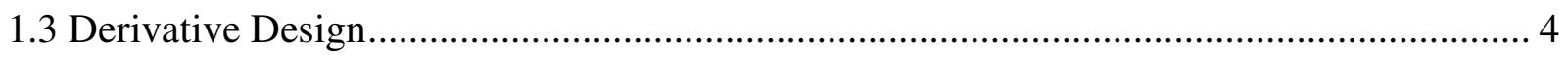

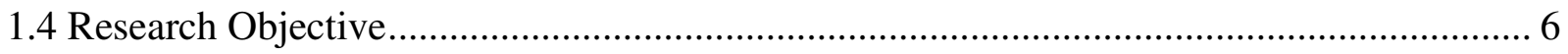

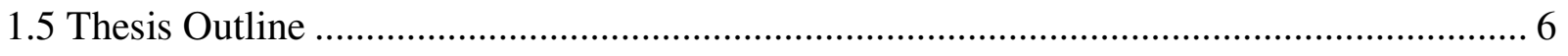

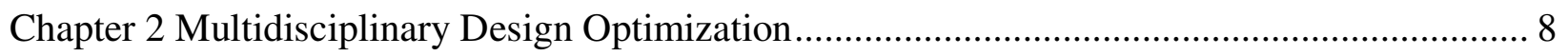

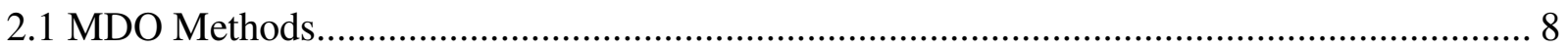

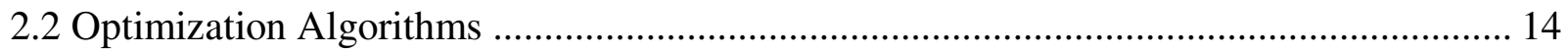

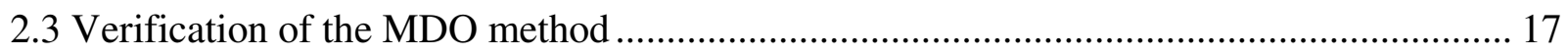

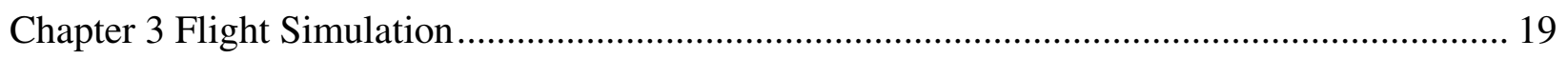

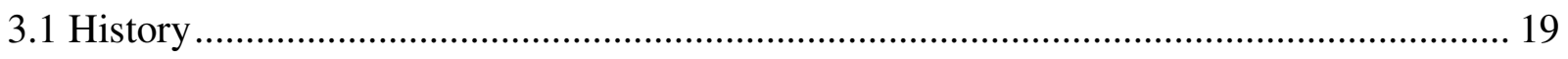




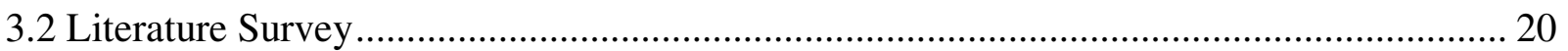

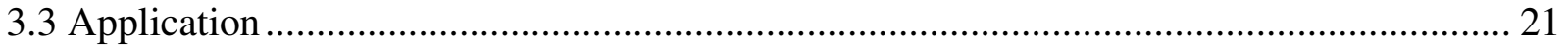

Chapter 4 UAV Derivative MDO Methodology for Flight Simulation......................................... 29

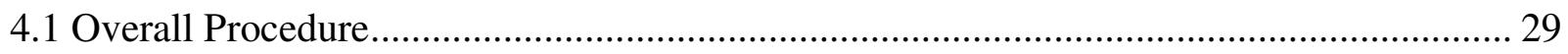

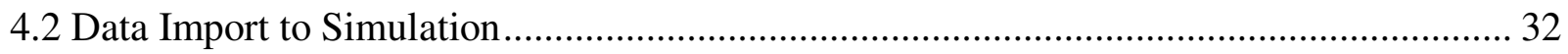

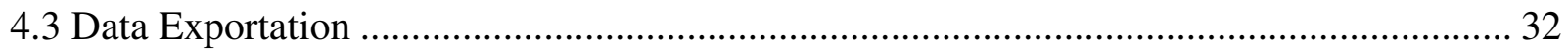

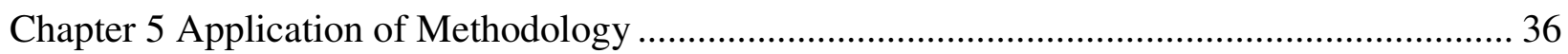

5.1 Mission Definition and Aircraft Selection ...................................................................... 36

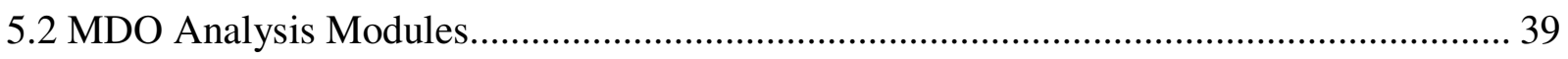

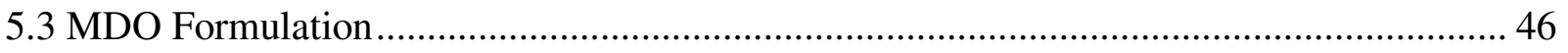

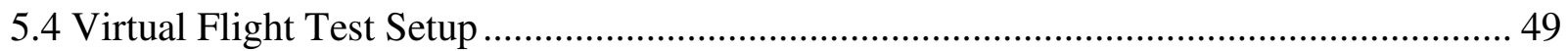

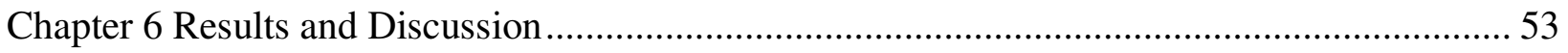

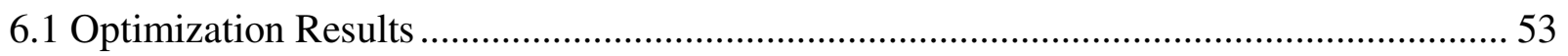

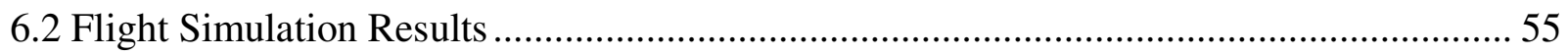

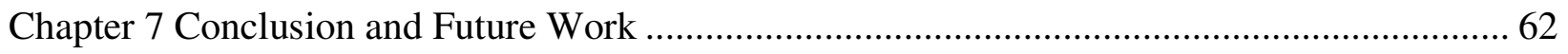

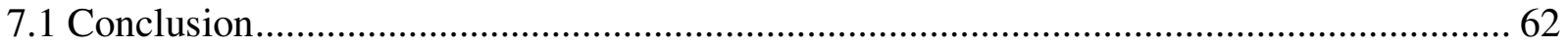

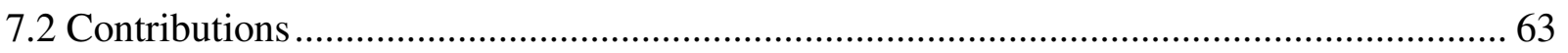

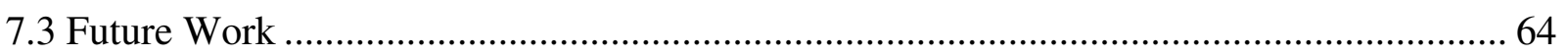

Appendix A - UAV: Civilian mission - technology allocation table ............................................ 66

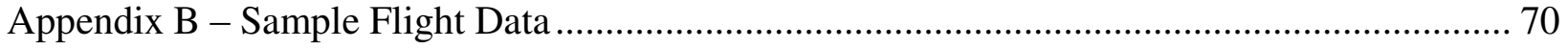


Appendix D - Cruise Performance at different altitudes, 2600RPM .................................... 73

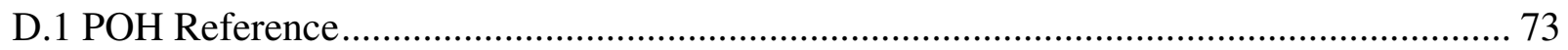

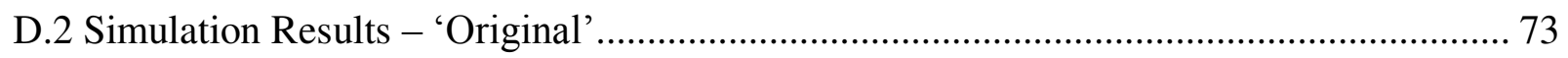

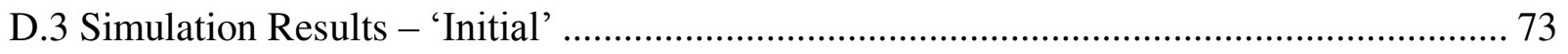

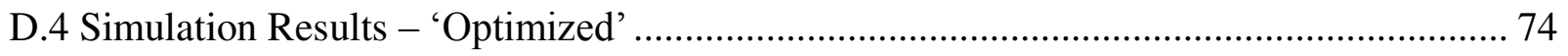

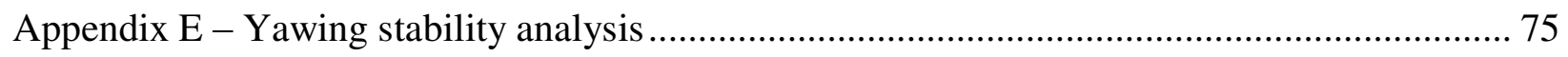

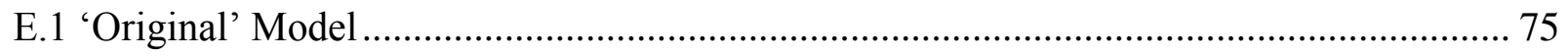

E.2 'Initial' Model....................................................................................................... 76

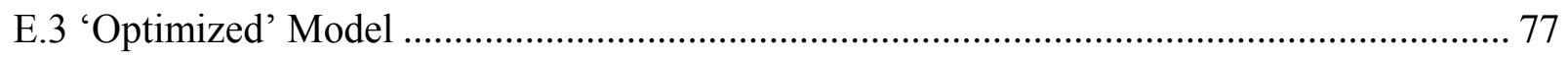

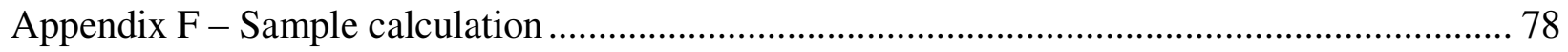

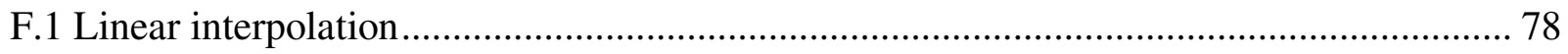

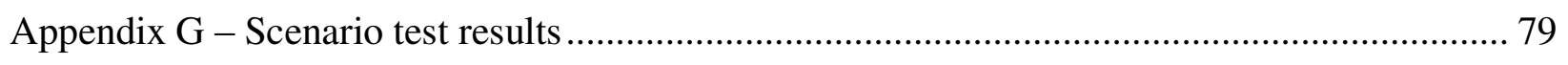

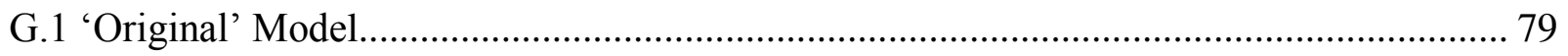

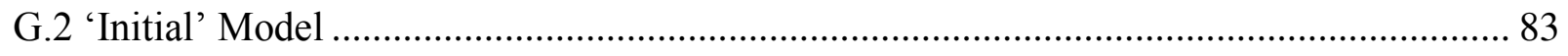

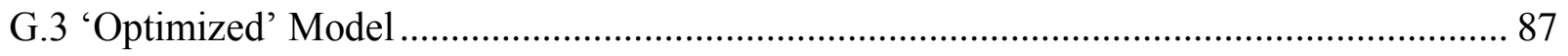

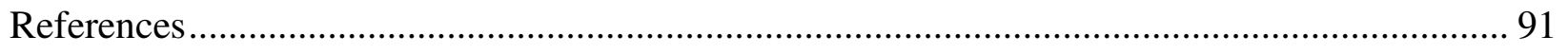




\section{List of Figures}

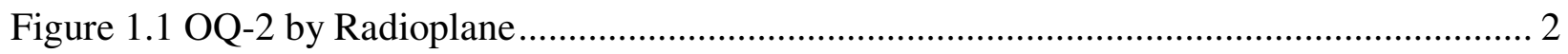

Figure 1.2 Example of commercial and civil UAV ................................................................ 4

Figure 1.3 Derivatives of Diamond aircraft's DA42 …………............................................ 5

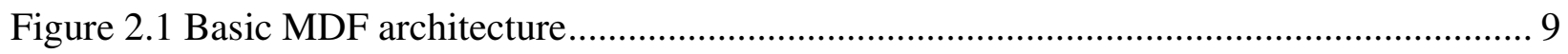

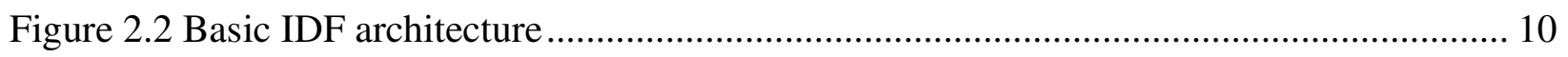

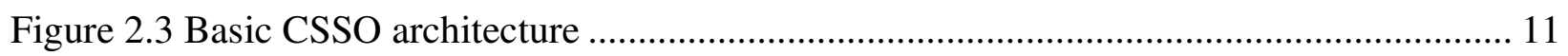

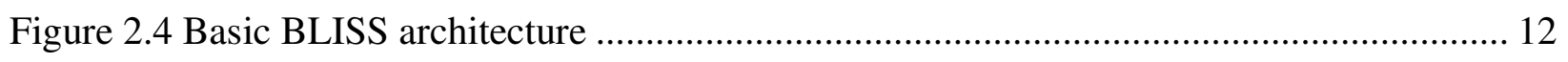

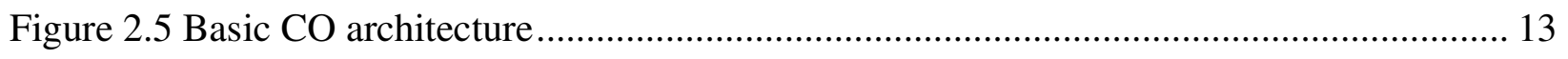

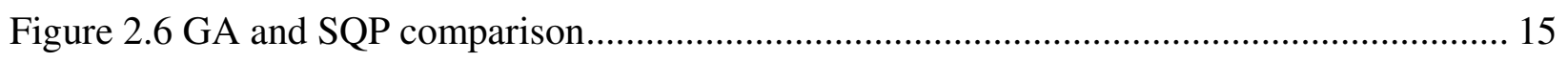

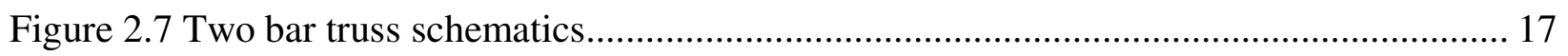

Figure 3.1 Typical composition of a flight simulation system ……………………………...... 21

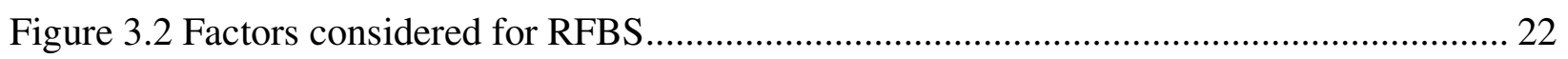

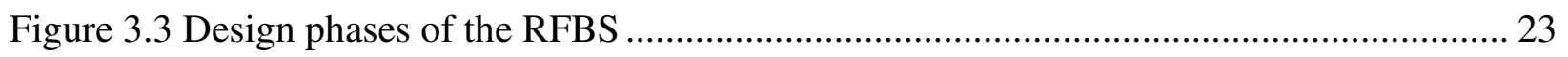

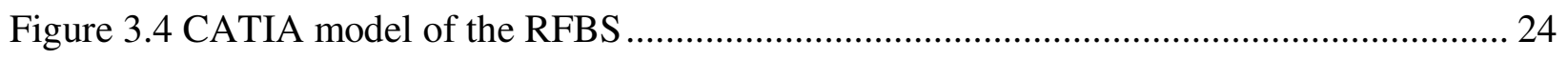

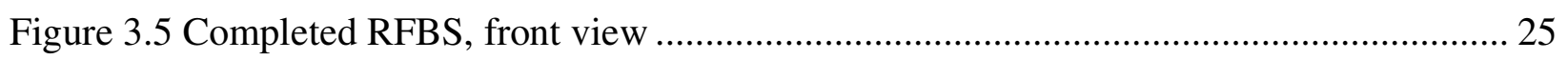

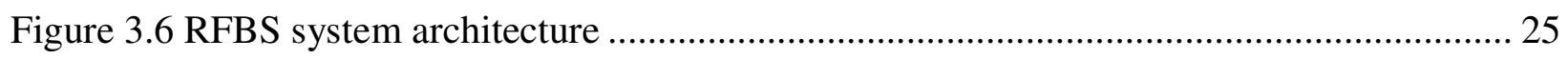

Figure 4.1 UAV derivative MDO methodology for flight simulation .......................................... 31

Figure 4.2 Example of input of optimization result to PlaneMaker ............................................. 32

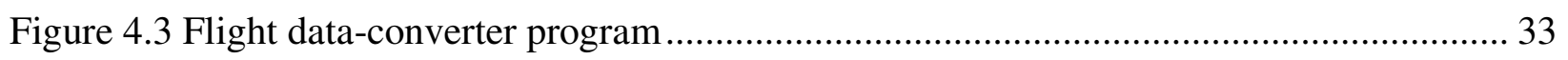

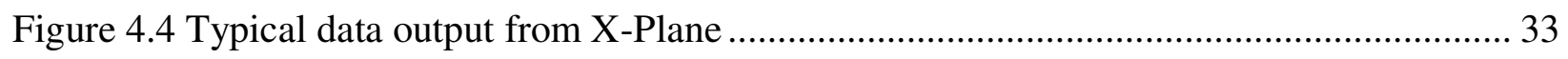

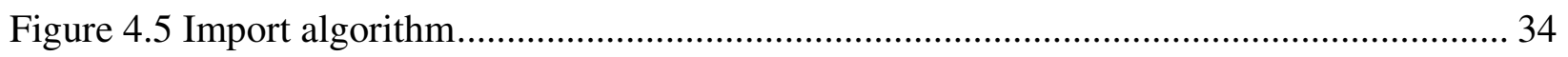




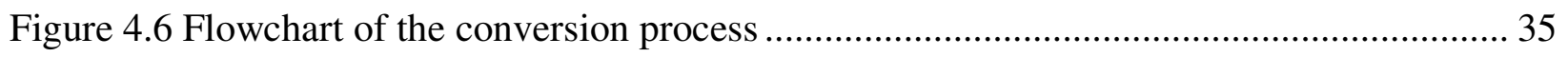

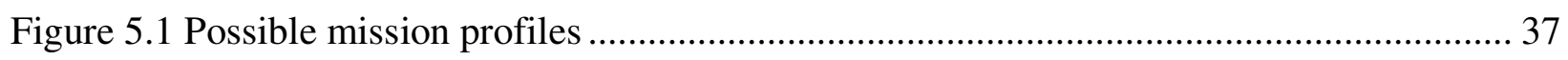

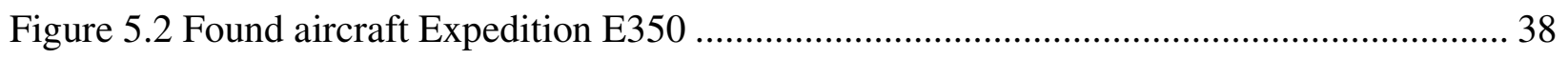

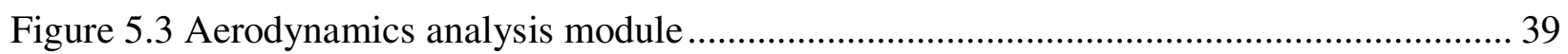

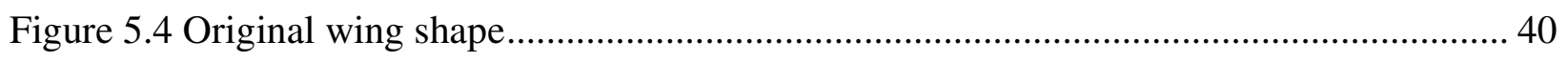

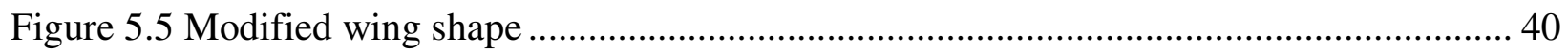

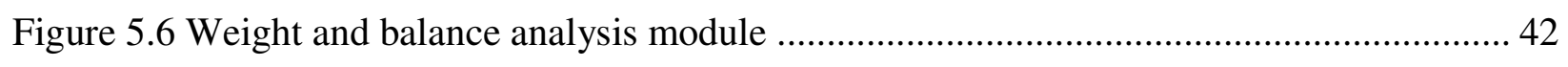

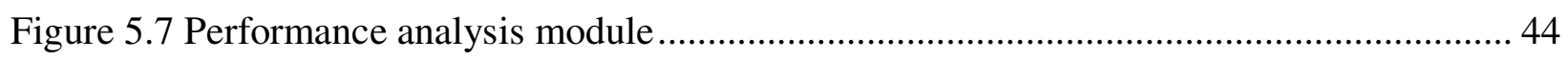

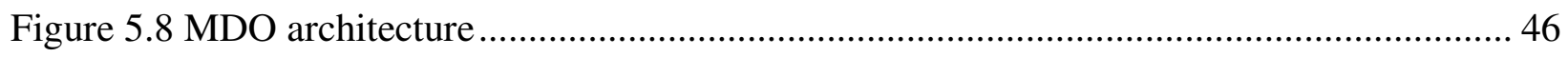

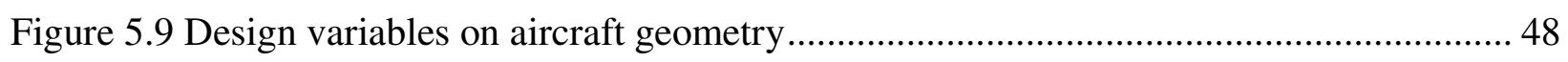

Figure 5.10 'Original', 'Initial' and 'Optimized' aircraft models from left to right ................... 49

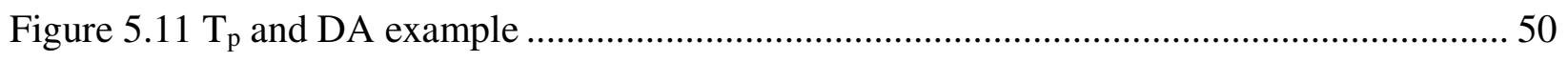

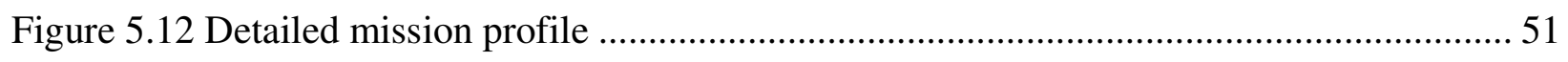

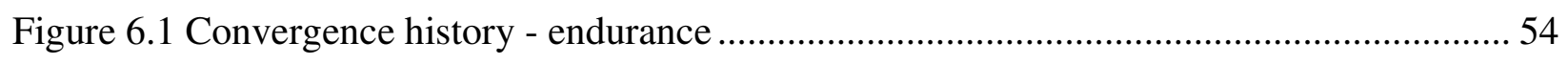

Figure 6.2 Front, side, top view of the optimized UAV ................................................. 54

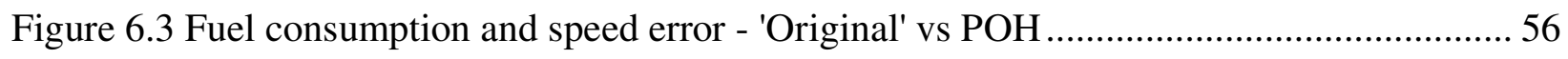

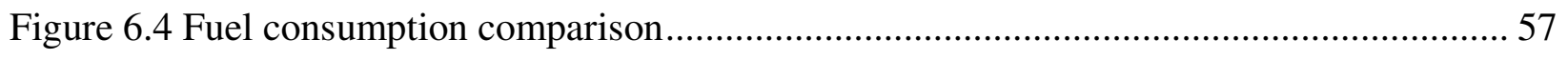

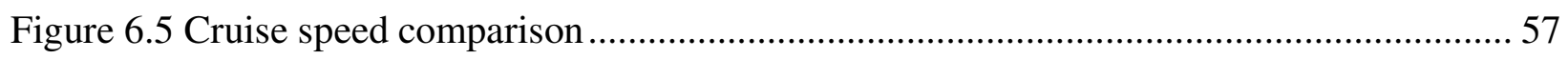

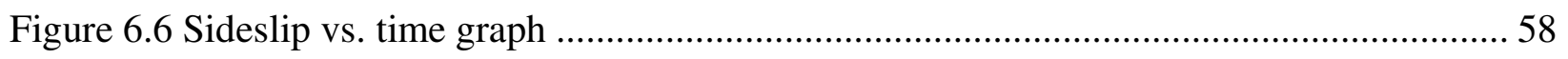

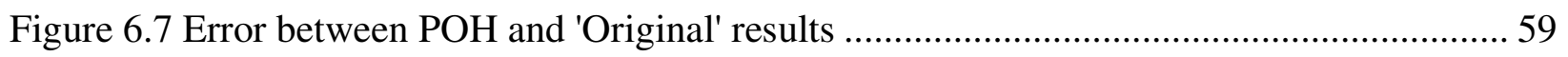

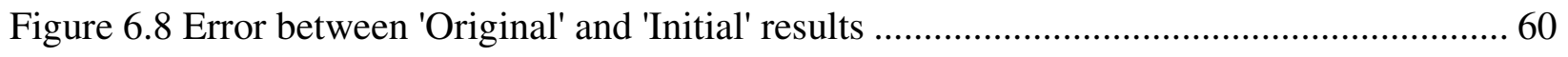

Figure 6.9 Error between numerical and simulated results........................................... 61

Figure E.1 Sideslip vs time graph of 'Original' model ..................................................... 75 
Figure E.2 Sideslip vs time graph of 'Initial' model........................................................ 76

Figure E.3 Sideslip vs time graph of 'Optimized' model ................................................... 77 


\section{List of Tables}

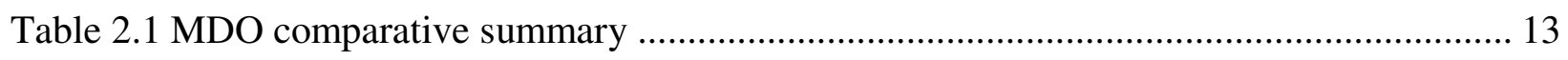

Table 2.2 Initial value of each variable for both tests .............................................................. 15

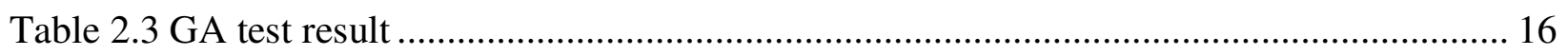

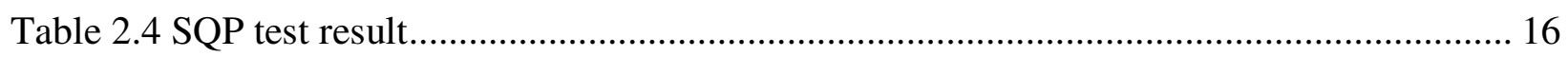

Table 2.5 Convergence time average for both algorithms ...................................................... 16

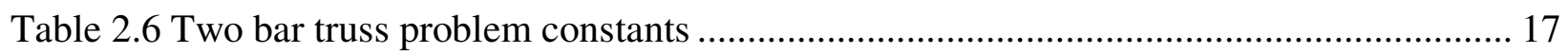

Table 2.7 Two bar truss problem variables and boundaries ..................................................... 18

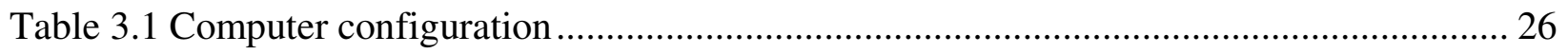

Table 5.1 Performance specification of Expedition E350 ….................................................... 38

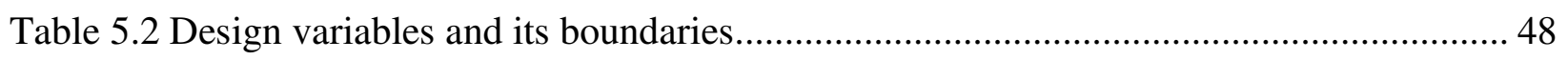

Table 5.3 Selected airports for scenario test flight ………………………………………….... 51

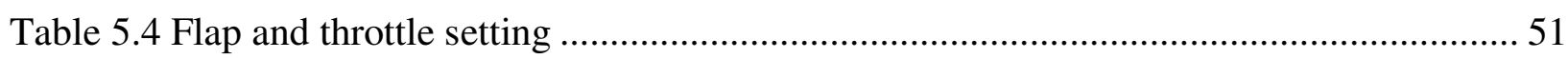

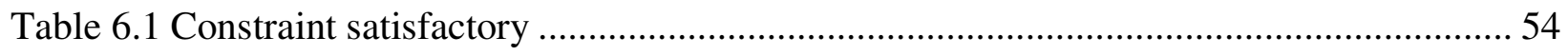

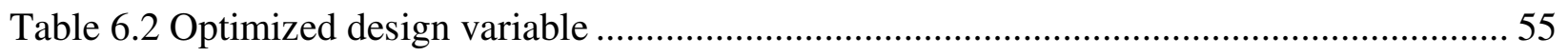

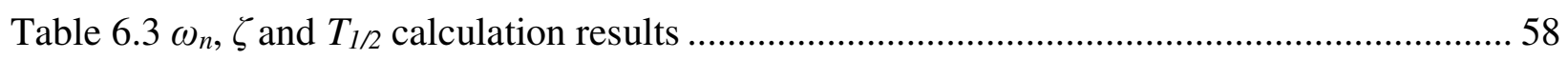

Table 6.4 Virtual flight test result comparison - POH \& 'Original' ............................................. 59

Table 6.5 Virtual flight test result comparison - 'Original' \& 'Initial' .......................................... 60

Table 6.6 Virtual flight test result comparison - numerical \& simulated....................................... 61

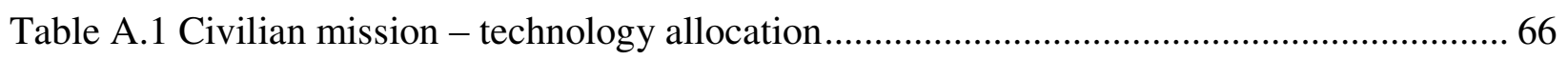

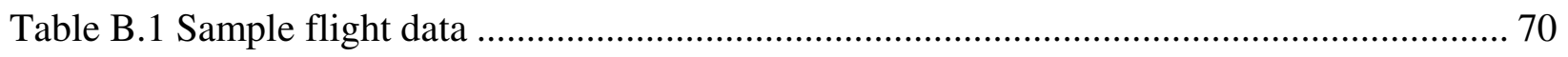

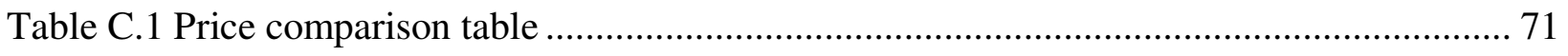




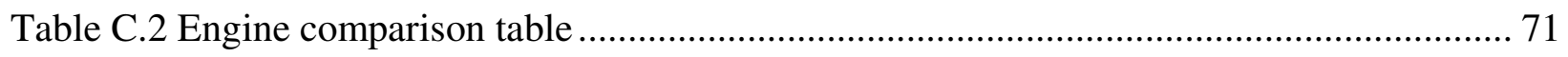

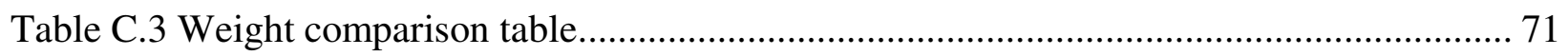

Table C.4 Takeoff distance over a 50ft obstacle at gross weight @ sea level ............................... 72

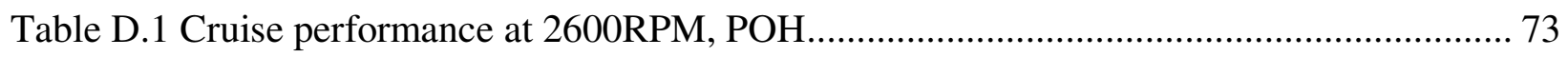

Table D.2 Cruise performance at 2600RPM, 'Original' simulated .............................................. 73

Table D.3 Cruise performance at 2600RPM, 'Initial' simulated .................................................. 73

Table D.4 Cruise performance at 2600RPM, 'Optimized' simulated............................................. 74

Table E.1 Variables used for $\omega_{n}, \zeta$ and $T_{1 / 2}$ calculation - 'Original' .......................................... 75

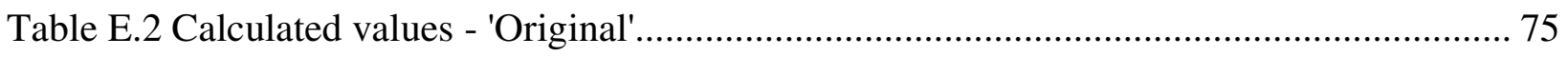

Table E.3 Variables used for $\omega_{n}, \zeta$ and $T_{1 / 2}$ calculation - 'Initial'................................................ 76

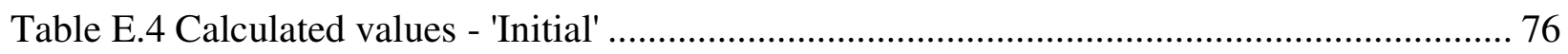

Table E.5 Variables used for $\omega_{n}, \zeta$ and $T_{1 / 2}$ calculation - 'Optimized' ........................................ 77

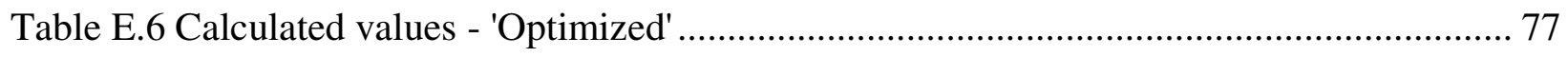

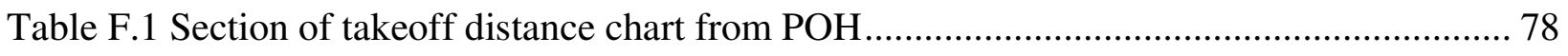

Table G.1 Scenario test result - 'Original' - Flight 1 ……....................................................... 79

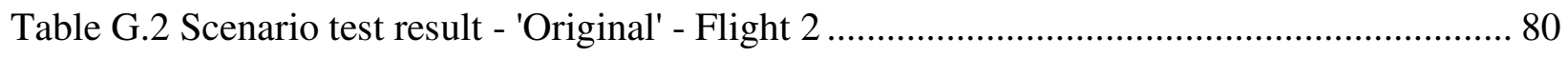

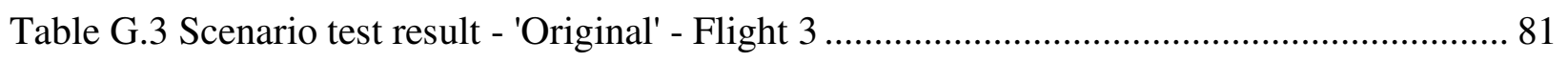

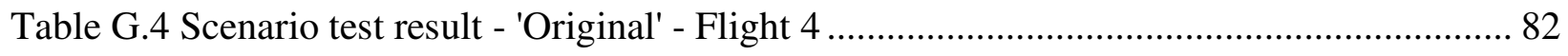

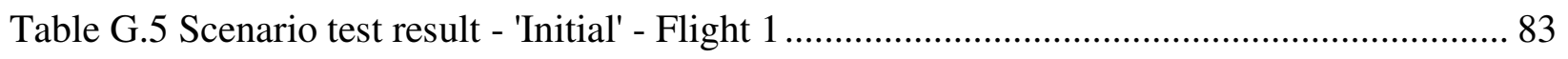

Table G.6 Scenario test result - 'Initial' - Flight 2 ……................................................................ 84

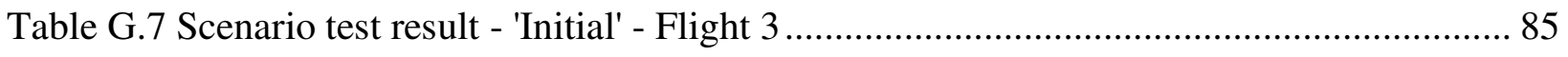

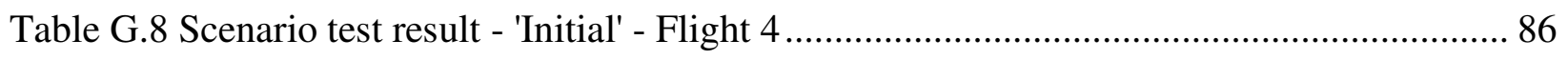

Table G.9 Scenario test result - 'Optimized' - Flight 1................................................................. 87 
Table G.10 Scenario test result - 'Optimized' - Flight 2 ................................................. 88

Table G.11 Scenario test result - 'Optimized' - Flight 3.................................................. 89

Table G.12 Scenario test result - 'Optimized' - Flight 4.................................................. 90 


\title{
Nomenclature
}

\author{
Acronyms
}

\begin{tabular}{ll} 
AAO & All At Once \\
AC & Aerodynamic Centre \\
AFFTC & Air Force Flight Test Center \\
BLISS & Bi-Level Integrated System Synthesis \\
BSFC & Break Specific Fuel Consumption \\
CAPECON & Civil Applications and Economical efficiency of potential UAV Configuration \\
CFD & Computational Fluid Dynamics \\
CG & Centre of Gravity \\
CO & Collaborative Optimization \\
CSSO & Concurrent Sub-Space Optimization \\
FAA & Federal Aviation Administration \\
FDR & Flight Data Recorder \\
FPS & Frames Per Second \\
FSX & Flight Simulator X \\
GA & Genetic Algorithm \\
GMT & Greenwich Mean Time \\
GUI & Graphic User Interface \\
HDD & Hard Disk Drive \\
HMI & Human Machine Interface \\
HS & Horizontal Stabilizer \\
\hline
\end{tabular}




$\begin{array}{ll}\text { IDF } & \text { Individual Discipline Feasible } \\ \text { LAN } & \text { Local Area Network } \\ \text { LSA } & \text { Light Sport Aircraft } \\ \text { MDF } & \text { Multi-Discipline Feasible } \\ \text { MDO } & \text { Multidisciplinary Design Optimization } \\ \text { MIMS } & \text { Mixed-reality Immersive Motion Simulator } \\ \text { OPV } & \text { Optionally Piloted Vehicle } \\ \text { POH } & \text { Pilot's Operating Handbook } \\ \text { RFBS } & \text { Ryerson Fixed Base Simulator } \\ \text { RFMS } & \text { Ryerson Full-Motion Simulator } \\ \text { RPM } & \text { Revolutions Per Minute } \\ \text { SQP } & \text { Sequential Quadratic Programming } \\ \text { SSD } & \text { Solid State Drive } \\ \text { TEMS } & \text { Test and Evaluation Modeling and Simulation } \\ \text { TPR } & \text { Transient Peak Ratio } \\ \text { UAV } & \text { Unmanned Aerial Vehicle }\end{array}$

\section{Greek Symbols}

$\begin{array}{ll}\alpha_{w} & \text { Angle of attack of the wing } \\ \varepsilon_{h s} & \text { Downwash angle } \\ \zeta & \text { Damping ratio } \\ \eta_{p r} & \text { Propeller efficiency } \\ \theta & \text { Angle of flight path from liftoff position to } 50 \mathrm{ft} \text { obstacle }\end{array}$




$\begin{array}{ll}\Lambda_{h s} & \text { Horizontal stabilizer sweep back angle } \\ \Lambda_{v s} & \text { Vertical stabilizer sweep back angle } \\ \Lambda_{w} & \text { Wing sweep back angle } \\ \lambda_{h s} & \text { Horizontal stabilizer tapered ratio } \\ \lambda_{v s} & \text { Vertical stabilizer tapered ratio } \\ \lambda_{w} & \text { Wing tapered ratio } \\ \mu & \text { Runway friction coefficient } \\ \pi & \text { 3.14159 } \\ \rho & \text { Material density } \\ \sigma & \text { Stress } \\ \sigma_{b u c k l i n g} & \text { Buckling stress } \\ \sigma_{y i e l d} & \text { Yield stress } \\ \omega_{n} & \text { Natural frequency }\end{array}$

\section{Other Symbols}

$\begin{array}{ll}A R_{w} & \text { Wing aspect ratio } \\ B & \text { Base width of the two bar truss } \\ b_{h s} & \text { Horizontal stabilizer span } \\ b_{w} & \text { Wing span } \\ C_{D_{c r u i s e}} & \text { Drag coefficient at cruising } \\ C_{D_{w}} & \text { Wing drag coefficient } \\ C_{d_{w}} & \text { Two dimensional wing drag coefficient } \\ C_{D_{o_{w}}} & \text { Wing form drag coefficient }\end{array}$




\begin{tabular}{|c|c|}
\hline$C_{L_{\text {cruise }}}$ & Lift coefficient at cruising \\
\hline$C_{L_{w}}$ & Wing lift coefficient \\
\hline$C_{l_{w}}$ & Two dimensional wing lift coefficient \\
\hline$C_{M_{w}}$ & Wing moment coefficient \\
\hline$C_{m_{w}}$ & Two dimensional wing moment coefficient \\
\hline$c_{r_{w}}$ & Wing root chord \\
\hline$c_{t_{h s}}$ & Horizontal stabilizer tip chord \\
\hline$c_{t_{w}}$ & Wing tip chord \\
\hline $\bar{c}_{w}$ & Mean aerodynamic chord \\
\hline$C G_{x}$ & Centre of gravity $-\mathrm{x}$ axis \\
\hline$D$ & Tube diameter for the two bar truss \\
\hline $\bar{D}$ & Drag at mean kinetic energy airspeed \\
\hline$D A$ & Peak to trough distance \\
\hline$D_{\text {fuse }}$ & Fuselage depth \\
\hline$D_{w}$ & Wing drag \\
\hline E & Young's modulus \\
\hline$e_{w}$ & Oswald efficiency factor \\
\hline$H$ & Truss height \\
\hline$i_{w}$ & Wing incidence angle \\
\hline$K_{w}$ & Induced drag factor \\
\hline $\bar{L}$ & Lift at mean kinetic energy airspeed \\
\hline$L_{\text {fuse }}$ & Fuselage length \\
\hline
\end{tabular}


$l_{t} \quad$ Distance between the $x_{c g}$ and horizontal stabilizer mean aerodynamic chord

$L_{t} \quad$ Distance between the mean aerodynamic chord of the wing to the horizontal stab.

$L_{\text {total }} \quad$ Total lift generated by aircraft

$L_{w} \quad$ Wing lift

$M_{a c_{h s}} \quad$ Horizontal stabilizer moment

$M_{a c_{w}} \quad$ Wing moment on $\mathrm{AC}$

$M_{C G_{\text {long }}} \quad$ Net longitudinal moment

$M_{C G_{w}} \quad$ Wing moment on CG

$M_{w} \quad$ Wing moment

$N \quad$ Number of peaks

$N_{e n} \quad$ Number of engine

$N_{p a r} \quad$ Number of parameters in imported flight data

$N_{\text {row }} \quad$ Number of rows in imported flight data

$N_{z} \quad$ Limit load factor

$P \quad$ Load applied to the two bar truss

$q \quad$ Dynamic pressure

$R \quad$ Turn radius

$R_{\text {cruise }} \quad$ Cruise range

$S_{f} \quad$ Fuselage wetted area

$S_{h s} \quad$ Horizontal stabilizer surface area

$S_{T O} \quad$ Takeoff distance

$S_{T O A} \quad$ Takeoff distance, airborne portion

$S_{T O G} \quad$ Takeoff distance, ground roll portion 


\begin{tabular}{|c|c|}
\hline$S_{v s}$ & Vertical stabilizer surface area \\
\hline$S_{w}$ & Wing surface area \\
\hline $\bar{T}$ & Thrust at mean kinetic energy airspeed \\
\hline$T_{1 / 2}$ & Time to half amplitude \\
\hline$T_{p}$ & Time between peaks \\
\hline$t$ & Tube wall thickness for the two bar truss \\
\hline$t / c$ & Thickness to chord ratio \\
\hline$V_{L O F}$ & Liftoff velocity \\
\hline$W_{d g}$ & Design gross weight \\
\hline$W_{\text {empty }}$ & Empty weight of an aircraft \\
\hline$W_{e n}$ & Weight of uninstalled engine \\
\hline$W_{\text {en,installed }}$ & Weight of installed engine \\
\hline$W_{\text {fin }}$ & Final aircraft weight (after flight) \\
\hline$W_{\text {fuse }}$ & Fuselage weight \\
\hline$W_{F_{W}}$ & Fuel weight in wing \\
\hline$W_{h s}$ & Horizontal stabilizer weight \\
\hline$W_{i n i}$ & Initial aircraft weight (before flight) \\
\hline$W_{p l}$ & Payload weight \\
\hline$W_{\text {sum }}$ & Total takeoff weight \\
\hline$W_{v s}$ & Vertical stabilizer weight \\
\hline$W_{w}$ & Wing weight \\
\hline$x_{a c}$ & Location of $\mathrm{AC}$ from the reference point \\
\hline$x_{c g}$ & Location of CG from the reference point \\
\hline
\end{tabular}


$x_{b w_{F}} \quad$ Rear wall location from nose for fuselage fuel tank

$x_{b w_{p l}} \quad$ Rear wall location from nose for payload bay

$x_{f w_{F}} \quad$ Forward wall location from nose for fuselage fuel tank

$x_{f w_{p l}} \quad$ Forward wall location from nose for payload bay

$z_{c g} \quad$ Location of $\mathrm{CG}$ from reference $\mathrm{x}$ axis

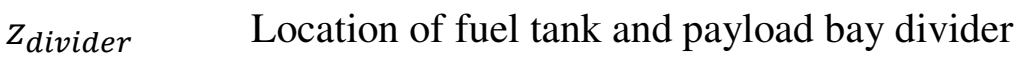




\section{Chapter 1 Introduction}

\subsection{Research Motivation}

The modern aircraft design process has often relied highly on past designs, or derivative designs [1]. Extensive information on how to design an airplane accumulated throughout aviation history. Engineers designed and built aircraft using existing historical resources; however, the design method was different for the Unmanned Aerial Vehicles (UAV). Engineers lacked information due to the UAVs short heritage. To overcome this problem, a possible method was to use the base design of an existing aircraft and then optimize it to meet certain requirements, instead of creating a new design. This derivative design process had certain advantages over conventional design, which was explained in section 1.3. Once the development of a UAV was completed, a verification process was essential to confirm that all requirements were satisfied. However, it was physically impossible to commence real flight tests because researchers did not own an actual 
aircraft. Nevertheless, the use of flight simulation allowed researchers to perform virtual flight tests in any circumstance. The essence of this thesis was the integration of the derivative design and virtual flight test, while utilizing Multidisciplinary Design Optimization (MDO) and flight simulation simultaneously. Section 1.4 explains the objective of the thesis in detail.

\subsection{UAV History}

The concept of a UAV dates back to the $19^{\text {th }}$ century. Douglas Archibald from England was one of the pioneers of aerial photography, using a camera-attached kite [2]. Although some may dispute that a kite is not technologically sophisticated enough to be classified as UAV, it is unmanned, generates aerodynamic forces and had some type of control just like a UAV. In modern days, a UAV was defined as an aircraft, which was intended to operate with no pilot on board. In the big picture, there were mainly two types of UAV: autonomous controlled aircraft and remotely piloted aircraft [3].

The development of UAV had taken its root from military applications like many other modern technologies. In the early 1900s, Montgomery Low developed the first data link system, and had a successful radio controlled flight in 1924. Soon after, the United States Air Force started using UAVs as a target drones. The OQ-3 a derivative of OQ-2 seen on Figure 1.1 was one of the most famous target drone of the age and over 9000 units served during the World War II [4].

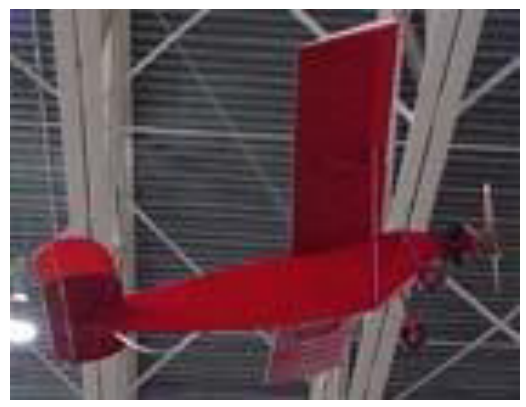

Figure 1.1 OQ-2 by Radioplane [5] 
Meanwhile, the autonomous UAV was developed using gyroscopes as the guidance control. All of the autonomous UAV at the time were used as bombs, because there was no way to change its path of it after the launch. The similarity between early UAVs was that it served a single sortie for their entire lifespan. The concept of recovering the UAV for multiple missions arose decades after.

In the early 1960s, the military elites of the United States began seriously researching UAVs. The highly classified products of this research were deployed in the skies of Vietnam [6]. The value of the UAVs went up as the missions they had undertaken were far more complex than those from earlier days. Recovering the UAV after its mission was crucial as it stored the data retrieved from its reconnaissance mission. The main recovery system used was a parachute and once the vehicle slowed down after parachute deployment, a helicopter specifically made for recovery missions recovered it. This efficient method had a $90 \%$ of success rates during the war [7].

After the terrorist attacks of the September 11, 2001, the UAV industry took big strides forward with the introduction of attacking UAVs, along with reconnaissance UAVs [8]. Around the same time, 'Civil Applications and Economical efficiency of potential UAV Configuration' (CAPECON) program of Europe had a vision of a growing market in the civilian sector. Their vision was "Within 10 years UAVs will be operated within civilian airspace on behalf of many civilian \& commercial missions" [9]. Throughout the decade, researches tried to find various civil missions for UAVs. As a result, civilian UAVs started to tackle scientific, public safety and commercial tasks as seen on the table in Appendix A [10]. However, UAVs were still used most in military applications [11]. This was mostly because of the cost to develop UAV was very high. Companies or organizations would not invest into a market where the growth or the potential of 
the market was not certain. Moreover, there was no concrete regulations on UAVs. No regulation leads to a lack of standards, leading to confusion for the manufactures, and investors. It was only in recent years that civilian companies showed interest in UAVs, focusing their investments on multicopters and smaller drones as seen on Figure 1.2 [12].

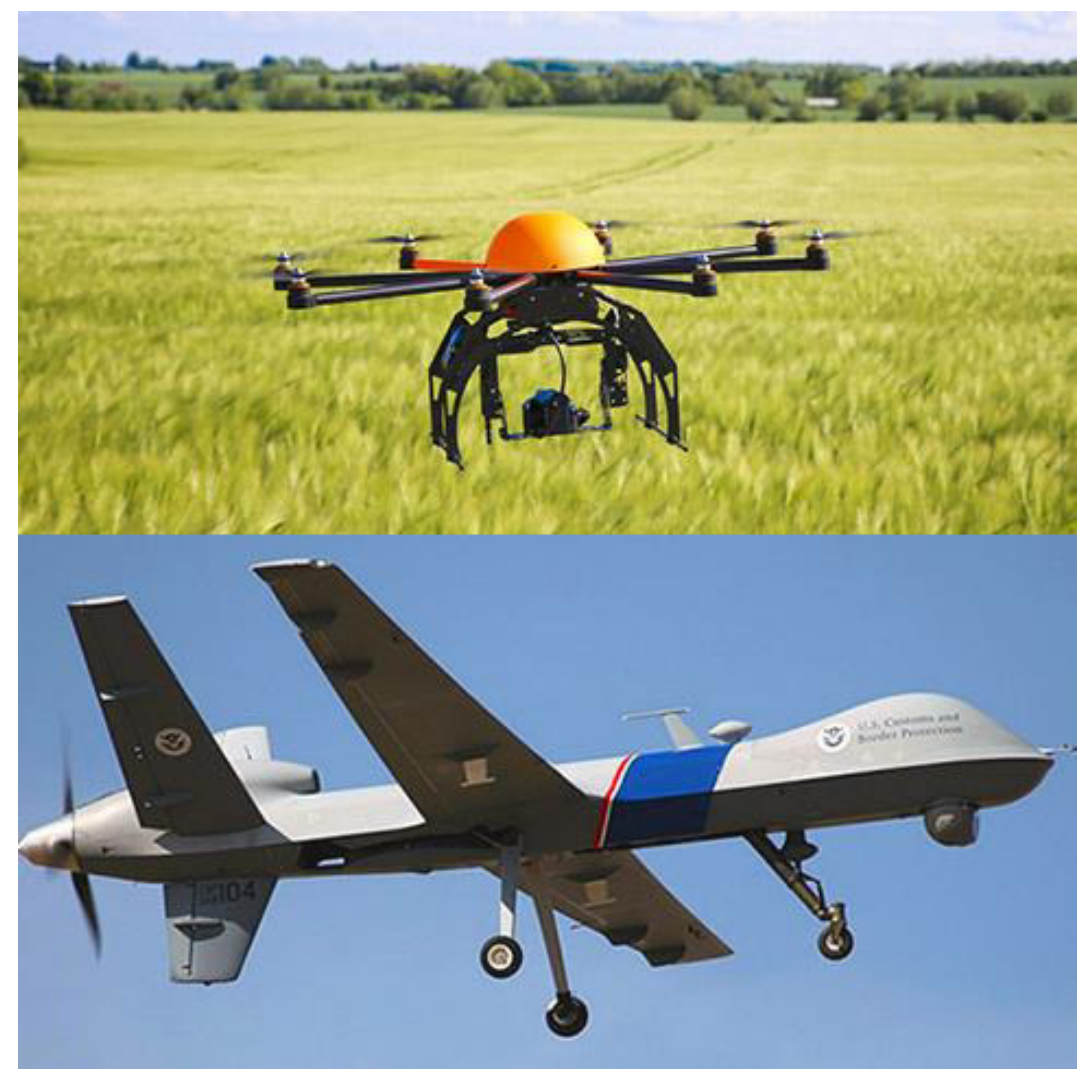

Figure 1.2 Example of commercial and civil UAV [13]

\subsection{Derivative Design}

When a demand grows in a new market sector there were two ways to meet the market demands; developing a completely new design, or developing a derivative design rooting off from the existing design, while keeping the development time and cost to a minimum [14]. Developing a derivative had cost and time advantage because it shared many components with the base aircraft. In addition, a base aircraft that the derivative was designed from were already certified. This eases the certification process of the derivative, depending on what type of changes were done. 
Diamond Aircraft's DA42 has numerous derivative designs to suit different flying environment and missions as seen on Figure 1.3.

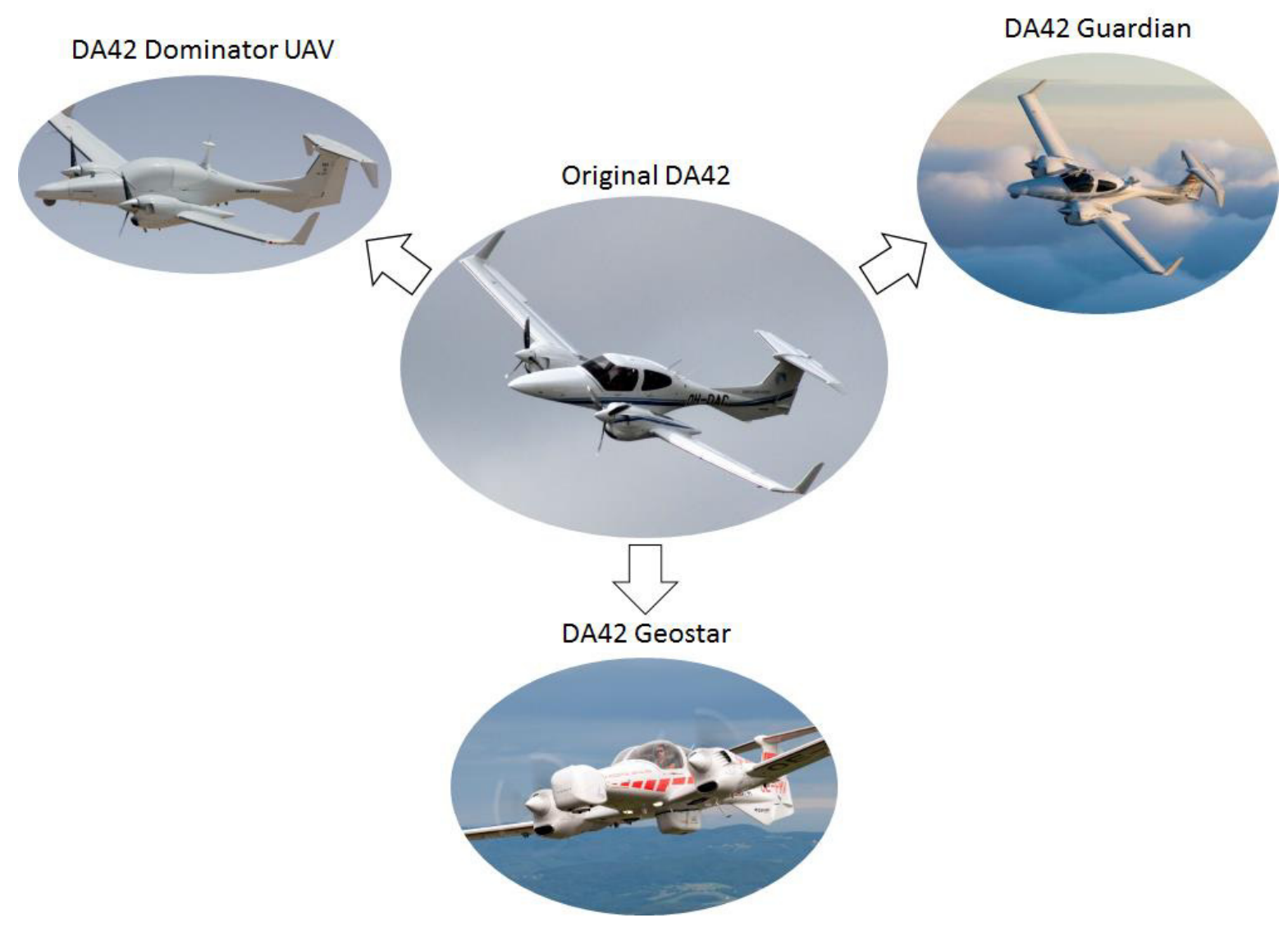

Figure 1.3 Derivatives of Diamond aircraft's DA42 [15]

The original DA42 was a four seat, twin engine, propeller-driven airplane, suited for casual flight. DA42 Guardian was specifically developed for surveillance and reconnaissance missions, with decreased fuel consumption and decreased cruising speed. DA42 Geostar was another derivation developed for geo survey and mapping equipped with laser-scanner and high-resolution camera. Both DA42 Guardian and DA42 Geostar were developed to be an Optionally Piloted Vehicle (OPV). Finally, DA42 Dominator was a medium altitude long endurance UAV developed by Aeronautics Defense System in Israel. It had even longer endurance with higher maximum altitude [15]. 


\subsection{Research Objective}

The objective of this thesis is to introduce a new approach to develop a civil UAV. This approach includs the transformation of a civil light aircraft into a UAV derivative using the MDO method. The optimized model was created in a flight simulator to perform various virtual flight tests in a simulated environment. In this thesis, the Found aircraft's Expedition E350 was optimized into a UAV derivative to carry out a cargo mission. Light aircraft costs were comparably cheaper than similar sized UAVs in the market, while having similar performance compared to the UAVs. Some of the Light Sport Aircraft (LSA) were a fraction of the cost of the UAVs with similar performance. Furthermore, these aircraft were certified for piloted use, which ensures the integrity of the aircraft. Since it was designed for piloted use, the payload it could carry was significantly higher than airframes developed strictly for a UAV. More allowable payload meant flexibility on the carried equipment and fuel quantity.

\subsection{Thesis Outline}

This thesis consists of seven chapters. Chapter 1 introduces the research motivation and objective along with a brief introduction of the history of the UAV along with the description of derivative design. Chapter 2 introduces the theory of MDO and different methods of MDO. It briefly introduced and compared the typical optimization algorithms used: Genetic Algorithm (GA) and Sequential Quadratic Programming (SQP). Chapter 3 explaines the flight simulation portion of the thesis. Starting with a brief history of flight simulation, this chapter focused heavily on the flight simulation system and a detailed review on the building process of Ryerson Fixed Base Simulator. At the end of the chapter, two commercially available flight simulators were compared. Chapter 4 explaines the methodologies introduced in this thesis. This includes the entire process starting from the optimization to virtual flight test. This chapter also explains how the flight data- 
retrieving program worked in detail. Chapter 5 exhibits the application of the previous chapters. A chosen aircraft went through the entire process of derivative design, virtual flight tests and flight data analysis. Chapter 6 presents the result from the optimization and virtual flight tests, with discussions. Chapter 7 completes the thesis with conclusion and future works. 


\section{Chapter 2 Multidisciplinary Design Optimization}

\subsection{MDO Methods}

The act of seeking the best possible result under a given circumstance is the definition of optimization. The practice of optimization is undertaken in our daily lives as we pursuit excellence for tasks we do even if we do not realize it [16]. In terms of mathematics, the optimization process is a very old technique of calculus where extreme values of simple functions are calculated. MDO, in contrast, is a methodology that optimized a problem with multiple disciplines simultaneously thus utilized by many researchers [17-19]. To design an aircraft properly, an engineer must consider disciplines such as aerodynamics, structures, weight, balance, stability and control simultaneously, to achieve best possible result. MDOs characteristics made it a popular 
optimization methodology in aircraft optimization because it can handle complex multidisciplinary-coupled problems well [20].

MDO methods can be divided into two big categories: single level and multilevel. In single level optimization, the system optimizer determines both the disciplinary and system design variables. In multilevel optimization, disciplinary optimizers determines the disciplinary design variables and the system optimizer determines the system design variables.

\subsubsection{Single Level Methods}

\subsubsection{Multi-Discipline Feasible (MDF)}

The MDF is a simple MDO method that consisted of a system with a single global optimizer and various subsystems [21,22]. All of the variables came from the system and were distributed to the various sub systems. Here a subspace analysis was used and then the outputs were sent back to the system level for analysis and optimization. In addition, this method requires coupling variables to exchange between the various disciplines. The only disadvantage to this type of MDO method was that the solution of a system could be very costly due to the lack of system level optimization.

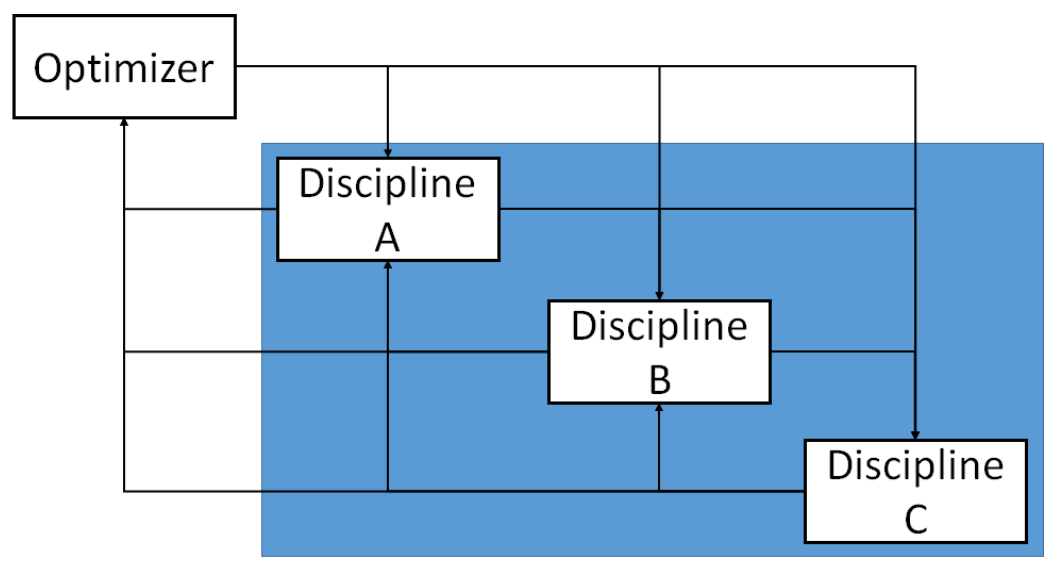

Figure 2.1 Basic MDF architecture [27] 


\subsubsection{Individual Discipline Feasible (IDF)}

Individual Discipline Feasible while similar to MDF had a few differences that made it more complicated, but could decrease computation time. This method allowed the optimizer to optimize individual disciplines by controlling the interdisciplinary design variables [23]. Simply the coupling variables were treated as optimization variables because unlike the MDF method, the IDF method is decoupled [24].

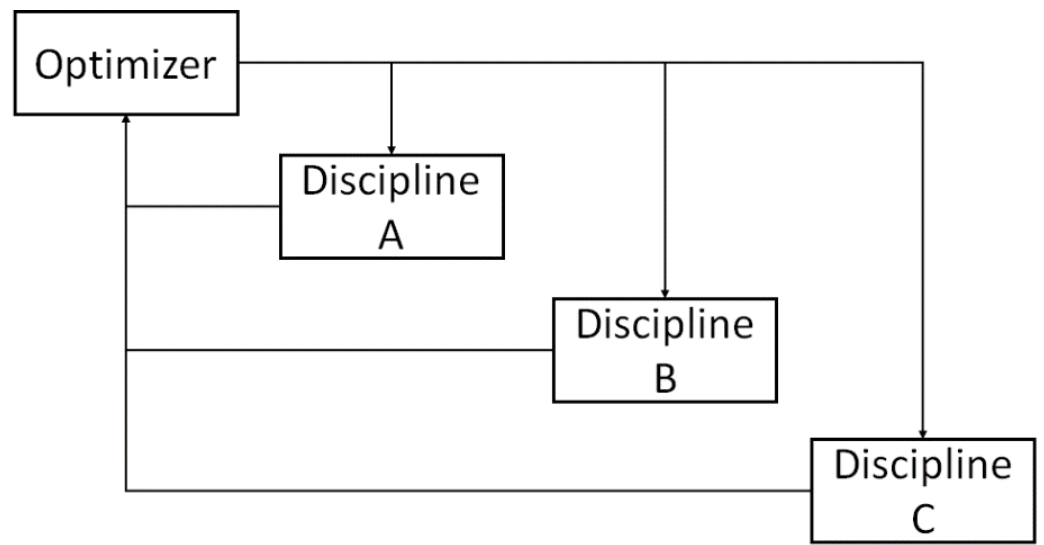

Figure 2.2 Basic IDF architecture [27]

\subsubsection{All At Once (AAO)}

As the name suggests this method computed all of the tasks at once. Specifically this method solves the governing equations within each discipline and optimizes the problem at the same time. This method can be used for multi or single discipline problems. It can be very efficient however, it is not considered because it is based off the IDF method [25].

\subsubsection{Multilevel Methods}

\subsubsection{Concurrent Sub-Space Optimization (CSSO)}

The CSSO method is a non-hierarchic system optimization that optimized subspaces simultaneously. Once the subspaces are analysed and optimized the results went to an organization procedure where the system was directed towards convergence of the problem and resolving 
subspace conflicts. The subspaces within the CSSO acts as their own system level analysis, where the non-local variables were approximated using various global sensitivity analysis equations [24]. While this method does decrease the amount of computation power necessary to solve the system, it does make the setup and formulation of the system very complex [26].

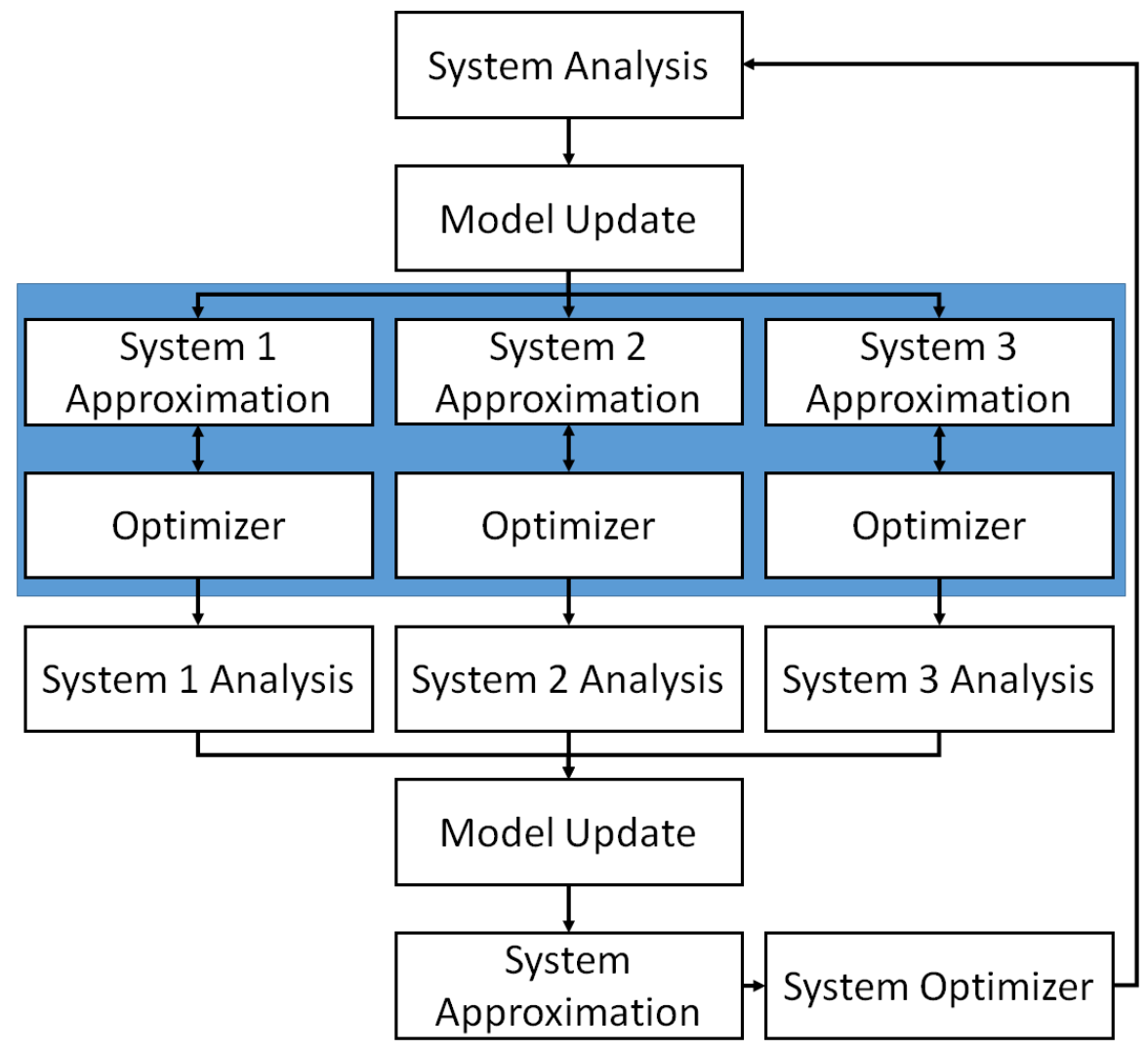

Figure 2.3 Basic CSSO architecture [27]

\subsubsection{Bi-Level Integrated System Synthesis (BLISS)}

BLISS is a MDO method that has a hierarchal structure which provides each discipline with a certain level of autonomy. It relies heavily on the use of coupled sensitivities. The main process consist of analyzing the system, analyzing the subsystems, performing a system sensitivity analysis, optimizing the subsystems and finally performing a second system sensitivity analysis and optimization. The process to set up and solve a BLISS analysis is complex [24]. However, 
once the system is set up it will require few design variables and a low amount of computation power [26].

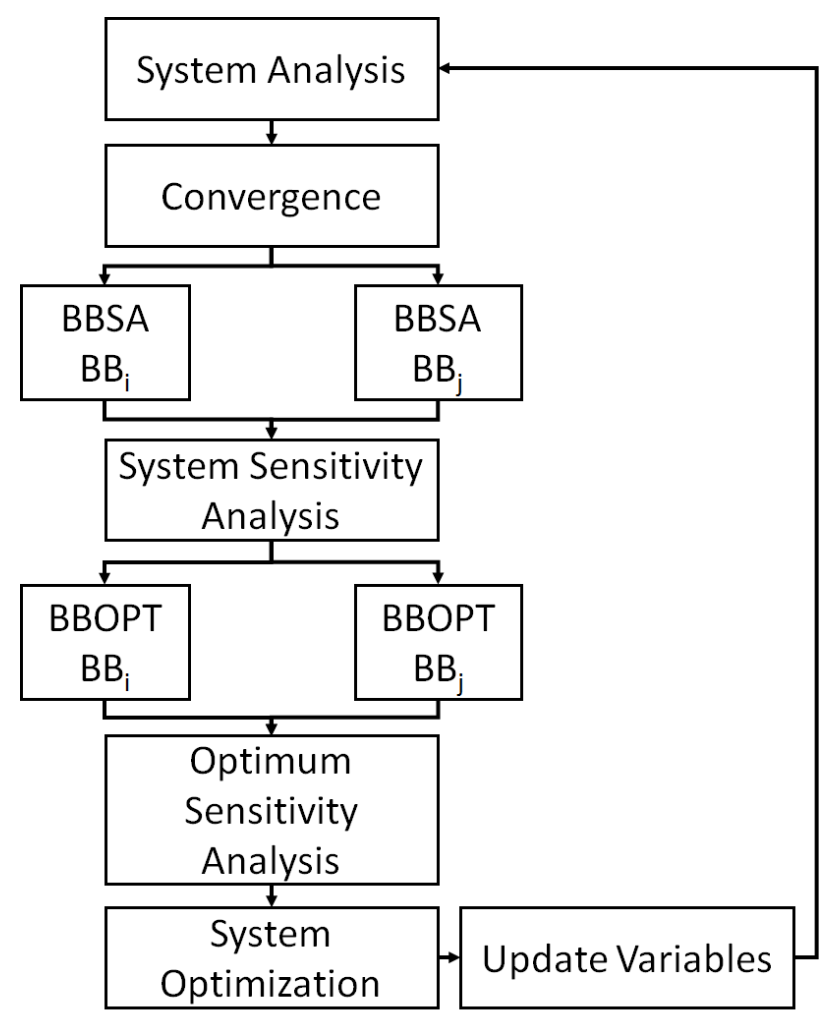

Figure 2.4 Basic BLISS architecture [27]

\subsubsection{Collaborative Optimization (CO)}

Collaborative Optimization (CO) is a two level hierarchal MDO method. This method is considered a relatively simple multilevel MDO method. It consist of one system level optimizer followed by the subsequent subspace optimization. Each subspace shares variables with the other subspaces and the system. The process consist of sending the system variable from the system level down to the subspaces where it optimizes with respect to its own variables and constraints. The subspace then sends the variables back to the system for further optimization and for passing it to other subspaces. This type of design process is useful for situations where the number of disciplinary variables is higher than the number of interdisciplinary variables. Thus, if the 
disciplines have less coupling, this method will be beneficial. One drawback of this method however, is that it will consume a lot of computation resource due to its high number of necessary function calls [26].

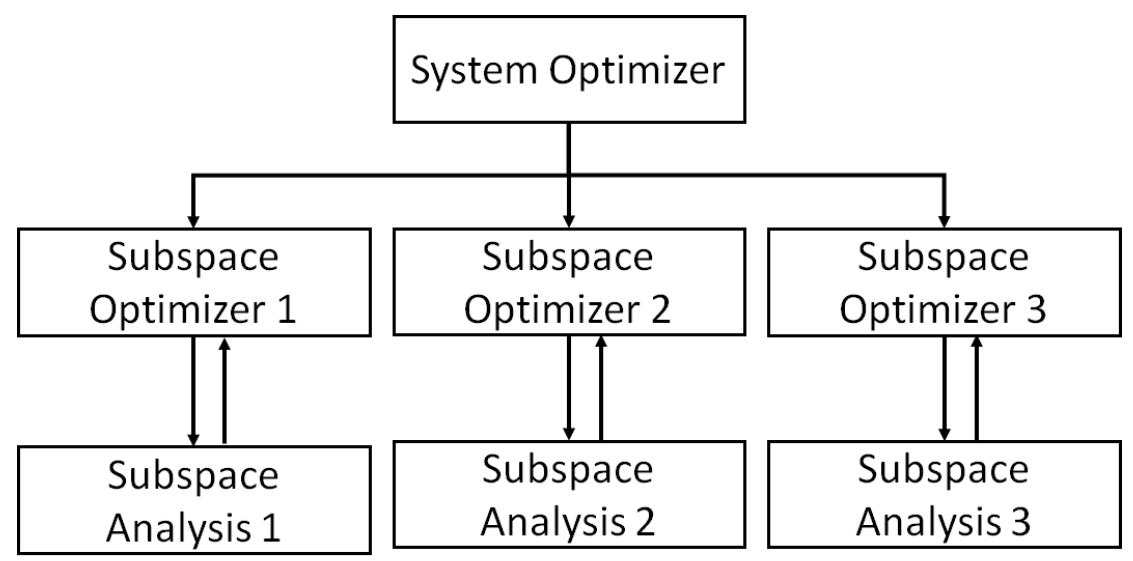

Figure 2.5 Basic CO architecture [27]

\subsubsection{Method Selection}

Researchers selected two test cases to compare the above MDO methods. Methods were compared in five categories, however AAO method was not considered because of its similarity with the IDF method [27]. The first test case was an analytical example and the second test case was aircraft conceptual design. In the first example, a sample mathematical function was minimized under given constraint [28]. In the second example, a supersonic business jet was optimized to achieve maximum range [29]. Table 2.1 shows the result, 'good' to 'bad' from top to bottom.

Table 2.1 MDO comparative summary [27]

\begin{tabular}{|c|c|c|c|c|}
\hline Accuracy & Efficiency & Transparency & Simplicity & Portability \\
\hline MDF & IDF & MDF & MDF & CO \\
\hline IDF & BLISS & IDF & IDF & CSSO \\
\hline BLISS & CSSO & CO & CO & BLISS \\
\hline CO & CO & CSSO & CSSO & IDF \\
\hline CSSO & MDF & BLISS & BLISS & MDF \\
\hline
\end{tabular}


The accuracy represents the result accuracy of each methods. The efficiency represents the computational efficiency, or how quickly the solution was reached. Transparency represents how easily the method could be implied to the optimization problem. Similarly, simplicity represents how quickly the method can be implied to the optimization problem. Finally, portability represents how easily the method can be adapted directly to existing organizational structures. For this thesis, the MDF method was chosen. It has the highest accuracy, transparency, and simplicity. Efficiency was not a big concern because the problem solved in this thesis was not computationally demanding, and converged rapidly. Portability was not important because once the optimization problem was established, it did not require much changes.

\subsection{Optimization Algorithms}

Optimization algorithms are methodical sets of calculations, which aims to find the best solution to a set of parameters to minimize or maximize an objective function while meeting a specific set of constraints and boundaries [16]. In this thesis, two algorithms were studied then one was chosen to be used for actual application.

Genetic Algorithm (GA) is based on the mechanics of natural selection and natural genetics. It is capable of solving optimization problem with discrete variables. It is also capable of finding the global minimum. However, it takes long time to find the global solution and the search for an absolute solution is not guaranteed [30,31].

Sequential Quadratic Programming (SQP) is one of the most efficient gradient-based algorithms for constrained nonlinear optimization problem. It quickly converges to an optimal solution. However it can not solve any problem with discrete variables and there are no guarantee that the solution was the global minimum [30,31]. 


\subsubsection{Algorithm Selection}

Five test runs were conducted for each algorithm, using the UAV optimization similar to the one formulated in Chapter 5. Tests were run with the same initial condition as seen on Table 2.2; the only difference was the algorithm used to solve the problem. The GA result showed some discrepancy between the tests as seen on Table 2.3. Average time to converge was 358.14 seconds. This phenomenon happens because the GA uses random sampling methods to create generations of random candidate. So each time the optimization is performed, the algorithm takes different paths to reach the optimized solution. On the other hand, the SQP result showed no discrepancy between the tests, as seen on Table 2.4. Average time to converge was 9.53 seconds. Figure 2.6 visualizes the difference between the GA and the SQP.

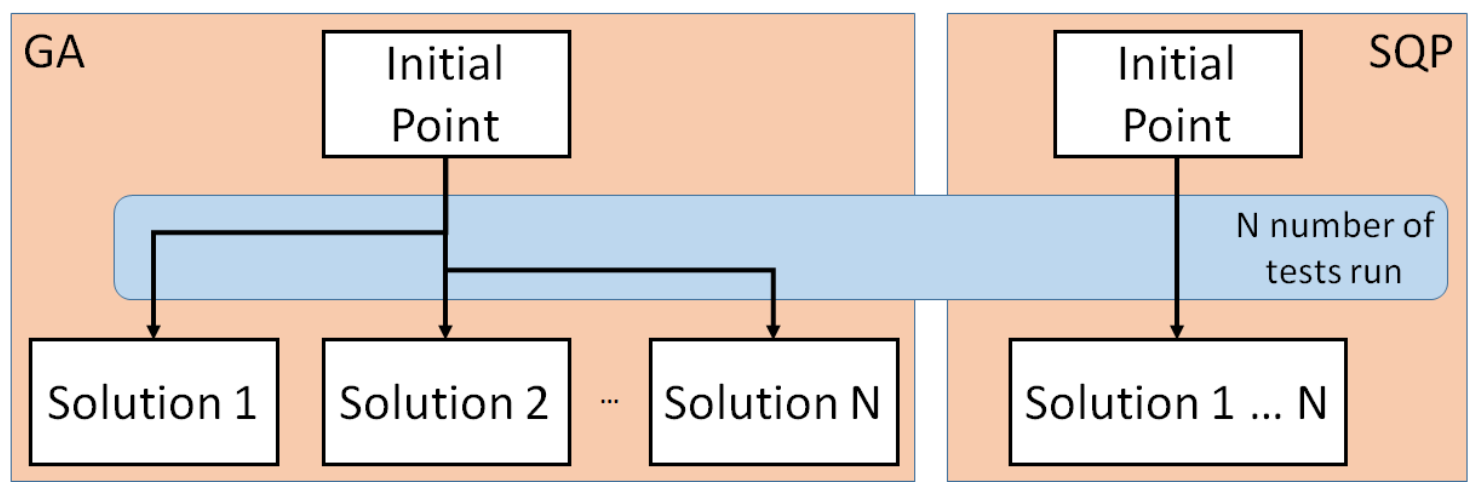

Figure 2.6 GA and SQP comparison

Table 2.2 Initial value of each variable for both tests

\begin{tabular}{|c|c|}
\hline Variable & Initial Value \\
\hline 1 & 4.28 \\
\hline 2 & 38.167 \\
\hline 3 & 1.8123 \\
\hline 4 & 11.4383 \\
\hline 5 & 5.067 \\
\hline 6 & 12.913 \\
\hline 7 & 5.067 \\
\hline 8 & 12.913 \\
\hline 9 & 7.26 \\
\hline 10 & 900 \\
\hline
\end{tabular}


Table 2.3 GA test result

\begin{tabular}{|l|c|c|c|c|c|}
\hline GA & Run1 & Run2 & Run3 & Run4 & Run5 \\
\hline Variable 1 & 5.7083 & 5.7083 & 5.7083 & 5.7083 & 5.7083 \\
\hline Variable 2 & 42.8592 & 44.1697 & 43.9299 & 37.3019 & 44.1381 \\
\hline Variable 3 & 4.825 & 4.825 & 4.825 & 4.825 & 4.825 \\
\hline Variable 4 & 17.1574 & 17.1574 & 17.1574 & 17.1574 & 17.1574 \\
\hline Variable 5 & 7.257 & 8.0024 & 7.9284 & 6.4555 & 7.9845 \\
\hline Variable 6 & 12.914 & 12.914 & 12.9139 & 12.914 & 12.914 \\
\hline Variable 7 & 8.05 & 8.05 & 8.05 & 8.05 & 8.05 \\
\hline Variable 8 & 12.914 & 12.914 & 12.914 & 12.914 & 12.914 \\
\hline Variable 9 & 6.5173 & 6.2727 & 6.2937 & 7.0874 & 6.2762 \\
\hline Variable 10 & 900 & 900 & 900 & 900 & 900 \\
\hline Convergence Time (s) & 549.6382 & 85.05817 & 455.3627 & 611.4315 & 89.19024 \\
\hline $\begin{array}{l}\text { Convergence } \\
\text { Generation }\end{array}$ & 50 & 8 & 50 & 50 & 8 \\
\hline
\end{tabular}

Table 2.4 SQP test result

\begin{tabular}{|l|c|c|c|c|c|}
\hline SQP & Run1 & Run2 & Run3 & Run4 & Run5 \\
\hline Variable 1 & 5.7083 & 5.7083 & 5.7083 & 5.7083 & 5.7083 \\
\hline Variable 2 & 43.9765 & 43.9765 & 43.9765 & 43.9765 & 43.9765 \\
\hline Variable 3 & 4.7406 & 4.7406 & 4.7406 & 4.7406 & 4.7406 \\
\hline Variable 4 & 17.1574 & 17.1574 & 17.1574 & 17.1574 & 17.1574 \\
\hline Variable 5 & 8.05 & 8.05 & 8.05 & 8.05 & 8.05 \\
\hline Variable 6 & 12.914 & 12.914 & 12.914 & 12.914 & 12.914 \\
\hline Variable 7 & 8.05 & 8.05 & 8.05 & 8.05 & 8.05 \\
\hline Variable 8 & 12.914 & 12.914 & 12.914 & 12.914 & 12.914 \\
\hline Variable 9 & 6.261 & 6.261 & 6.261 & 6.261 & 6.261 \\
\hline Variable 10 & 900 & 900 & 900 & 900 & 900 \\
\hline Convergence Time (s) & 9.309767 & 9.768097 & 9.661082 & 9.449912 & 9.475839 \\
\hline
\end{tabular}

Table 2.5 Convergence time average for both algorithms

\begin{tabular}{|l|l|l|}
\hline avg. & SQP & GA \\
\hline Time (s) & 9.532939 & 358.1361 \\
\hline
\end{tabular}




\subsection{Verification of the MDO method}

After finalizing the formulation of the optimization code, it was verified by running the optimization problem and comparing the results with already existing works. Researchers had studied the sample optimization problem chosen for their verification process [32,33]. This problem optimizes a simple two-bar truss, where each bar element had tubular cross section.

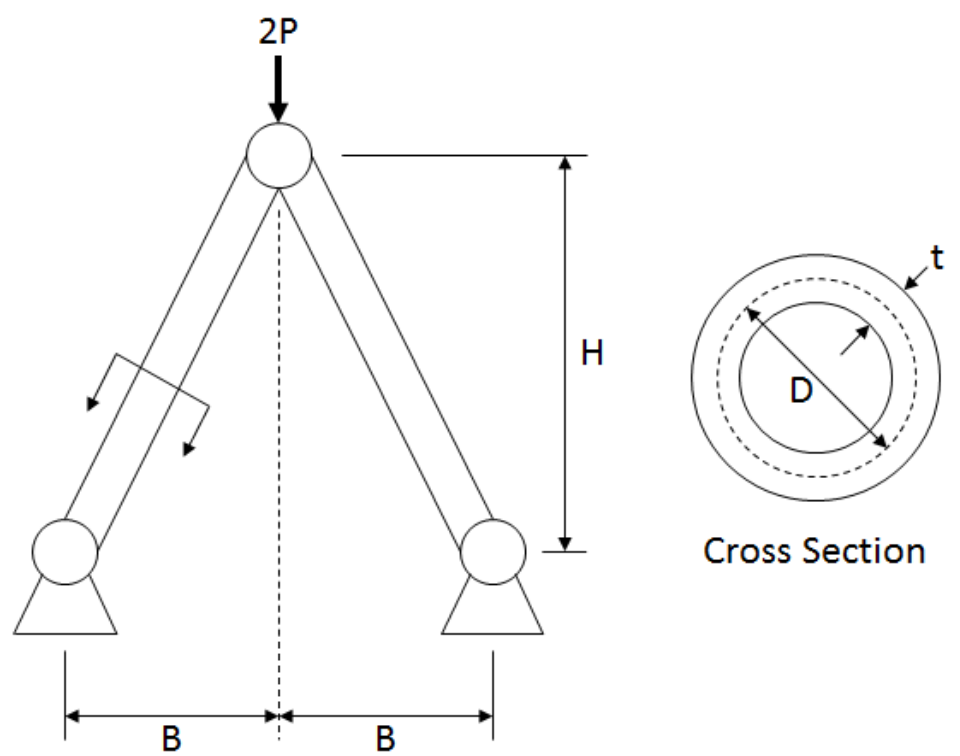

Figure 2.7 Two bar truss schematics

The objective of the optimization was minimizing the total weight of the structure while satisfying the constraints in equation (4) and (5). Table 2.6 and Table 2.7 list the constants, design variables, boundaries, and requirements. The problem was formulated using MDF method. The solver used the SQP algorithm.

Table 2.6 Two bar truss problem constants

\begin{tabular}{|c|c|}
\hline Constants & Value \\
\hline Base width $(B)$ & $30(\mathrm{in})$ \\
\hline Load $(P)$ & $33000(\mathrm{lb})$ \\
\hline Yield stress $(\sigma)$ & $60000(\mathrm{ps})$ \\
\hline Tube wall thickness $(t)$ & $0.1(\mathrm{in})$ \\
\hline Material density $(\rho)$ & $0.3\left(\mathrm{lbs}_{\mathrm{in}}{ }^{3}\right)$ \\
\hline Young's modulus $(E)$ & $30000000(\mathrm{psi})$ \\
\hline
\end{tabular}


Table 2.7 Two bar truss problem variables and boundaries

\begin{tabular}{|c|c|c|c|}
\hline Variable & Initial Value & $\begin{array}{c}\text { Lower } \\
\text { Boundary }\end{array}$ & $\begin{array}{c}\text { Upper } \\
\text { Boundary }\end{array}$ \\
\hline Tube Diameter $(D)$ & $2($ in $)$ & $0.5($ in $)$ & $5($ in $)$ \\
\hline Truss Height $(H)$ & $20($ in $)$ & $5($ in $)$ & $50($ in $)$ \\
\hline
\end{tabular}

The weight of the entire structure was found by calculating its volume and multiplying it by the density of the material. This was also the cost function of the optimization problem.

$$
W=2 \rho \pi D t \sqrt{B^{2}+H^{2}}
$$

The buckling stress and stress were calculated using the equations below [33].

$$
\begin{gathered}
\sigma_{\text {buckling }}=\pi^{2} E \frac{B^{2}+H^{2}}{8\left(B^{2}+D^{2}\right)} \\
\sigma=\mathrm{P} \frac{\sqrt{B^{2}+H^{2}}}{\pi t D H}
\end{gathered}
$$

The constraints of the optimization problem was:

$$
\begin{gathered}
\sigma<\sigma_{\text {buckling }} \\
\sigma<\sigma_{\text {yield }}
\end{gathered}
$$

\subsubsection{Two bar truss problem results}

At the end of the optimization, the diameter of the tube was $2.4759 \mathrm{in}$. The height and weight of the structure was 30 in and $19.8 \mathrm{lbs}$ respectively. Finally the buckling stress and the actual stress caused by the load was $2.059 \times 10^{11}$ psi and $2.898 \times 10^{5}$ psi respectively. The variables were within the boundary and all of the constraints were satisfied. The results were also almost identical to the reference, proving that the optimization code was valid. 


\section{Chapter 3 Flight Simulation}

This chapter covers a brief history of flight simulation software and flight simulators. Literature studies were done on two subjects related to the flight simulation. The first subject focused on the hardware, studying how other institutes were utilizing the flight simulators. The second subject focused on the software and application, studying how other institutes and researchers utilized the flight simulation. This chapter also describes the development of the Ryerson Fixed Base Simulator (RFBS) in detail, in terms of its validity, manufacturing methods and the system specification. Finally, a decision making process was performed to choose the most suitable flight simulation software for this thesis.

\subsection{History}

As with any other technology, the 1900s was the century where flight simulation went through great leaps of technological improvements. Of them all, the most remarkable improvement 
was gained on 1970s with an introduction of microprocessors [34]. Microprocessors enhanced the performance of the flight simulator with improved computation efforts. The main purpose of the flight simulator was to train the pilots. Many of them were very sophisticated, and allowed to be used to log flight hours [35].

In recent years, flight simulators were used more than just to train pilots. Aircraft manufacturers and researchers used flight simulators to design and test during the aircraft development stage [36-39]. Aircraft simulation was also used in plane crashes or emergency investigations using the Flight Data Recorder (FDR). The data recorded in the FDR was animated using a flight simulator. Usually the FDR included important factors such as the velocity, heading, thrust, angle of each control surface and more. Using these essential data, the flight simulator was able to simulate a virtual world, making it easier for the investigator to understand what was actually happening to the plane. Additionally, enhanced computing power and high fidelity analysis models were developed and utilized for the virtual certification [40].

\subsection{Literature Survey}

Nowadays, Human Machine Interface (HMI) units and computation units make up flight simulators as seen on Figure 3.1. The human interface units interacted with the user as the control input and feedback system. The computational units solves aircraft equations of motions and other mathematical models. This was the backbone of modern flight simulator, despite the fact that this concept was established decades ago [41]. 


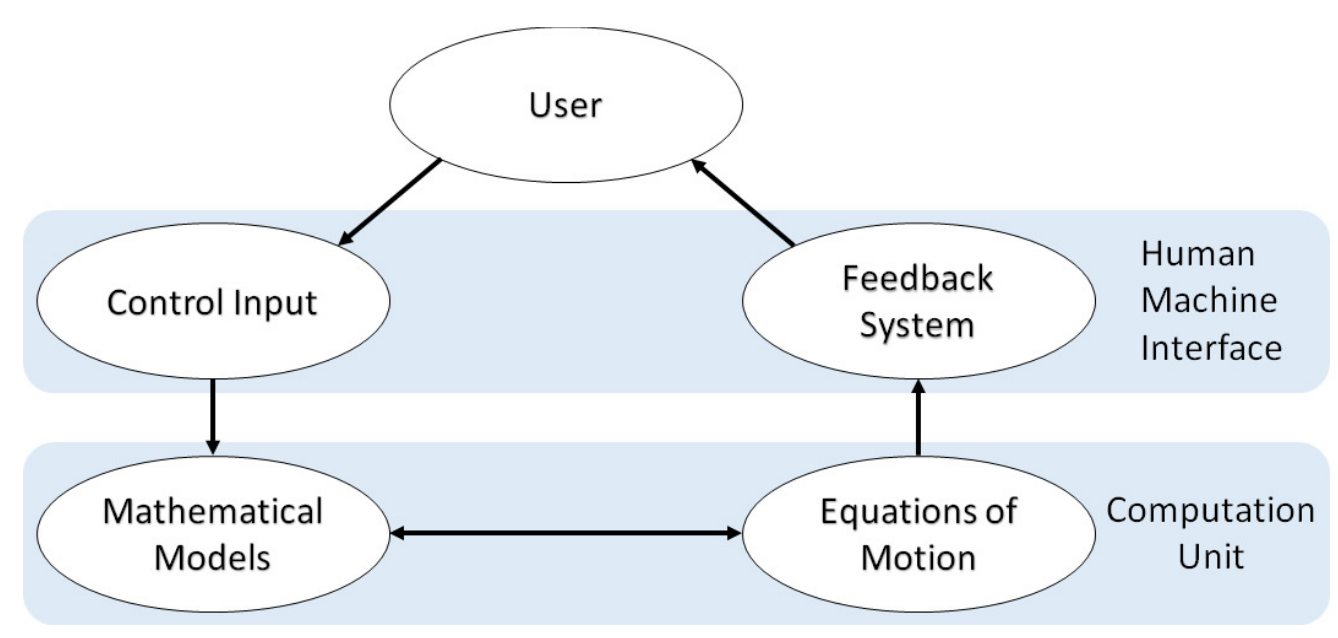

Figure 3.1 Typical composition of a flight simulation system

Renowned universities such as Georgia Institute of Technology and University of Toronto own multi-purpose high fidelity simulators. Utilizing in-house programs, they were used as a tool for various research projects such as solving time delays in visually coupled systems during simulation [42] and developing new software architectures [43]. More literature survey showed that researchers from around the world developed various flight simulators to be used as training tools for engineers and pilots, and as engineering tools $[44,45]$. Some of these were mission specific simulators focusing on icing studies [46]. Others developed flight simulator to educate engineers [47]. Finally, the Test and Evaluation Modeling and Simulation (TEMS) facility at Air Force Flight Test Center (AFFTC) Edwards Air Force Base built realistic cockpit simulators to study the relation between the reconfigurability and fidelity of the simulator [48].

\subsection{Application}

For Ryerson University, the necessity of the flight simulator arose from gathering flight data for aircraft design studies. Flight data were proprietary information of a manufacturing company or an airline, making it costly and difficult to acquire for academic purposes. Flight simulation integrated with data generation solved this problem. Flight simulation allowed 
researchers to recreate any flight situation, anywhere, anytime. Training the pilots and engineers was another important role of a flight simulator In addition to the data generation. To enhance the quality of training it was necessary for the simulator to replicate the cockpit environment and avionics as much as possible.

\subsubsection{The RFBS}

The Mixed-reality Immersive Motion Simulator (MIMS) Facility housed the Ryerson Fixed-Base Simulator (RFBS) and the Ryerson Full-Motion Simulator (RFMS). The RFBS focused on the accurate data generation and cockpit representation. The RFMS focused on the motion and dynamics of an aircraft, creating opportunities to study human factors in a motion environment.

The RFBS focused on combining all the positive factors and minimizing the negative factors of already existing flight simulators. While many previous engineering flight simulators focused on computation and data communication than the cockpit environment. The RFBS (Figure 3.2) is a true multi-purpose simulator because it integrates all aspects of flight simulation, flight data generation, and the data analysis system [49].

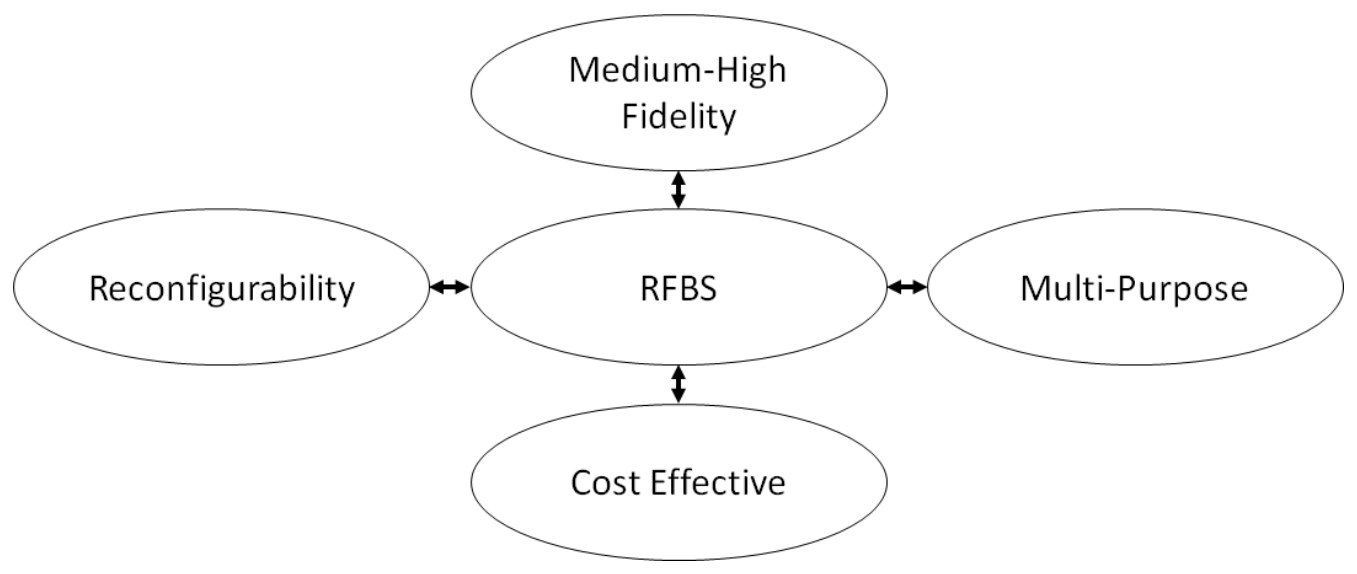

Figure 3.2 Factors considered for RFBS [49] 
A multi-purpose simulator is also very cost-effective, as it is too costly to purchase multiple simulators for different purposes. Advancement in computing power also allows single system to handle multiple simulating features. Academically, multi-purpose simulators can be used to educate the students about avionics and flight dynamics. The RFBS' reconfigurability is achieved by replacing hardware buttons with touch screens; it can virtually simulate any aircraft.

\subsubsection{Design and build of the simulator}

Five main components of a flight simulator included visual, audio, avionics, flight control, and motion components [50]. Visual and audio were feedbacks from the simulator while flight controls were inputs into the simulator. Avionics serve as both input and feedback as the pilot was required to input commands and see the aircraft status through it. Motion was disregarded, as the RFBS was a fixed-base simulator. After several design phases shown on Figure 3.3, the simulator's rendering was complete as seen on Figure 3.4.

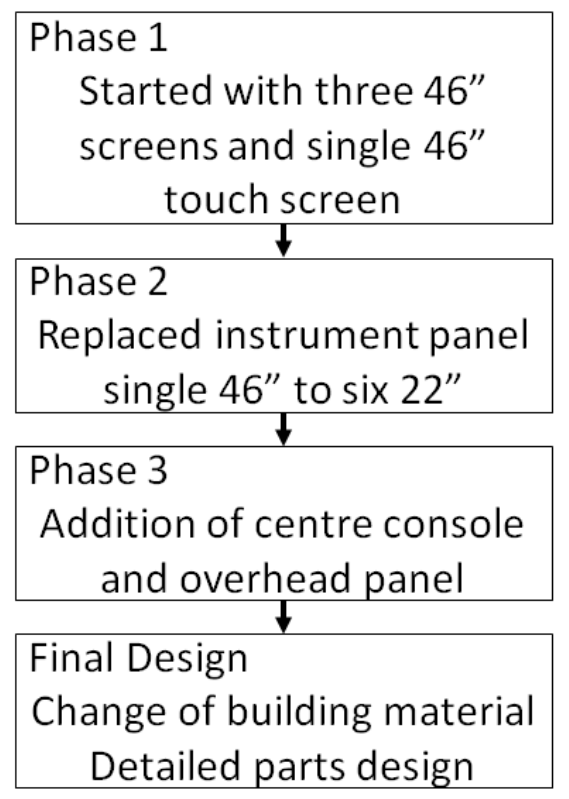

Figure 3.3 Design phases of the RFBS 


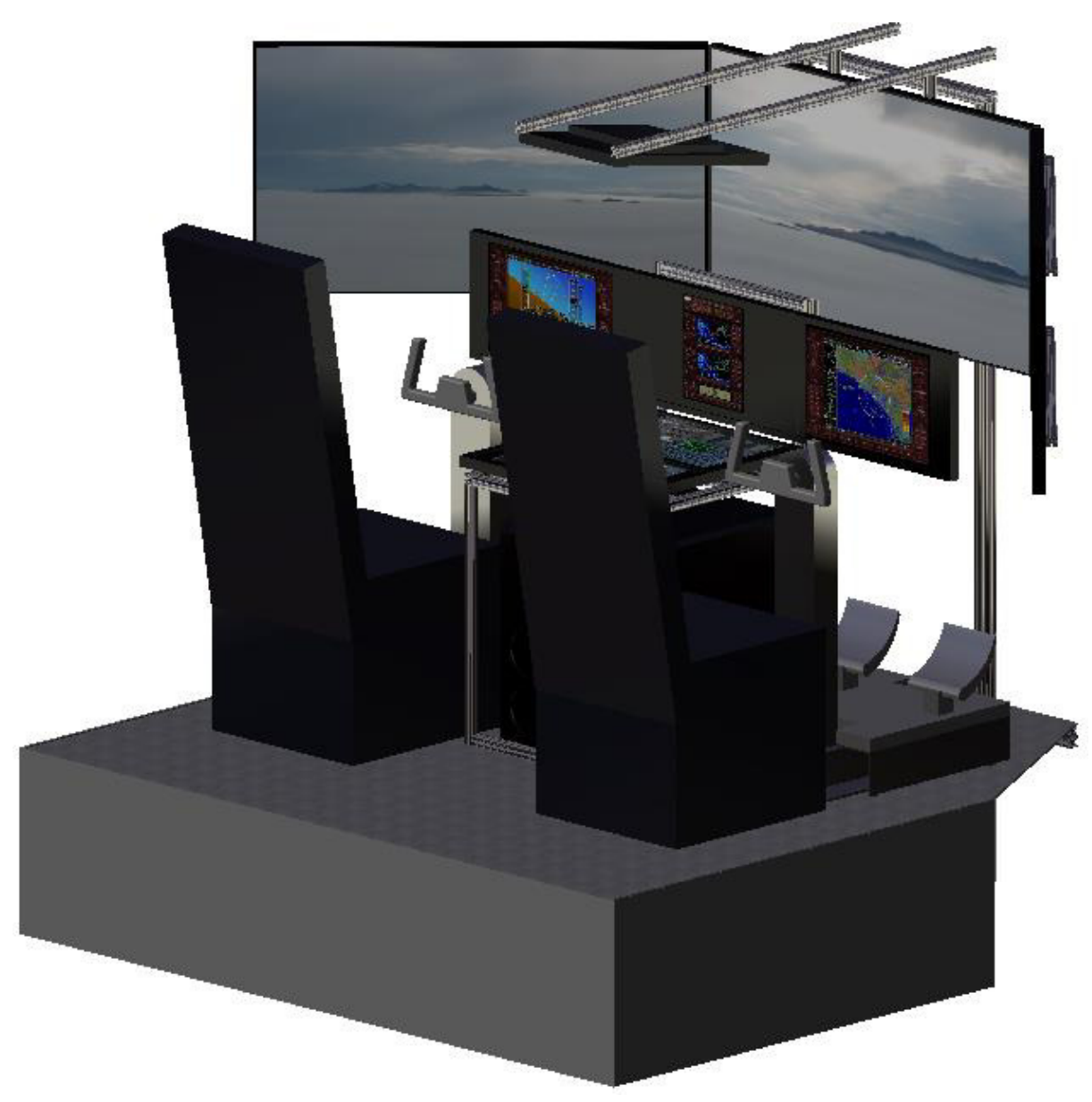

Figure 3.4 CATIA model of the RFBS

As seen on Figure 3.5, the final design of the RFBS included three 46" screens as main visualization and six 22 " touch screens as an instrument panel, where the overhead panel used two of them. The pilot seat on the left hand side was equipped with a rudder pedal and a yoke, and the right hand side was equipped with a rudder pedal and a joystick. This configuration allowed to simulate both Boeing and Airbus aircraft with more realistic feelings. The throttle lever was located on the centre console, easily reachable by both pilots. Entire structure including the base, centre console and overhead panel was built by pre-cut aluminum extrusion. 


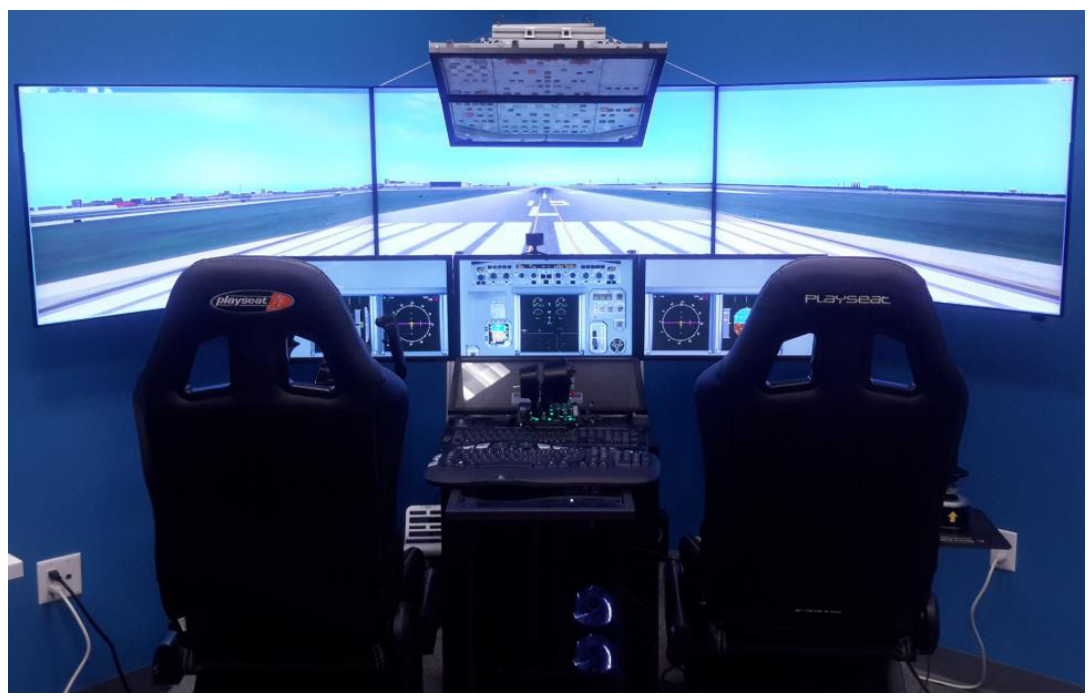

Figure 3.5 Completed RFBS, front view

\subsubsection{System configuration}

The RFBS utilized two computers; one handled the visualization, computation and flight data generation while the other handled the flight control input and instrument panel. Both computers must be on in order for the RFBS to run on its full capability. A Local Area Network (LAN) data cable connected the computers, allowing real time communication as seen on Figure 3.6. Hardware configurations for each computer were listed on Table 3.1.

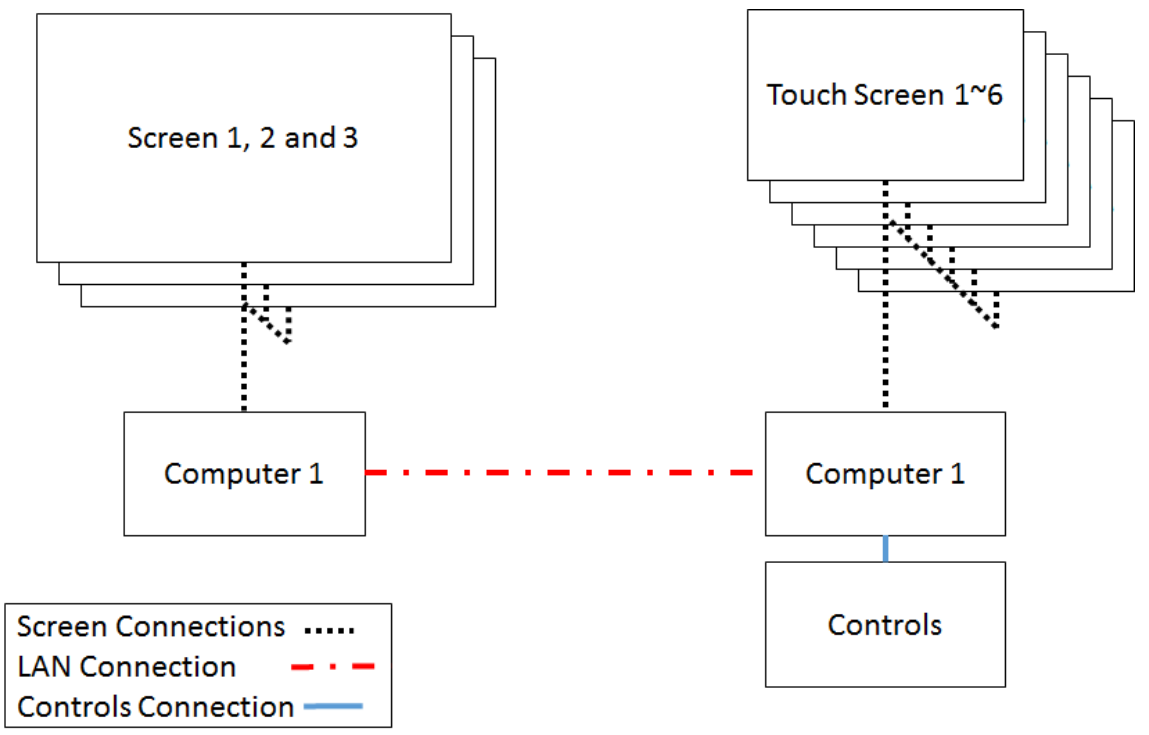

Figure 3.6 RFBS system architecture 
Table 3.1 Computer configuration

\begin{tabular}{|l|l|l|}
\hline & \multicolumn{1}{|c|}{$\begin{array}{c}\text { Computer 1 } \\
\text { Simulation }\end{array}$} & \multicolumn{1}{|c|}{$\begin{array}{c}\text { Computer 2 } \\
\text { Instruments \& } \\
\text { controls }\end{array}$} \\
\hline $\begin{array}{l}\text { Operation } \\
\text { System }\end{array}$ & $\begin{array}{l}\text { Windows 7 } \\
\text { Professional }\end{array}$ & $\begin{array}{l}\text { Windows 7 } \\
\text { Professional }\end{array}$ \\
\hline CPU & Intel i7-4770K & Intel i7-3770K \\
\hline RAM & 32 GB & 16GB \\
\hline $\begin{array}{l}\text { Graphics } \\
\text { card }\end{array}$ & GTX 760 & Two GTX 670 \\
\hline HDD & 256 GB SSD & 1TB HDD \\
\hline
\end{tabular}

\subsubsection{Choice of Flight Simulation Program}

Since a flight simulator was a basic platform of this thesis, it was important to find the right software to work with. Following criteria was considered:

Physics: Chosen flight simulator must be able to represent real world physics accurately, from the motion of the aircraft to the physics of the environment (wind etc.)

Data Extraction: Chosen flight simulator must be able to provide the user with the data required

Visual Representation: Chosen flight simulator must be able to visualize the accurate behaviour of the aircraft as the user inputs a command. Rendering quality will not be a main concern

Availability: Chosen flight simulator must enable user to access its full capability

Although there were numerous flight simulators out there, the lab had full access to only two commercial flight simulators available to the public: X-Plane from Laminar Research and the Flight Simulator X (FSX) from Microsoft. Taking into account the abovementioned criteria, the simulation software was chosen. 


\subsubsection{Microsoft's Flight Simulator $X$}

Microsoft's FSX was the tenth flight simulator the company had developed. After the FSX, Microsoft had cancelled the programming and discontinued its series. In the FSX, an aircraft's flight was represented by calculating predetermined aerodynamic properties that were compiled in

a file. Therefore, the behavior of the aircraft was calculated with the user input, virtual world conditions, and pre-set properties from the file. This allowed any object to fly in FSX, as long as its data properties were compiled as a flyable object even when it was physically unable to fly.

FSX provided a built in function called 'Flight Analysis' to analyze an already flown aircraft. This provided essential information such as the global position, altitude, heading and airspeed of the aircraft along with the actual path of the aircraft on the map. The user could slide the time slider to adjust the flight phase, and the data would change to the corresponding time set. Unfortunately, it was impossible for the user to extract these data to be used externally from the FSX with simple maneuver.

The FSX provided a stunning visual representation of the aircraft and the environment. Another advantage of the FSX was that it had a vast user community where they built and shared sceneries and aircraft, which could be directly inputted to the simulator, increasing the reality in terms of visual effects. However, due to the high graphic rendering requirement, the actual frame rate of the flight was averaged to about 25 30 frames per second, where the choppiness of the video was detected.

\subsubsection{Laminar Research's X-Plane 9}

Laminar Research's X-Plane 9 was another popular aircraft simulator that was available to the public. It took a different approach from the FSX in terms of calculating the equation of motion 
of the aircraft. Laminar Research recently released X-Plane 10, which enhanced the graphics capability of the simulator.

Unlike the FSX, X-Plane used blade element theory to calculate the flight dynamic of the aircraft. X-Plane put the solid model of the aircraft under the environment flow. This flow incorporated both the atmosphere conditions and the aircraft's flying condition. Then the program calculated the aerodynamic effects of the flow on small elements of the aircraft mesh. Then the results were integrated across the entire aircraft to output total flight dynamics.

The data extraction system in the X-Plane was quite useful. Users could freely choose required data and express it in different methods. Users could choose to show the data on the cockpit, on the graph, export the entire data into a hard drive as a text array file, or all of the above simultaneously. This freedom of data extraction was a unique feature of X-Plane, garnering much attention from other engineers who use the program for their research.

Compared to the FSX, X-Plane did not provide fancy land geometry rendering. It focused on the basics: land, water, and the atmosphere. Nevertheless, due to the reduced number of the object, the rendering speed was quite fast, providing a high Frames Per Second (FPS).

\subsubsection{Choosing the Flight Simulation Program}

Overall, Microsoft's FSX provided stunning graphics but limited access to the flight data. Laminar Research's X-Plane provided less sophisticated graphics, but allowed full access to the flight data. Most importantly, the Federal Aviation Administration (FAA) certified the simulation and vehicle models so this program could be used for pilot training [51]. In addition, X-Plane had a series of engineering tools and equations to simulate its aircraft models [52]. For these reasons, X-Plane had been chosen for this thesis as well as being utilized in numerous aircraft and UAV research as a visualization and validation tool [53-55]. 


\section{Chapter 4 UAV Derivative MDO}

\section{Methodology for Flight}

\section{Simulation}

\subsection{Overall Procedure}

The pre-MDO process started by defining the mission objective of a UAV. Then the design requirements were established, according to the mission of the UAV. During this phase, a base aircraft was chosen to be optimized into a derivative design. Selected aircraft must suit the design objective, to have least changes on the design. This was because cost and time saving was the purpose of the derivative design. The aircraft characteristics were carefully inspected to identify areas for improvement. Once points of improvement were settled, the disciplines and design variables were selected to prepare for aircraft optimization process. Common disciplines chosen 
for conceptual design of an aircraft is aerodynamic, weight \& balance and performance. However, this can vary depending on the nature of the optimization problem.

Two sets of results (configuration and performance) were generated after the optimization. If there were any errors, changes must be made to the selected disciplines and variables. Usually, changes are made on the boundary of the design variables. Time to time, a change must be done on the constraint to have optimal solution. In extreme cases, a new design variables are selected. It is important for the designer to know the formulated problem thoroughly, to apply the correct fixes. The configuration set was the physical attributes of the optimized aircraft. This set includes any physical attributes that affect the performance of the aircraft. The performance set included the usual performance characteristics of the aircraft such as cruise range, but extending to the stability and control, or any non-physical attributes that are quantifiable. These sets take two different paths after optimization. The configuration set was sent to the flight simulation phase where the performance set was saved to be used for flight data evaluation phase.

First task done in the flight simulation phase was to make a virtual aircraft using PlaneMaker. It used the configuration set from optimization phase to make the virtual aircraft. Once enough aircraft models were made, series of virtual flight tests were performed. Data generated by the flight tests were polished using the Flight Data Conversion Program, so the flightdata analysis program could use it. The data was reviewed once more where only the important data were saved.

Flight data evaluation phase came after the flight simulation phase. In this phase, the performance set from optimization was used as the numerical result, then compared with the polished data from the flight simulation phase. If they did not coincide, the consistency of the flight simulation result must be checked. If the flight simulation result was inconsistent, a human pilot 
error may have occurred during the virtual flight testing, and it must be re-tested. If the flight simulation result was consistent, then the error could have occurred during the formulation of the optimization problem. In this case, a through study of the formulated MDO problem is needed, to find out the cause of the error. If the numerical result and simulated result coincide, the design procedure ends with a final report, if necessary.

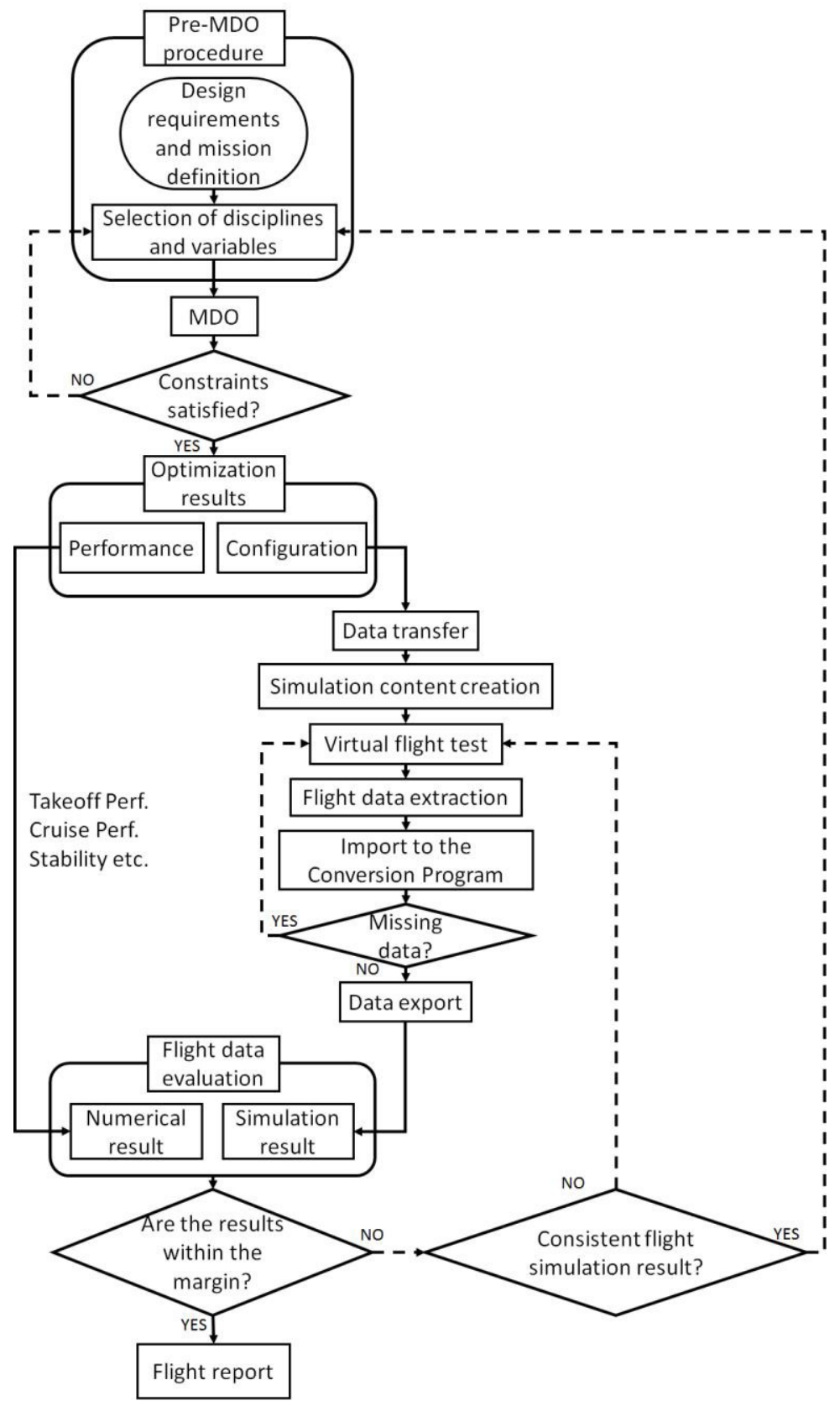

Figure 4.1 UAV derivative MDO methodology for flight simulation 


\subsection{Data Import to Simulation}

The PlaneMaker, a complimentary software specifically made for X-Plane was the tool to generate an aircraft model. Some of the mandatory data required for the model was engine specification, wing geometry, fuselage geometry, and weight $\&$ balance. Once the optimization was complete, data was saved in separate file. The data was converted in such format where the user can easily put it into the PlaneMaker; in the order of its input menu, left to right then top to bottom. Figure 4.2 showed the one of the input case in PlaneMaker with optimization result.

\begin{tabular}{c|c}
\hline \multicolumn{2}{c}{ Wing 1-Foil Specs } \\
\hline Semi-length & 19.71 \\
Long arm & 8.7 \\
Root chord & 5.7 \\
Sweep & 0 \\
Lat arm & 2.21 \\
Tip chord & 4.27 \\
Dihedral & 0 \\
Vert arm & 2.16 \\
\hline
\end{tabular}
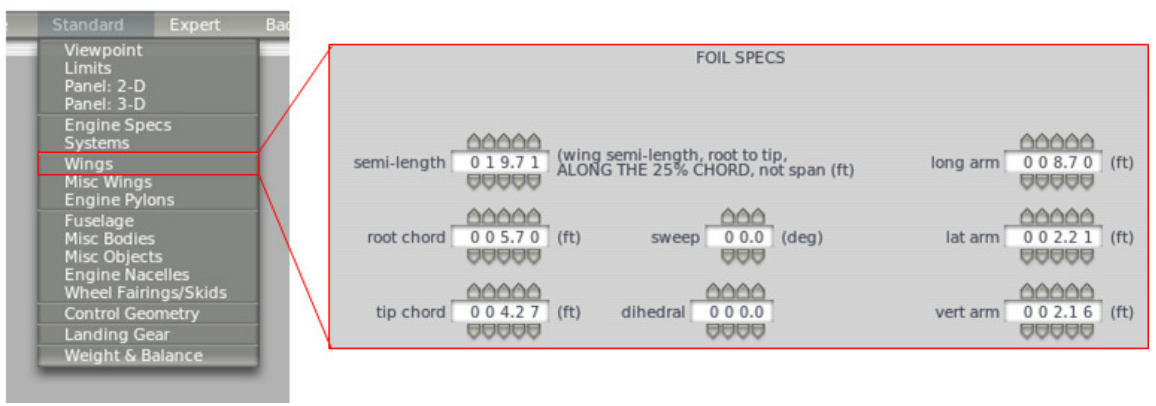

Figure 4.2 Example of input of optimization result to PlaneMaker

\subsection{Data Exportation}

Commercial flight-data analysis program required flight data to analyze and animate. The development of the methodology and the data converter allowed the flight data generated by XPlane to be import into the flight-data analysis software. The data converter was coded in MATLAB [56] and was developed into an executable program with a Graphic User Interface (GUI) with MATLAB GUIDE as seen on Figure 4.3. 


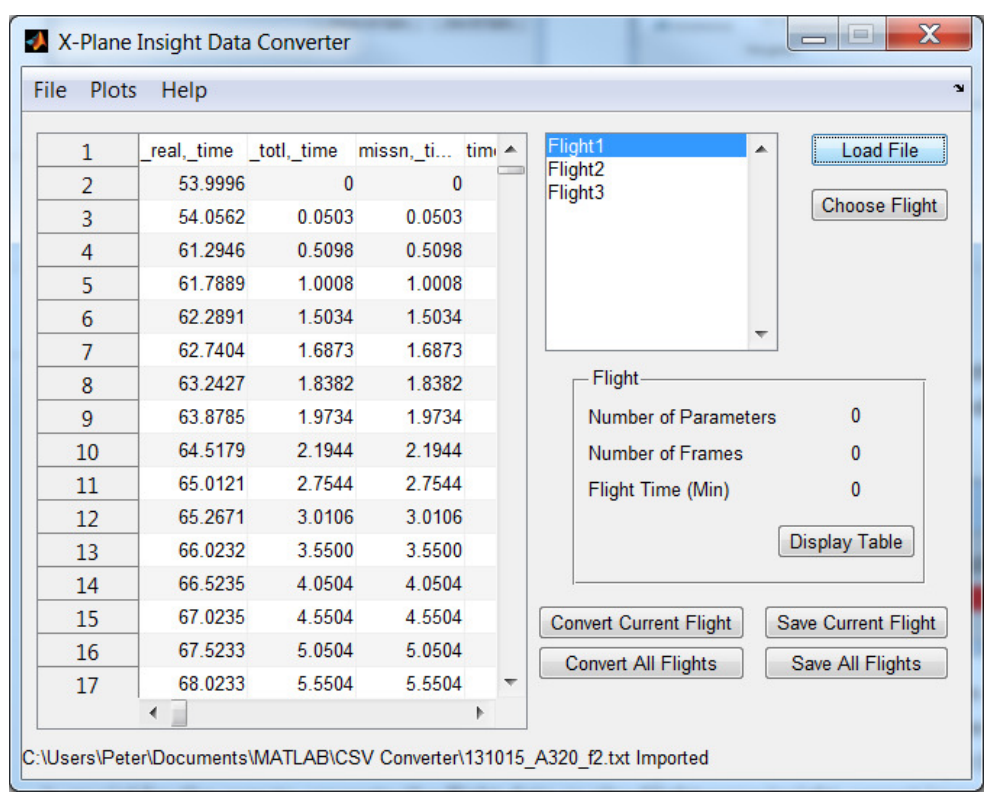

Figure 4.3 Flight data-converter program

\subsubsection{Data Importation to the Data Converter}

The flight data generated by X-Plane used its own naming convention to fit the data within its fixed width variable format. As seen on Figure 4.4 each column was composed of 14 characters. A separate database that had both X-Plane naming convention and common names used in aviation industry was made. This database held the unit of the numerical parameters and the type of the parameter as well. Sample flight data could be seen on appendix B also.

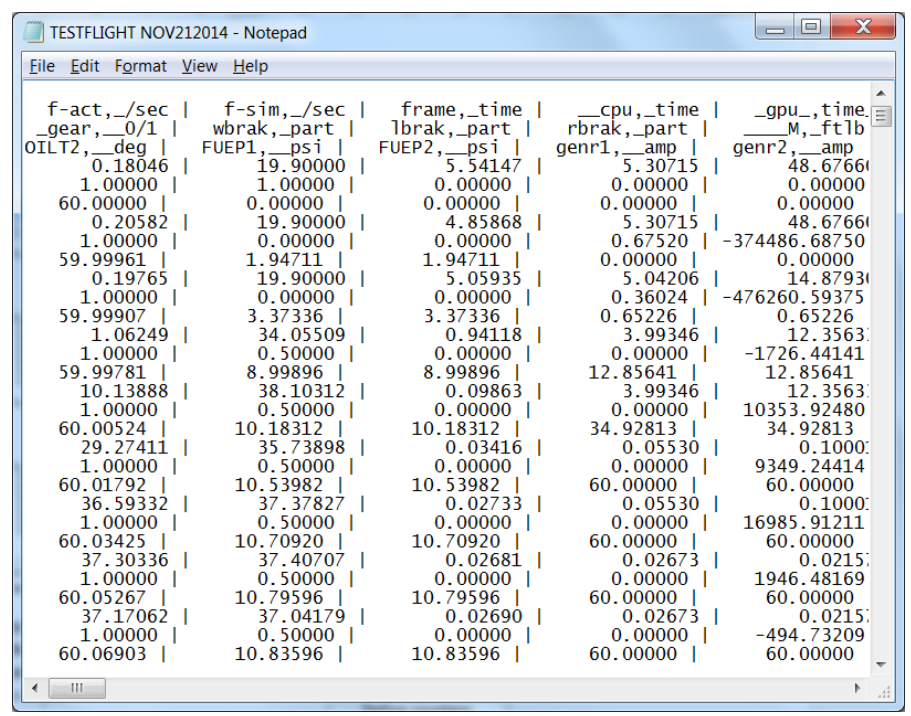

Figure 4.4 Typical data output from X-Plane 
The data loaded went through the import algorithm seen on Figure 4.5 to sort the data efficiently. Depending on the export setting on the X-Plane, the data could have couple of parameters to hundreds of parameters. To adapt to any number of parameters, the importation algorithm arranges the data in single column matrix. If the content of the matrix changed from characters to numbers, the $N_{\text {par }}$ counter goes up by one. If the content did not change, the $N_{\text {row }}$ counter goes up by one. This repeats until the end of the file, sorting the imported data in a matrix size of $N_{\text {par }}$ by $N_{\text {row }}$.

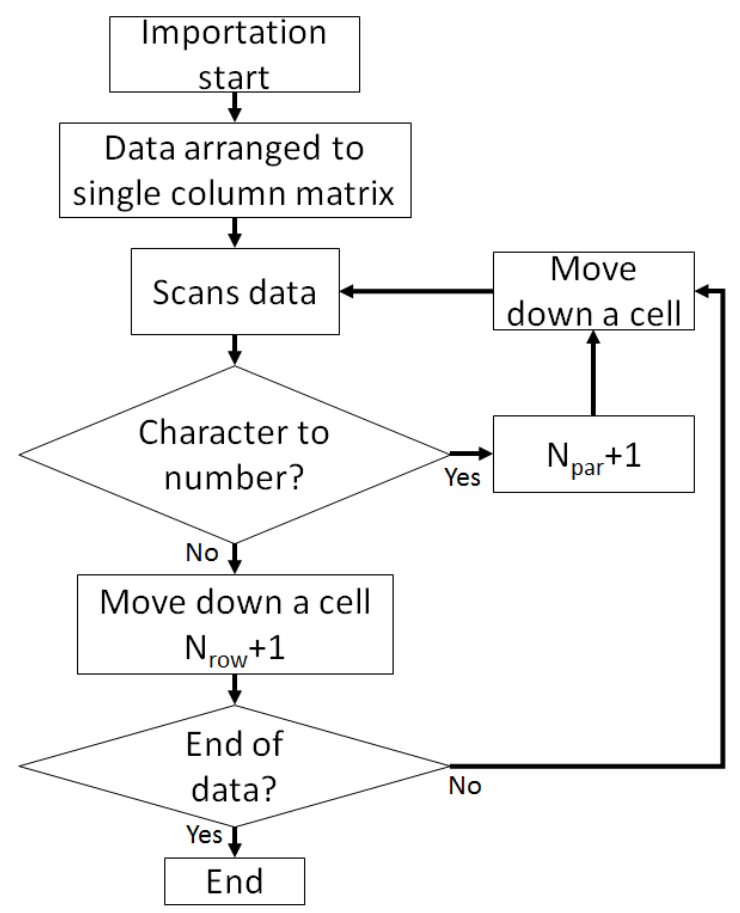

Figure 4.5 Import algorithm

\subsubsection{Data Conversion and Data Save}

Load data was inspected carefully to check if there were any error or missing parameters. Data conversion process converts the imported data into a format that can be directly used in common flight analysis software as seen on Figure 4.6. During this process, all parameter names were switched to standard names accepted by the flight analysis software. Also, three new rows of 
data were created below the parameter names with unit, format and type information of the corresponding parameter. Finally, conversion was made for the Greenwich Mean Time (GMT) time and local time. These parameters were represented in hours originally, however it was mandatory for these parameter to have standard time format: HH:MM:SS.

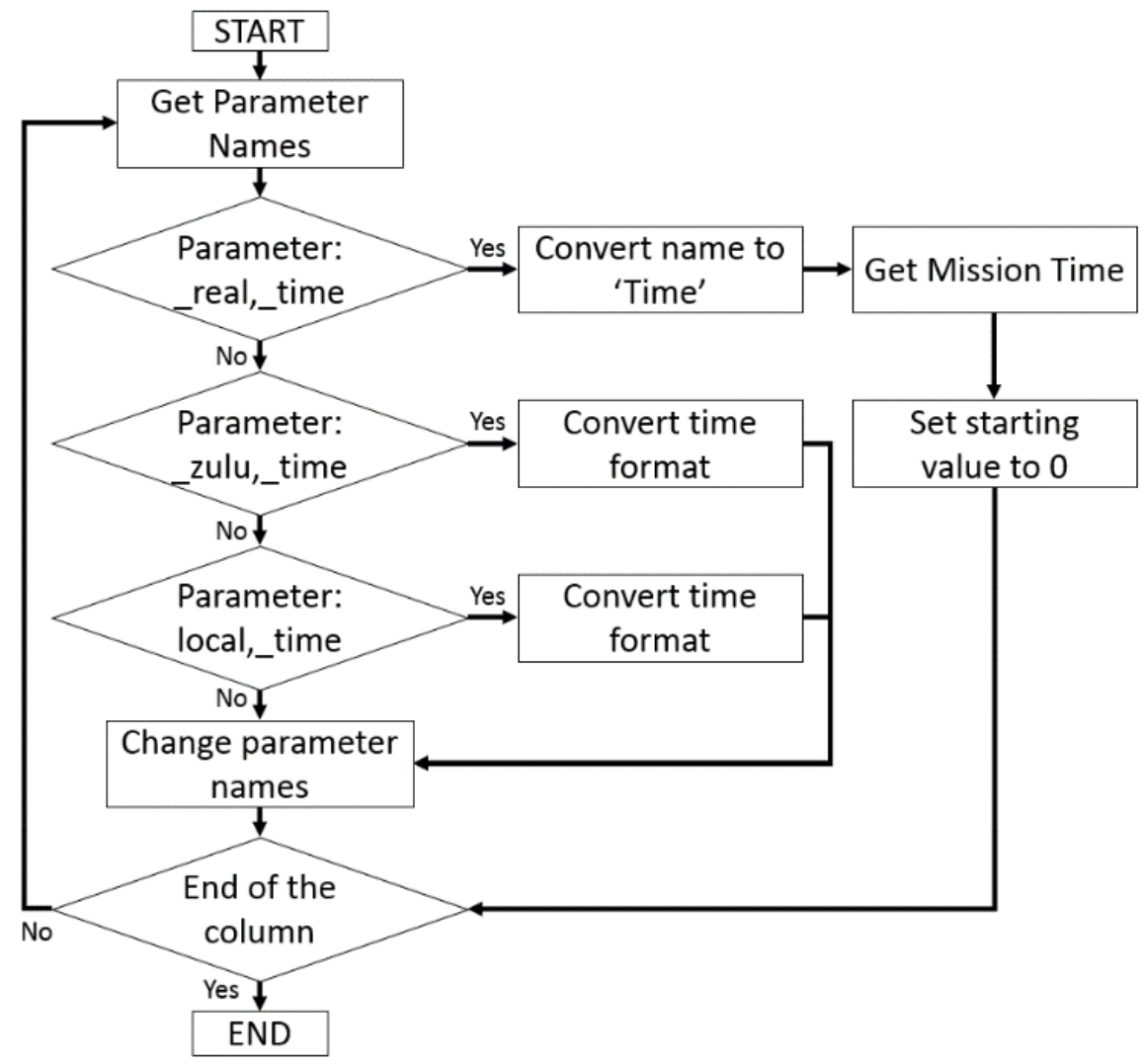

Figure 4.6 Flowchart of the conversion process

Finally, the program used cell to csv function to save the converted data into a csv format as a typical flight analysis software can import csv data file. 


\section{Chapter 5 Application of Methodology}

\subsection{Mission Definition and Aircraft Selection}

The mission objective of the UAV derivative was payload delivery under crisis due to natural disaster. It is difficult to secure a long airstrip when a city has been hit by a tsunami or an earthquake. Thus, the aircraft should be able to lift off in a short distance. In addition, it should have a long range and endurance to deliver further, or stay in the air longer to wait for aftershocks to pass by. The aircraft should be able to perform other missions such as payload para-dropping or surveillance of the disaster zone. Both of these missions take advantage from having long endurance. Possible mission profiles of the aircraft is shown in Figure 5.1. 


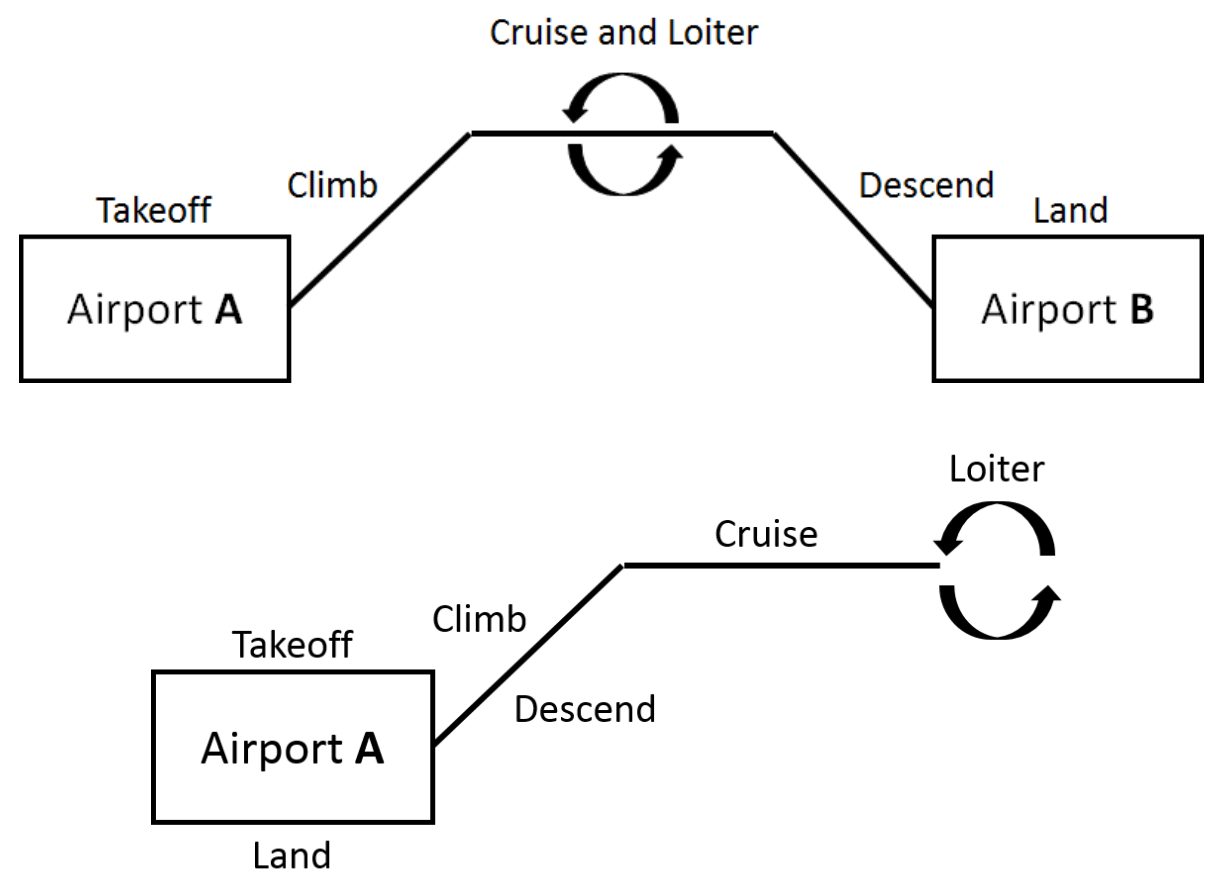

Figure 5.1 Possible mission profiles

Found Aircraft Canada was a Canadian aircraft company founded in 1996. It acquired the right to produce the FBA-2C, an aircraft manufactured by Found Brothers Aviation Ltd. in the 1960s. Although the manufacturing of FBA-2C ceased in 1967 due to business related reasons, its reputation remained high over the next forty years. FBA-2C was the successor of the FBA-1, which was a successful bush plane with versatile landing capabilities. It was rugged enough to land and takeoff on gravel, turf, snow and ice. These characteristics were included in the newly designed Expedition E350, seen on Figure 5.2. Table 5.1 lists some of the performance specification of Expedition E350. 


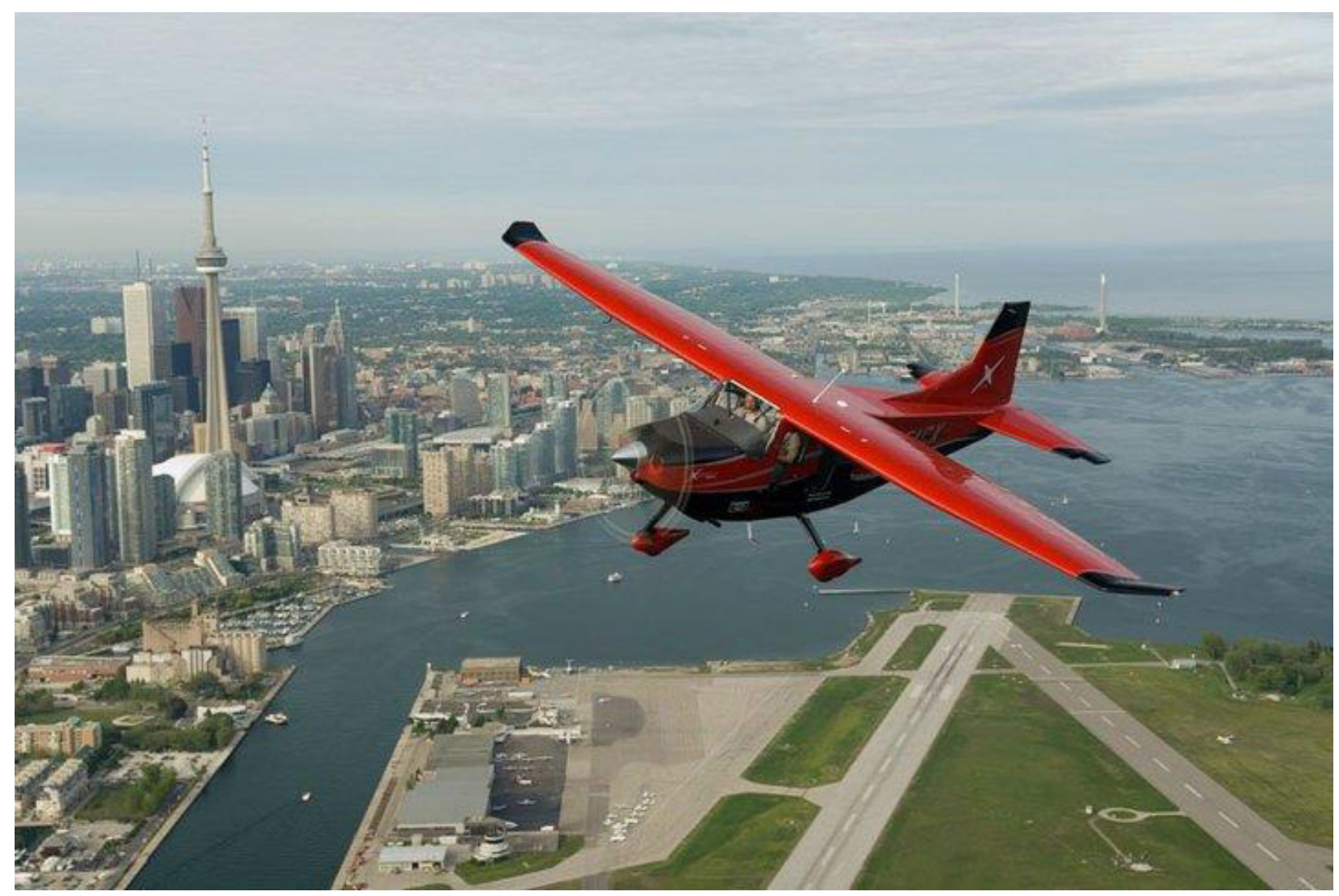

Figure 5.2 Found aircraft Expedition E350

Table 5.1 Performance specification of Expedition E350

\begin{tabular}{|c|c|}
\hline Parameters & Values \\
\hline Engine Model & IO-580-B1A \\
\hline $\begin{array}{c}\text { Maximum Engine Power } \\
(H P)\end{array}$ & 315 @ 2700RPM \\
\hline Dry Engine Weight $(l b)$ & 444 \\
\hline $\begin{array}{c}\text { Engine Dimension } \\
\text { (height-width-length, } \text { in })\end{array}$ & $21.04-34.25-39.34$ \\
\hline Compression Ratio & $8.9: 1$ \\
\hline $\begin{array}{c}\text { Fuel Flow @ 75\% Power } \\
\text { (gallon/hr) }\end{array}$ & 19.63 \\
\hline Propeller & 3800 \\
\hline $\begin{array}{c}\text { Maximum Takeoff Weight } \\
(l b)\end{array}$ & 3800 \\
\hline $\begin{array}{c}\text { Maximum Landing Weight } \\
(l b)\end{array}$ & 100 \\
\hline Total Fuel $($ gallon $)$ & 400.25 \\
\hline Cruising Distance $($ nm $)$ & 146.29 \\
\hline Cruise Speed $($ knots $)$ & 8000 \\
\hline Pressure Altitude $(f t)$ & \\
\hline
\end{tabular}


This aircraft was chosen for the thesis because of its performance characteristics and the mission objective. Compared to other aircraft in similar category, it exceled in many performance criteria, as seen on Appendix C. Moreover, it was a bush plane with a rugged design, capable of takeoff and landing on rough airstrips in relatively short distances. In addition, this aircraft was FAA type certified. Finally, the availability of the aircraft data was a big factor. The necessary data was acquired from the Found Aircraft.

\subsection{MDO Analysis Modules}

\subsubsection{Aerodynamics}

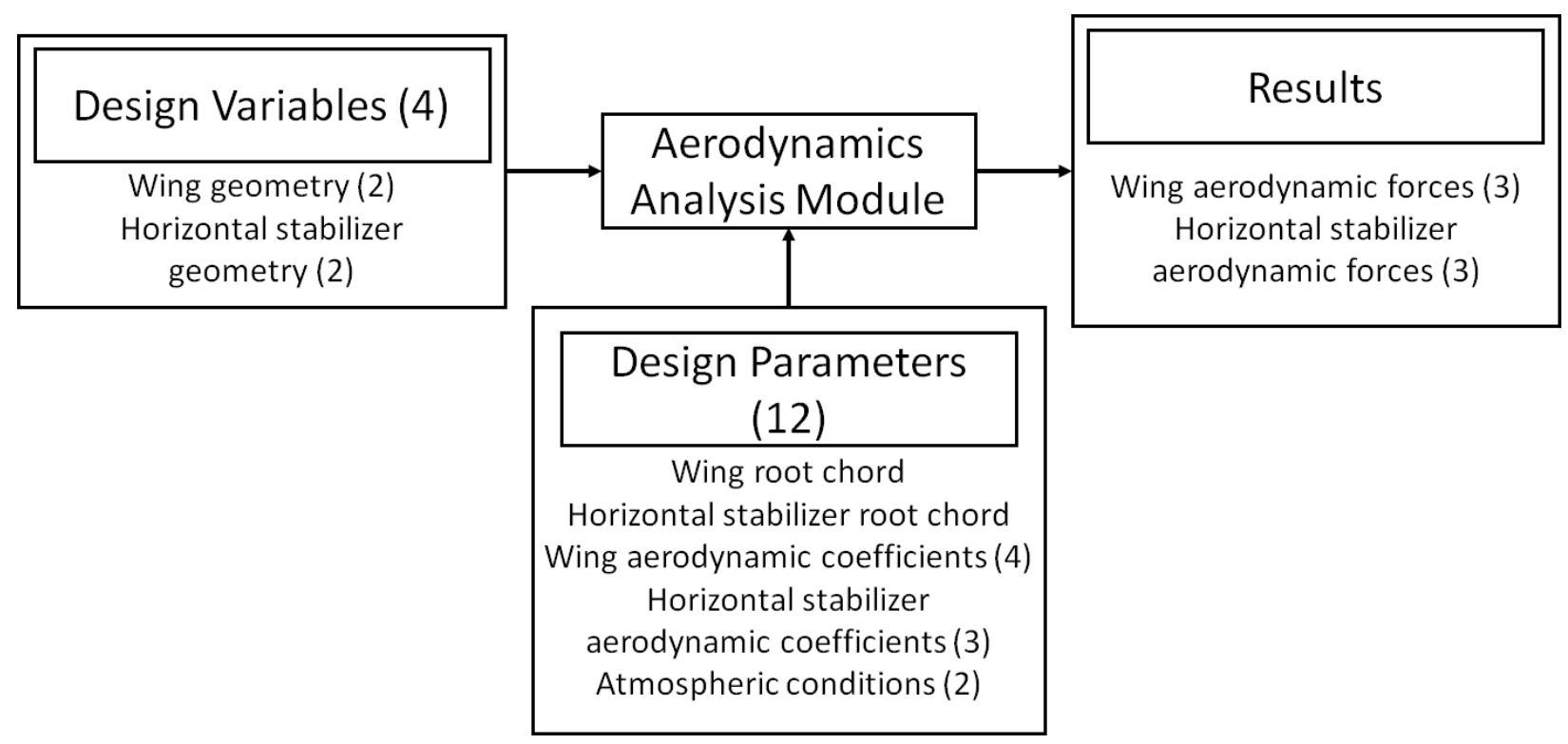

Figure 5.3 Aerodynamics analysis module

The aerodynamic module governed the shape and aerodynamics of the wing and the horizontal stabilizer. Figure 5.3 showed how the module was handled. The original shape of the main wing of the Expedition E350 was complicated. The root section of the wing was uniform where the tip section was tapered; forward swept and had linear change in airfoil thickness as it reaches the tip. The wing tip itself was backward swept Hoerner wing tip. 


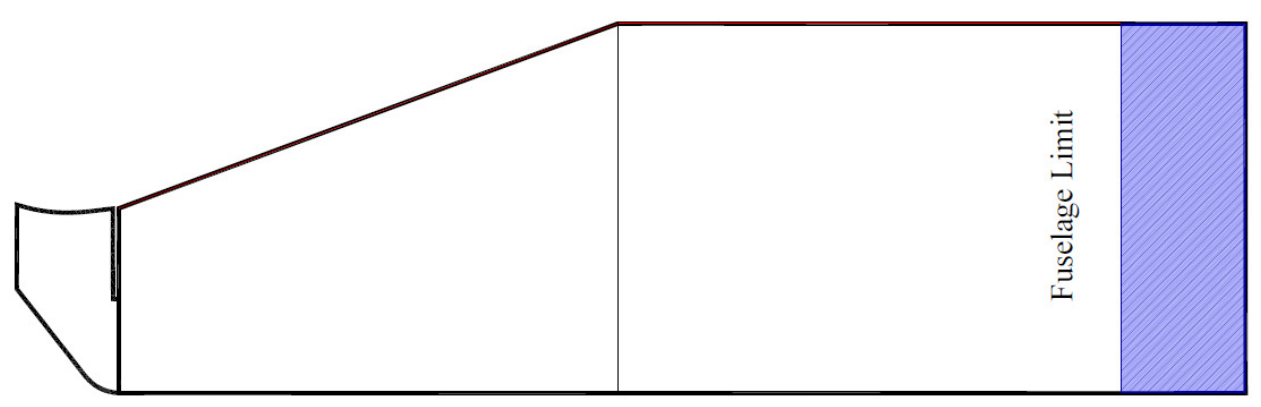

Figure 5.4 Original wing shape

This wing shape however was too complex to be applied to the thesis because it had too many variables. Therefore, the shape of the wing was simplified to a single sectioned tapered wing, where the taper of the wing started from the root rather than from half section.

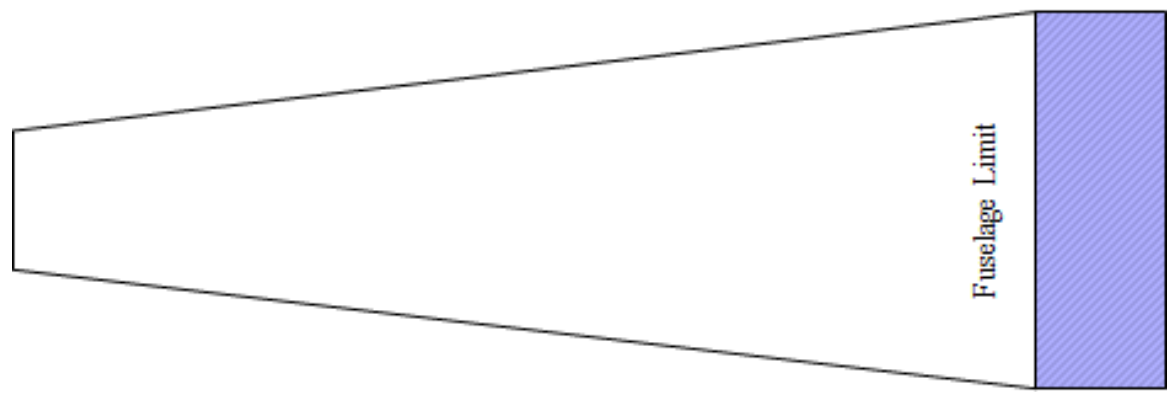

Figure 5.5 Modified wing shape

This allowed use of simpler aerodynamic calculations rather than resource-heavy options such as Computational Fluid Dynamics (CFD) for the module. Variables were calculated using the basic aerodynamics equations from various textbooks [58-62]: These equations were used because the thesis is dealing with the conceptual design stage.

$$
\lambda_{w}=\frac{c_{t_{w}}}{c_{r_{w}}}
$$

$\lambda_{w}$ was the wing tapered ratio, $c_{r w}$ and $c_{t w}$ were root and tip chord length of wing respectively.

$$
S_{w}=\frac{\left(c_{r_{w}}+c_{t_{w}}\right) b_{w}}{2}
$$

$S_{w}$ was the wing surface area, $b_{w}$ was the wing span length.

$$
\bar{c}_{w}=\frac{2}{3} c_{r_{w}}\left(\frac{1+\lambda_{w}+\lambda_{w}{ }^{2}}{1+\lambda_{w}}\right)
$$


$\bar{c}_{w}$ was the mean aerodynamic chord.

$$
A R_{w}=\frac{b_{w}{ }^{2}}{S_{w}}
$$

$A R_{w}$ was the aspect ratio of the wing.

$$
e_{w}=1.78\left(1-0.045 A R_{w}^{2}\right)-0.64
$$

$e_{w}$ was the Oswald efficiency factor and induced drag factor, $K_{w}$ was shown blow.

$$
\begin{gathered}
K_{w}=\frac{1}{\pi A R_{w} e_{w}} \\
C_{L_{w}}=\frac{C_{l_{w}}}{1+\frac{2}{A R_{w}}}
\end{gathered}
$$

$C_{L w}$ was the lift coefficient of the finite wing, and $C_{l w}$ was the lift coefficient of the 2dimensional wing.

$$
C_{D_{o_{w}}}=\frac{C_{d_{w}}}{1+\frac{2}{A R_{w}}}
$$

$C_{\text {Dow }}$ was the drag coefficient.

$$
C_{D_{w}}=C_{D_{o_{w}}}+K_{w} C_{L_{w}}^{2}
$$

$C_{D w}$ was the drag coefficient with induced drag.

$$
C_{M_{w}}=\frac{C_{m_{w}}}{1+\frac{2}{A R_{w}}}
$$

$C_{M w}$ was the moment coefficient the finite wing, and $C_{m w}$ was the moment coefficient of the 2-dimensional wing. The aerodynamic forces were calculated by:

$$
\begin{gathered}
L_{w}=q S_{w} C_{L_{w}} \\
D_{w}=q S_{w} C_{D_{w}} \\
M_{w}=q S_{w} C_{M_{w}} \bar{c}_{w}
\end{gathered}
$$


Where the $q$ was the dynamic pressure. The variables for the Horizontal Stabilizer (HS) used same equations for its aerodynamic calculation, with subscript $h s$. Two-dimensional aerodynamic coefficients were found by using JavaFOIL [63], using NACA23016 airfoil for the main wing, and NACA0012 for the horizontal stabilizer.

\subsubsection{Weight and Balance}

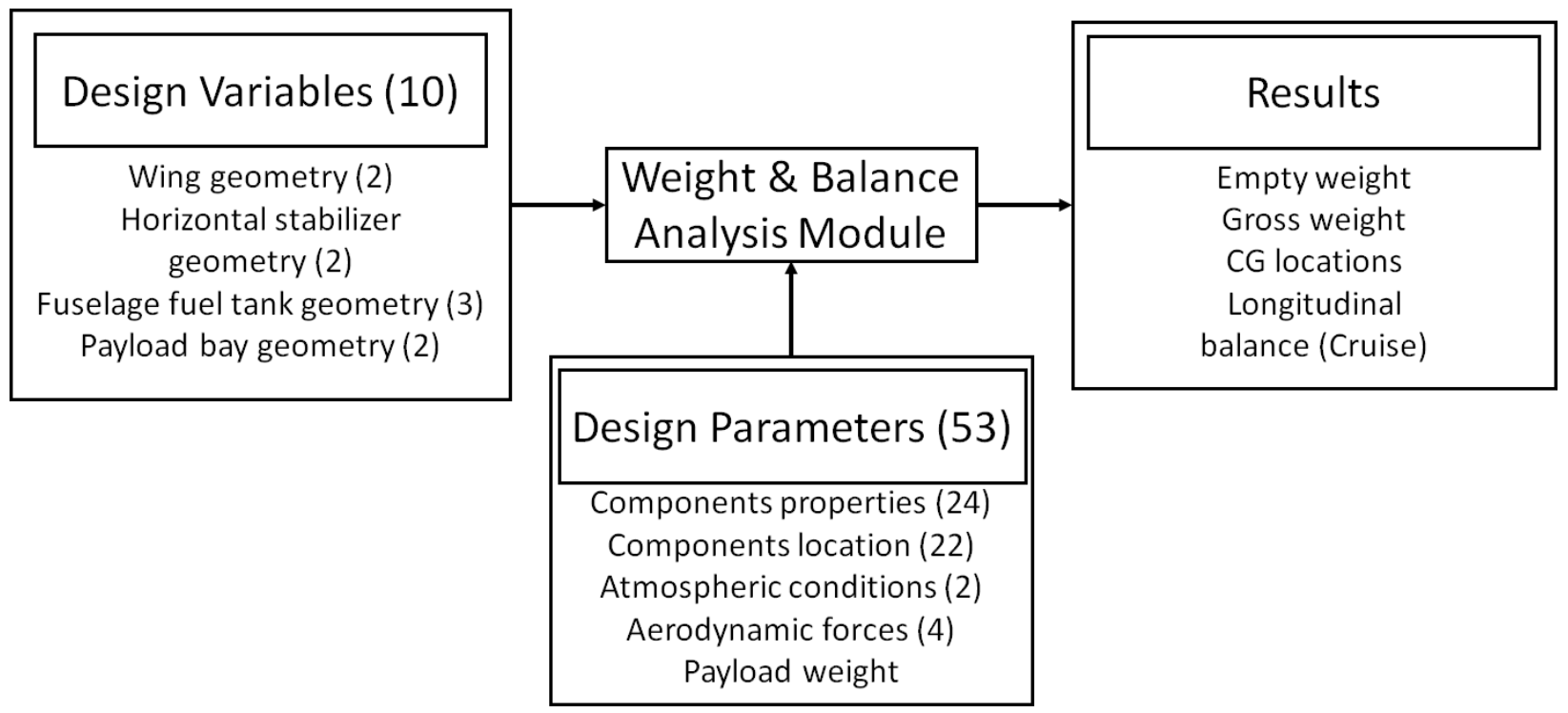

Figure 5.6 Weight and balance analysis module

Weight and Balance discipline calculated the empty weight of the aircraft along with the Centre of Gravity (CG) location in $\mathrm{x}$ and $\mathrm{z}$ axis. The CG in y direction was assumed to be zero. Figure 5.6 showed how the module was handled. This discipline also governed the longitudinal balance of the aircraft in cruising stage. The empty weight of the aircraft was calculated by adding the weight of each component [61].

$$
\begin{gathered}
W_{w}=0.036 S_{w}{ }^{0.758} W_{F_{w}}{ }^{0.0035}\left(\frac{A R_{w}}{\cos ^{2} \Lambda_{w}}\right)^{0.6} q^{0.006} \lambda_{w}{ }^{0.04}\left(\frac{100 t / c}{\cos \Lambda_{w}}\right)^{-0.3}\left(N_{z} W_{d g}\right)^{0.49} \\
W_{h s}=0.016\left(N_{z} W_{d g}\right)^{0.414} q^{0.168} S_{h s}{ }^{0.896}\left(\frac{100 t / c}{\cos \Lambda_{h s}}\right)^{-0.12}\left(\frac{A R_{h s}}{\cos ^{2} \Lambda_{h s}}\right)^{0.043} \lambda_{h s}{ }^{-0.02}
\end{gathered}
$$




$$
W_{v s}=0.073\left(N_{z} W_{d g}\right)^{0.376} q^{0.122} S_{v s}^{0.873}\left(\frac{100 * t / c}{\cos \Lambda_{v s}}\right)^{-0.49}\left(\frac{A R_{v s}}{\cos ^{2} \Lambda_{v s}}\right)^{0.357} \lambda_{v s}{ }^{-0.039}
$$

$S$ was the wing area, $W_{F_{w}}$ was the total fuel weight stored in the wing, $A R$ was the aspect ratio, $\Lambda$ was the sweep back angle, $q$ was the dynamic pressure, $\lambda$ was the taper ratio $t / c$ was the thicknessto-chord ratio, $N_{\mathrm{z}}$ was the limit load factor, and $W_{d g}$ was the design gross weight. Subscript $w, h s$ and $v s$ represented wing, horizontal stabilizer and vertical stabilizer respectively.

$$
W_{\text {fuse }}=0.052 S_{f}^{1.086}\left(N_{z} * W_{d g}\right)^{0.177} L_{t}{ }^{-0.051}\left(L_{\text {fuse }} / D_{\text {fuse }}\right)^{-0.072} q^{0.241}
$$

$S_{f}$ was the wetted area of the fuselage, $L_{t}$ was the distance between the mean aerodynamic chords of the wing and the horizontal stabilizer, $L_{\text {fuse }}$ was the length of the fuselage, $D_{\text {fuse }}$ was the depth of the fuselage.

$$
W_{\text {en,installed }}=2.575 W_{e n}{ }^{0.922} N_{e n}
$$

Where $W_{e n}$ was the weight of uninstalled engine and $N_{e n}$ was the number of engines. After components weight calculation, the empty weight of the aircraft was calculated by:

$$
W_{\text {empty }}=\sum_{i=1}^{12} W_{i}
$$

The CG of the aircraft was calculated by finding the net moment of every components of the aircraft, then dividing it by the empty weight.

$$
C G_{x}=\frac{\sum_{i=1}^{12} W_{i} x_{i}}{W_{e m p t y}}
$$

The CG for the $z$ axis was found similarly, but with $z$ coordinates for moment computation. The CG with gross weight was found similarly. Final calculation performed in this module was the longitudinal balance in cruising state. This was computed by finding net moment about the CG caused by the aerodynamic forces, then summing them up for net moment about the CG [62]. 


$$
\begin{gathered}
M_{C G_{w}}=L_{w} \cos \left(\alpha_{w}-i_{w}\right)\left(x_{c g}-x_{a c}\right)+D_{w} \sin \left(\alpha_{w}-i_{w}\right)\left(x_{c g}-x_{a c}\right) \\
+L_{w} \sin \left(\alpha_{w}-i_{w}\right)\left(z_{c g}\right)-D_{w} \cos \left(\alpha_{w}-i_{w}\right)\left(z_{c g}\right)+M_{a c_{w}}
\end{gathered}
$$

Where $\alpha_{w}$ was the angle of attack, $i_{w}$ was the wing incidence angle, $x_{c g}$ was the location of CG from the reference point, $x_{a c}$ was the location of aerodynamic centre from the reference $z$ axis, and $z_{c g}$ was the location of $\mathrm{CG}$ from reference $x$ axis. The reference lines can be seen on in section 5.3. Finally, $M_{a c_{w}}$ was the moment generated by the wing.

$$
\begin{aligned}
& M_{C G_{h s}}=-l_{t}\left[L_{w} \cos \left(i_{h s}+\varepsilon_{h s}\right)+D_{w} \sin \left(i_{h s}+\varepsilon_{h s}\right)\right] \\
& -z_{c g}\left[D_{h s} \cos \left(i_{h s}+\varepsilon_{h s}\right)-L_{h s} \sin \left(i_{h s}+\varepsilon_{h s}\right)\right]+M_{a c h s}
\end{aligned}
$$

$l_{t}$ was the distance between the $x_{c g}$ and horizontal stabilizer mean aerodynamic chord, $\varepsilon h s$ was the downwash generated by the main wing and $M_{a c}$ ws was the moment generated by the horizontal stabilizer. The net longitudinal moment then was computed by:

$$
M_{C G_{\text {long }}}=M_{C G_{w}}+M_{C G_{h s}}
$$

\subsubsection{Performance}

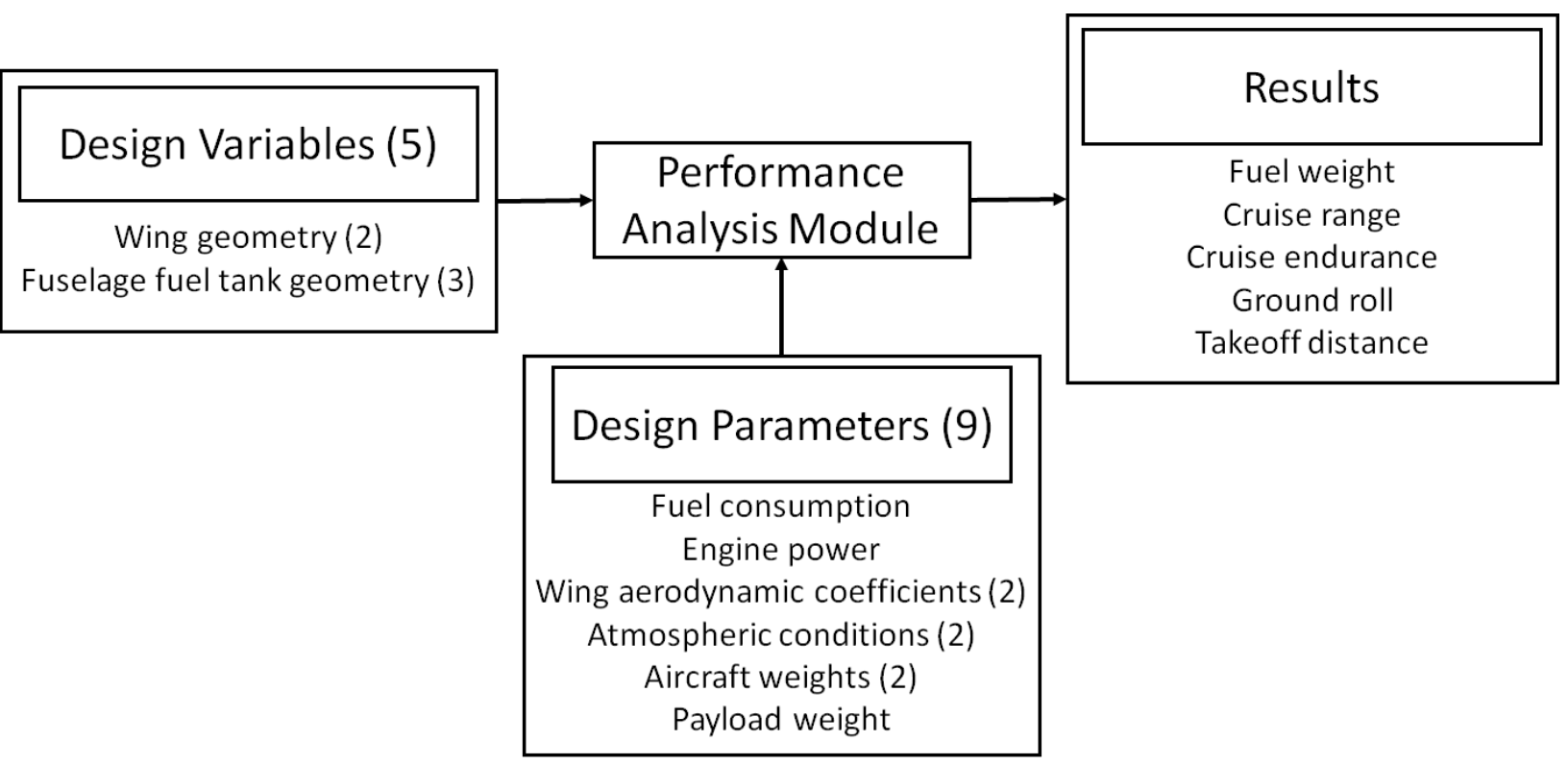

Figure 5.7 Performance analysis module 
The performance discipline calculated total fuel weight, range, endurance, ground-roll and total takeoff distance. The total fuel weight was calculated in this discipline rather than the weight and balance discipline because it was a critical factor to the range and endurance. The UAV derivative of the Expedition E350 had an interior configuration slightly different from the passenger version. The interior was horizontally split where the upper section was used for fuselage fuel tank and the lower section was used for payload bay. The total fuel weight was calculated by adding fuel weight from the wing tank and the new fuselage tank. The range and endurance was calculated by using conventional Breguet range equation [58]:

$$
R_{\text {cruise }}=\frac{\eta_{p r}}{B S F C} \frac{C_{L_{\text {cruise }}}}{C_{D_{\text {cruise }}}} \ln \frac{W_{\text {ini }}}{W_{\text {fin }}}
$$

Where $\eta_{p r}$ was the propeller efficiency, $B S F C$ was the brake specific fuel consumption, $\frac{C_{L_{\text {cruise }}}}{C_{D_{\text {cruise }}}}$ was the lift to drag ratio in cruise, $W_{\text {ini }}$ was the initial weight and $W_{\text {fin }}$ was the final weight. The endurance was found by dividing the calculated range by the cruise velocity. The takeoff distance was found by:

$$
S_{T O}=S_{T O G}+S_{T O A}
$$

Where $S_{T O}$ was the total takeoff distance, $S_{T O G}$ was the ground roll and $S_{T O A}$ was distance from takeoff to $50 f t$ obstacle. $S_{T O G}$ was found by:

$$
S_{T O G}=\frac{V_{L O F}{ }^{2} / 2}{\left({ }^{g} / W_{\text {sum }}\right)\left(\bar{T}-\bar{D}-\mu\left(W_{\text {sum }}-\bar{L}\right)\right)}
$$

Where $\mathrm{V}_{\text {LOF }}$ was the liftoff velocity, $\mathrm{g}$ was the gravitational acceleration, $\mathrm{W}_{\text {sum }}$ was the total takeoff weight, $\bar{T}, \bar{D}, \bar{L}$ was the thrust, drag, lift at mean kinetic energy airspeed and $\mu$ was the friction coefficient of the runway. Finally, $S_{T O A}$ was found by:

$$
S_{T O A}=R \sin \theta
$$


Where $\mathrm{R}$ was the turn radius and $\theta$ was the angle of the flight path from the liftoff position to $50 f t$ obstacle.

\subsection{MDO Formulation}

The optimization code for this thesis was developed in MATLAB [56]. The optimization method used was MDF [53], as explained in chapter 2. Formulated problem had the architecture on Figure 5.8

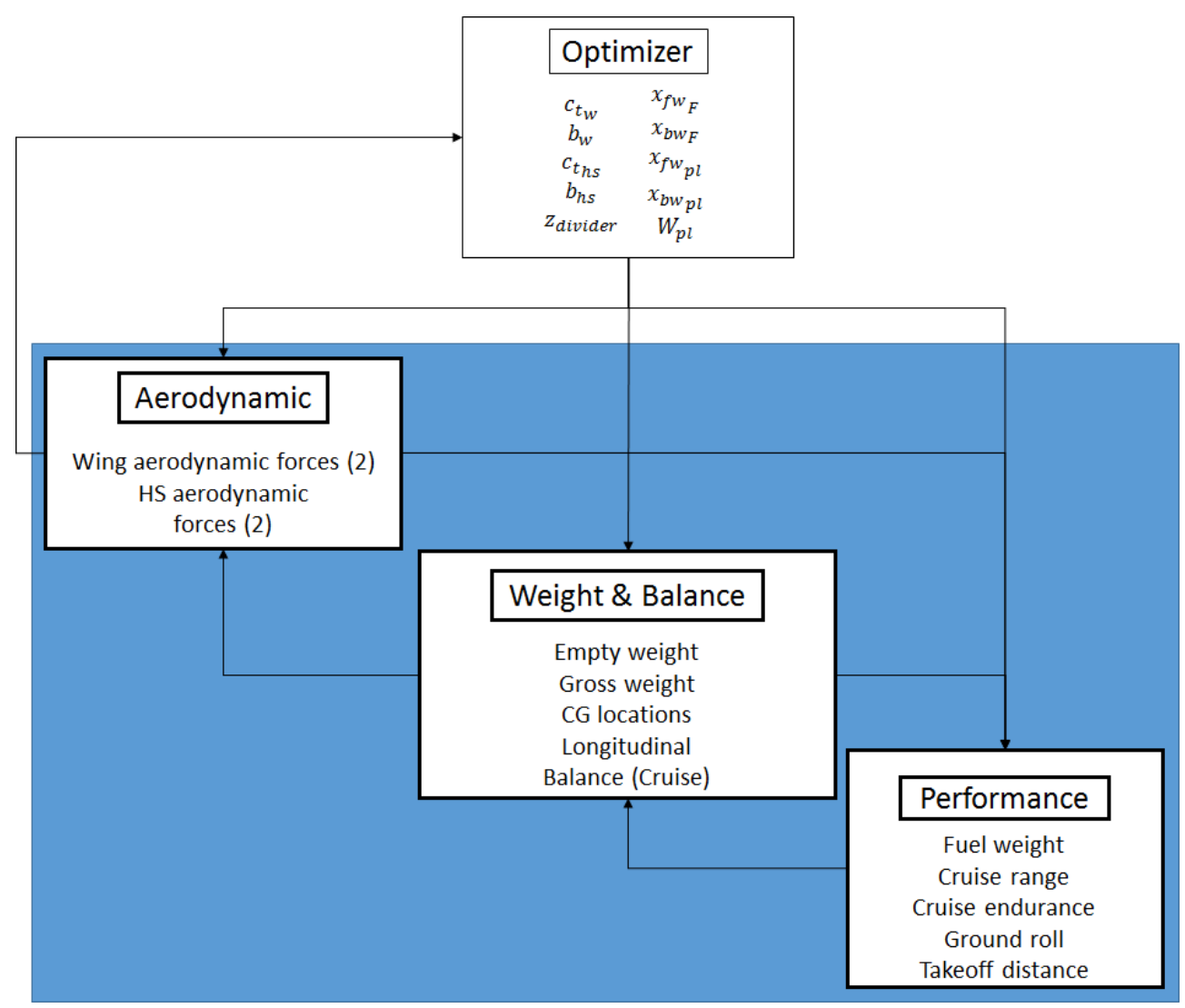

Figure 5.8 MDO architecture

The disciplines chosen for this MDO problem were aerodynamic, weight and balance and performance. The objective of the optimization was to maximize the endurance of the aircraft while meeting the constraints shown below. Optimization code was written in a way that it finds a minimum of a function. Therefore the actual cost function was the negative value of the endurance. 


$$
\begin{gathered}
c_{1}(X)=W_{\text {sum }}-L_{\text {total }} \\
c_{2}(X)=x_{c g}-10 \\
c_{3}(X)=W_{\text {sum }}-5000 \\
c_{4}(X)=S_{\text {TOG }}-1000 \\
c_{5}(X)=M_{c g}=0
\end{gathered}
$$

Equation (33) constrained the maximum takeoff weight $W_{\text {sum }}$ to be under the total lift generated by the aircraft $L_{\text {total }}$ while cruising. Equation (34) constrained that the location of the centre of gravity $x_{c g}$ does not exceed $10 f t$ from the nose of the aircraft along the $\mathrm{x}$ axis. Equation (35) constrained the aircraft from become too heavy, by limiting the maximum takeoff weight to 5000, a 32\% increase from the original aircraft. Equation (36) constrained the takeoff ground-roll distance $S_{T O G}$ to $1000 f t$ to keep the short take-off distance attribute of the aircraft. Finally, equation (37) constrained the moment generated at the centre of gravity $M_{c g}$ to be zero while cruising, to achieve longitudinal balance. $c_{5}$ was the only nonlinear equality constraint, and all of the other constraints were nonlinear inequality constraint.

Table 5.2 showed the design variables and its boundaries. These variables were chosen because they were the variables that affected the performance of the aircraft most, with least changes. Furthermore, if any dramatic changes were made to the aircraft such as changing the fuselage and empennage length or changing the airfoil of the wing, it would not be a derivative of the original aircraft, rather a new airplane.

The lower boundaries of $c_{t_{w}}, b_{w}$, were $50 \%$ of the root chord and $95 \%$ of the initial value respectively. $c_{t_{h s}}$ and $b_{h s}$ had lower boundaries of $85 \%$ of the initial value. The Upper boundaries of $c_{t_{w}}$, and $c_{t_{h s}}$ were set as the root chord of the wing and the HS simultaneously. The lower and upper boundaries of the wall and the divider locations were bounded by the physical geometry of 
the aircraft. Finally, the Payload weight had the lower boundary equal to the initial value, so the optimized aircraft carries at lease the same weight of payload as the initial aircraft. visualized some of the design variables.

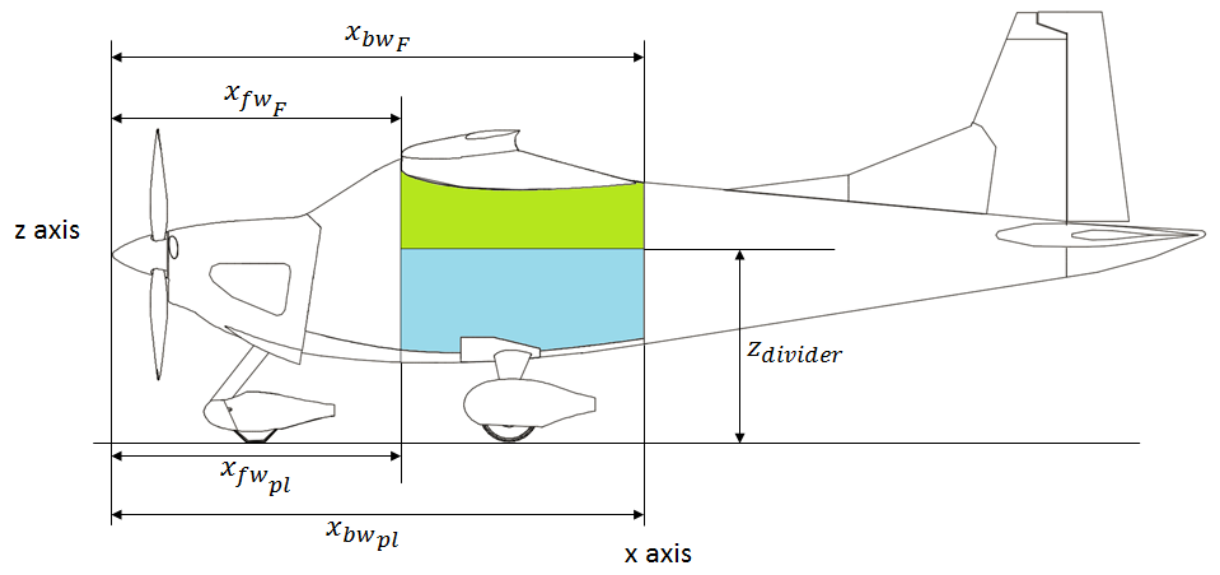

Figure 5.9 Design variables on aircraft geometry

Table 5.2 Design variables and its boundaries

\begin{tabular}{|c|c|c|c|c|c|}
\hline Name & Description & Unit & Initial Value & $\begin{array}{c}\text { Lower } \\
\text { Boundary }\end{array}$ & $\begin{array}{c}\text { Upper } \\
\text { Boundary }\end{array}$ \\
\hline$c_{t_{w}}$ & Wing Tip Chord & $f t$ & 4.28 & 2.85415 & 5.7083 \\
\hline$b_{w}$ & Wing Span & $f t$ & 38.167 & 36.2587 & 47.709 \\
\hline$c_{t_{h s}}$ & HS Tip Chord & $f t$ & 1.8123 & 1.54045 & 4.825 \\
\hline$b_{h s}$ & HS Span & $f t$ & 11.4383 & 9.72255 & 17.1574 \\
\hline$x_{f w_{F}}$ & $\begin{array}{c}\text { Forward wall } \\
\text { location from nose } \\
\text { for fuselage fuel } \\
\text { tank }\end{array}$ & $f t$ & 5.067 & 5.066 & 8.05 \\
\hline$x_{b w_{F}}$ & $\begin{array}{c}\text { Rear wall location } \\
\text { from nose for } \\
\text { fuselage fuel tank }\end{array}$ & $f t$ & 12.913 & 9.05 & 12.914 \\
\hline$x_{f w_{p l}}$ & $\begin{array}{c}\text { Forward wall } \\
\text { location from nose } \\
\text { for payload bay }\end{array}$ & $f t$ & 5.067 & 5.066 & 8.05 \\
\hline$x_{b w_{p l}}$ & $\begin{array}{c}\text { Rear wall location } \\
\text { from nose for } \\
\text { payload bay }\end{array}$ & $f t$ & 12.913 & 9.05 & 12.914 \\
\hline$z_{\text {divider }}$ & $\begin{array}{c}\text { Location of fuel tank } \\
\text { and payload bay } \\
\text { divider }\end{array}$ & $f t$ & 7.26 & 3.27 & 7.27 \\
\hline$W_{p l}$ & $\begin{array}{c}\text { Payload Weight } \\
\text { Pand }\end{array}$ & $l b$ & 900 & 900 & 1500 \\
\hline
\end{tabular}




\subsection{Virtual Flight Test Setup}

The test flights had been done on three aircraft models: 'Original', 'Initial' and 'Optimized' models as seen on Figure 5.10. The first model or 'Original' model represented with the exact size and shape of the Expedition E350. The second model or 'Initial' model represented with the simplified wing and horizontal stabilizer with initial variables. The final model or 'Optimized' model represented with the results from the optimization. Each aircraft model went through different series of virtual flight tests.
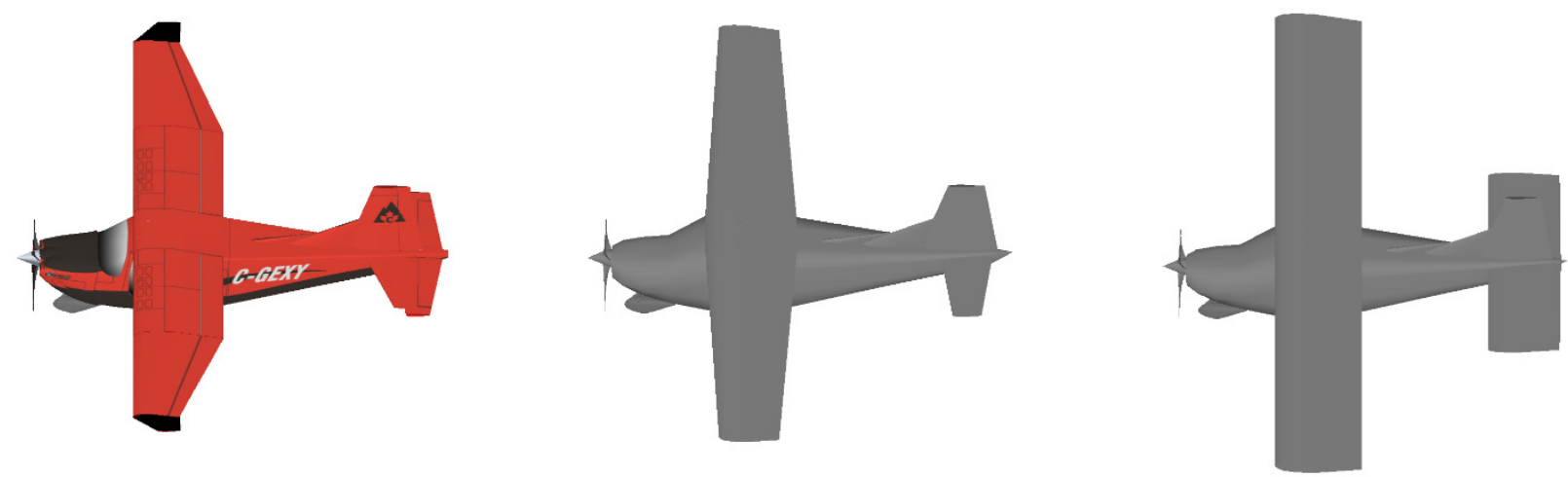

Figure 5.10 'Original', 'Initial' and 'Optimized' aircraft models from left to right

\subsubsection{Test 1}

The main objective of the first test was verifying the cruise performance of the 'Original' model by comparing its result with the reference from the Pilot's Operating Handbook (POH) [64]. Moreover, the cruise performance of each models were compared side by side. Each aircraft was flown at the pressure altitude of 2,000 to $12,000 \mathrm{ft}$, with 2,000 ft increments. Once the aircraft reached the designated altitude, its power was adjusted to 2,600 RPM then the aircraft was stabilized until it was in steady cruise state. From this test, the cruise speed and the fuel consumption of each aircraft was found. 


\subsubsection{Test 2}

The second test checked the yaw stability of the aircraft by plotting the sideslip angle after small disturbance. The test was performed at 8,000 ft pressure altitude with 2,600 engine RPM. After the aircraft was stabilized, a small disturbance was applied by a step input for rudder. To reduce human interface error, autopilot was engaged. When the autopilot was engaged, rudder was the only control activated. Hence only the yawing stability was checked. Natural frequency $\omega_{n}$, damping ratio $\zeta$ and time to half amplitude $T_{1 / 2}$ can be also computed from Figure 5.11 using following equations [65].

$$
\begin{gathered}
\zeta=\frac{|\ln (T P R)|}{\sqrt{\pi^{2}+\ln ^{2}(T P R)}} \\
\omega_{n}=\frac{2 \pi}{T_{p} \sqrt{1-\zeta^{2}}}
\end{gathered}
$$

Where $T_{p}$ was time from peak to peak and TPR was Transient Peak Ratio, computed by:

$$
T P R=\frac{\left(\frac{D A_{2}}{D A_{1}}+\frac{D A_{3}}{D A_{2}}+\frac{D A_{4}}{D A_{3}}+\cdots+\frac{D A_{N+1}}{D A_{N}}\right)}{N}
$$

Where DA was the peak to trough distance, shown in Figure 5.11 below. $\mathrm{N}$ was number of peaks:

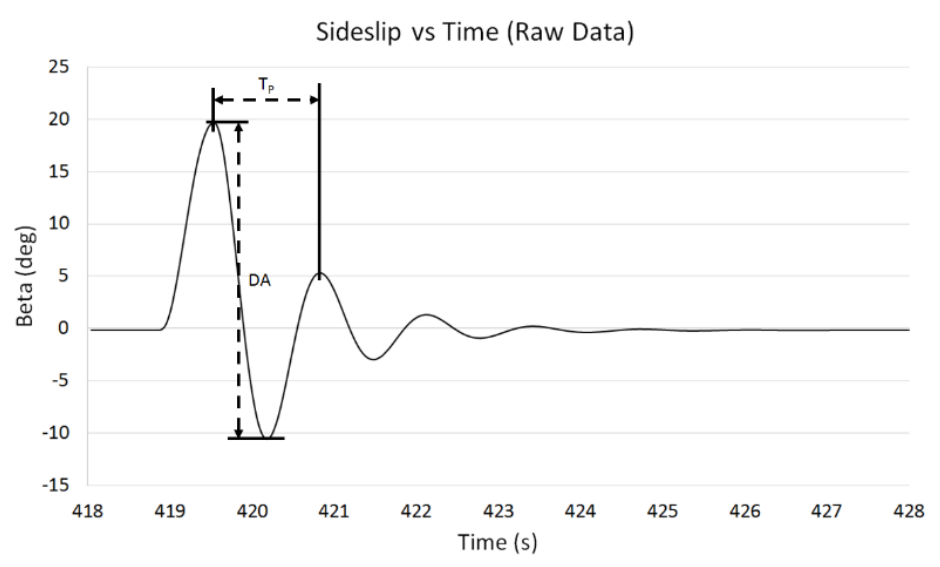

Figure 5.11 $T_{p}$ and DA example 


\subsubsection{Test 3}

The final test was a scenario test where two airports were selected and a full flight was commenced. Table 5.3 showed the two selected airports with their attributes. From takeoff to landing, the aircraft configuration was set to the setting from the $\mathrm{POH}$ as seen on Table 5.4. The detailed mission profile could be seen on Figure 5.12.

Table 5.3 Selected airports for scenario test flight

\begin{tabular}{|c|c|c|}
\hline & Takeoff airport & Landing airport \\
\hline Name & $\begin{array}{c}\text { Buttonville } \\
\text { Municipal, CYKZ }\end{array}$ & $\begin{array}{c}\text { Collingwood } \\
\text { Regional, CNY3 }\end{array}$ \\
\hline Wind (knots) & 0 & 0 \\
\hline Temperature $($ celsius $)$ & $20^{\circ}$ & $20^{\circ}$ \\
\hline Pressure Altitude $(f t)$ & 650 & 730 \\
\hline
\end{tabular}

Table 5.4 Flap and throttle setting

\begin{tabular}{|c|c|c|c|}
\hline & Takeoff Setting & Cruise Setting & Landing Setting \\
\hline Flap & $20^{\circ}$ & $0^{\circ}$ & $30^{\circ}$ \\
\hline Throttle (\%) & 100 & $\begin{array}{c}\text { Adjusted to meet } \\
\text { the required RPM }\end{array}$ & $\begin{array}{c}\text { Adjusted to } \\
\text { meet the v }\end{array}$ \\
\hline
\end{tabular}

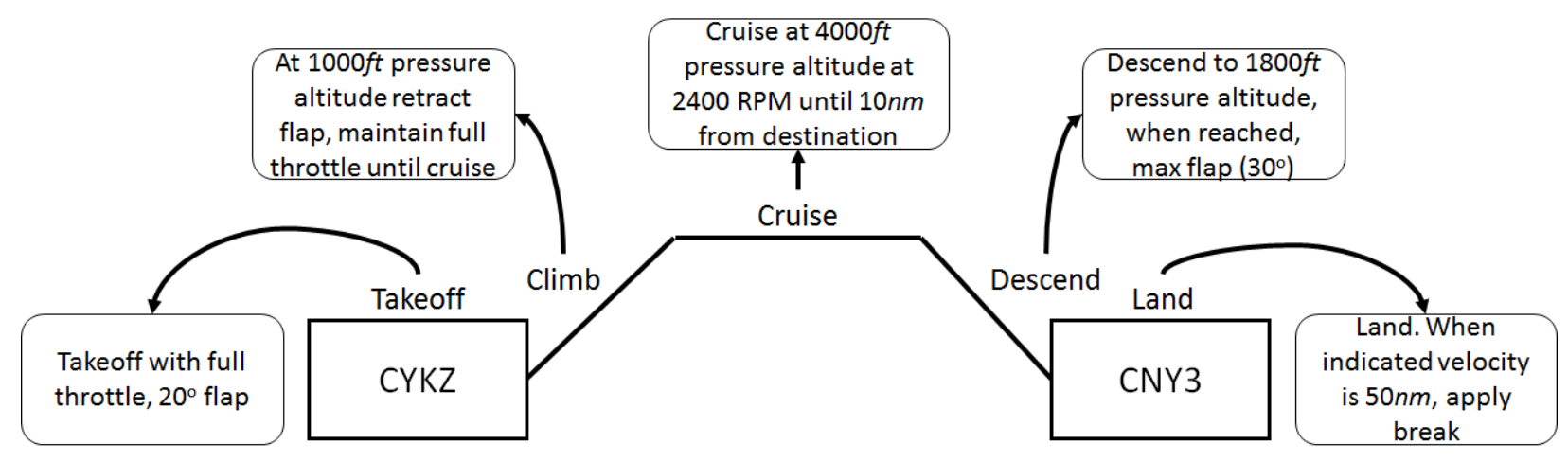

Figure 5.12 Detailed mission profile

This test focused on gathering general performance data; takeoff performance and cruise performance. Landing performance was disregarded because landing was done manually by less experienced operator whrereas the climb and cruise was done with autopilot engaged. The data 
collected was used differently for each model. The virtual flight test result of the 'Original' model was compared with the result calculated from the $\mathrm{POH}$ to find the accuracy of the simulation in terms of performance. Sample calculations from the $\mathrm{POH}$ was shown on Appendix F. The virtual flight test result of the 'Initial' model was compared with the test result of the 'Original; model to check how well the simplified model represented the original aircraft. Finally, the virtual flight test result of the 'Optimized' model was compared with the numerical result optained from the MDO. 


\section{Chapter 6 Results and Discussion}

\subsection{Optimization Results}

The convergence history of the optimization was shown in Figure 6.1. It represented the negative values of the cost function history. As seen on Table 6.1, the solution was converged without any constraint violation. Figure 6.2 demonstrated the physical shape of the optimized UAV. Compared to the original aircraft or initial aircraft, the wing and horizontal stabilizer's size increased. This was to ensure the wing generated enough lift for increased weight. A careful study of Table 6.1 and Table 6.2 indicated that the optimizer found the perfect balance between the weight (increased by fuel quantity) and lift. Analyzing the Breguet equation showed there were several ways to increase the cruise range. The propeller with higher efficiency or more efficient engine could not be used because it was not considered as a design variable. Another way to increase the cruise range was to increase the $C_{L} / C_{D}$ ratio. This was also not a valid option because the airfoil was not considered as a design variable. The change of engine, propeller and airfoil was 
not considered because this was a derivative design. The last option left to increase the cruise range was to increase the $W_{i n i} / W_{f i n}$ ratio. Assuming there were no changes in the payload weight, the only way to increase the $W_{\text {ini }} / W_{\text {fin }}$ ratio was increasing the fuel weight. The horizontal stabilizer's size increased to counter the extra moment generated by the main wing. The endurance of the aircraft increase to 21.715 hours, from 10 hours.

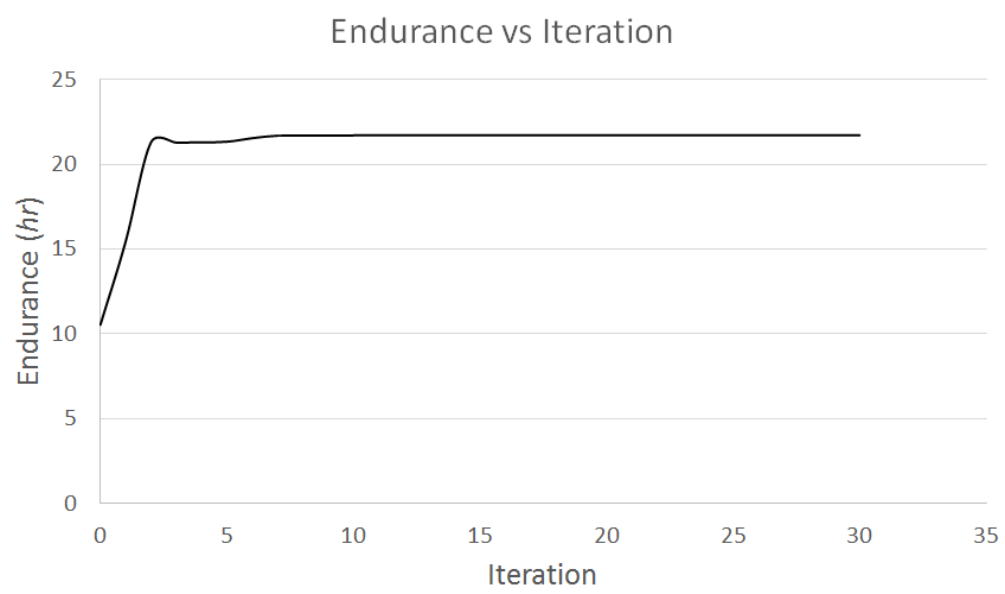

Figure 6.1 Convergence history - endurance

Table 6.1 Constraint satisfactory

\begin{tabular}{|c|c|c|c|}
\hline Constraint & Initial Value & Optimized Result & $\begin{array}{c}\text { Constraint } \\
\text { Achieved }\end{array}$ \\
\hline$c_{1}(X)=W_{\text {sum }}-L_{\text {total }}$ & -174.7 & 0 & $\checkmark$ \\
\hline$c_{2}(X)=X_{c g}-10$ & -1.9 & -1.0 & $\checkmark$ \\
\hline$c_{3}(X)=W_{\text {sum }}-5000$ & -1351.8 & 0 & $\checkmark$ \\
\hline$c_{4}(X)=S_{T O G}-2000$ & -1377.1 & -1067.5 & $\checkmark$ \\
\hline$c_{5}(X)=M_{c g}=0$ & -5477.3 & 0 & $\checkmark$ \\
\hline
\end{tabular}
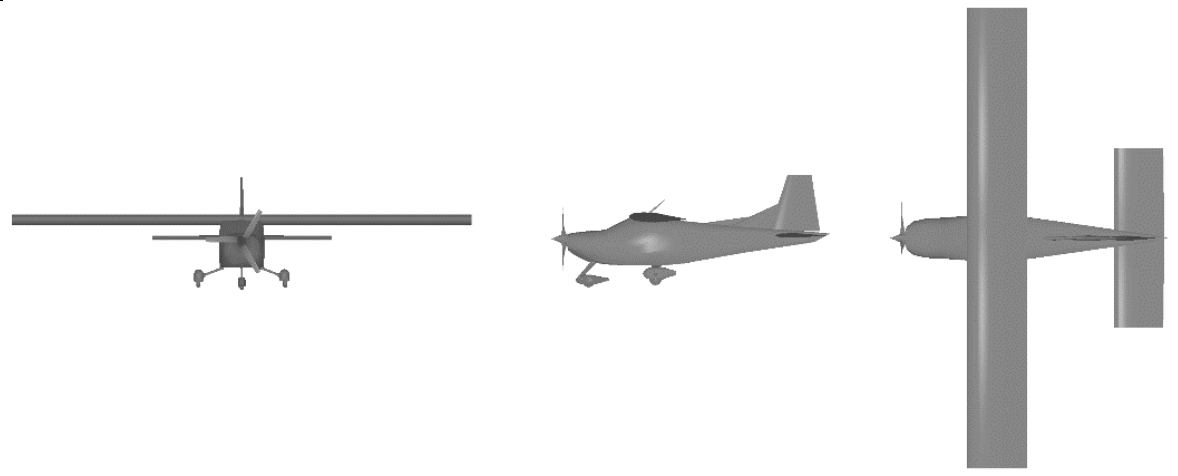

Figure 6.2 Front, side, top view of the optimized UAV 
Table 6.2 Optimized design variable

\begin{tabular}{|c|c|c|c|}
\hline Name & Unit & Initial Value & Optimized Value \\
\hline$c_{t_{w}}$ & $f t$ & 4.28 & 5.7083 \\
\hline$b_{w}$ & $f t$ & 38.167 & 43.9765 \\
\hline$c_{t_{h s}}$ & $f t$ & 1.8123 & 4.7406 \\
\hline$b_{h s}$ & $f t$ & 11.4383 & 17.1574 \\
\hline$x_{f w_{F}}$ & $f t$ & 5.067 & 8.05 \\
\hline$x_{b w_{F}}$ & $f t$ & 12.913 & 12.914 \\
\hline$x_{f w_{p l}}$ & $f t$ & 5.067 & 8.05 \\
\hline$x_{b w_{p l}}$ & $f t$ & 12.913 & 12.914 \\
\hline$z_{\text {divider }}$ & $f t$ & 7.26 & 6.261 \\
\hline$W_{p l}$ & $l b$ & 900 & 900 \\
\hline
\end{tabular}

\subsection{Flight Simulation Results}

\subsubsection{Test 1 Result}

The results from the first test was divided into each section with corresponding altitude. The fuel consumption was computed by subtracting the final fuel weight from the starting fuel weight, divided by the time segment. The airspeed average was calculated within the same range of data. These data were presented on Appendix D. Figure 6.3 showed the performance error between the 'Original' model and the actual flight data. The maximum error was at 6,000 ft pressure altitude with $9.75 \%$ error for the fuel consumption. The minimum error was at $10,000 \mathrm{ft}$ pressure altitude with $0.23 \%$ error for the speed. Generally, the error was below $10 \%$. Considering the actual flight data was taken from virtual flight tests which were performed in uncontrolled environment, this value was acceptable. 


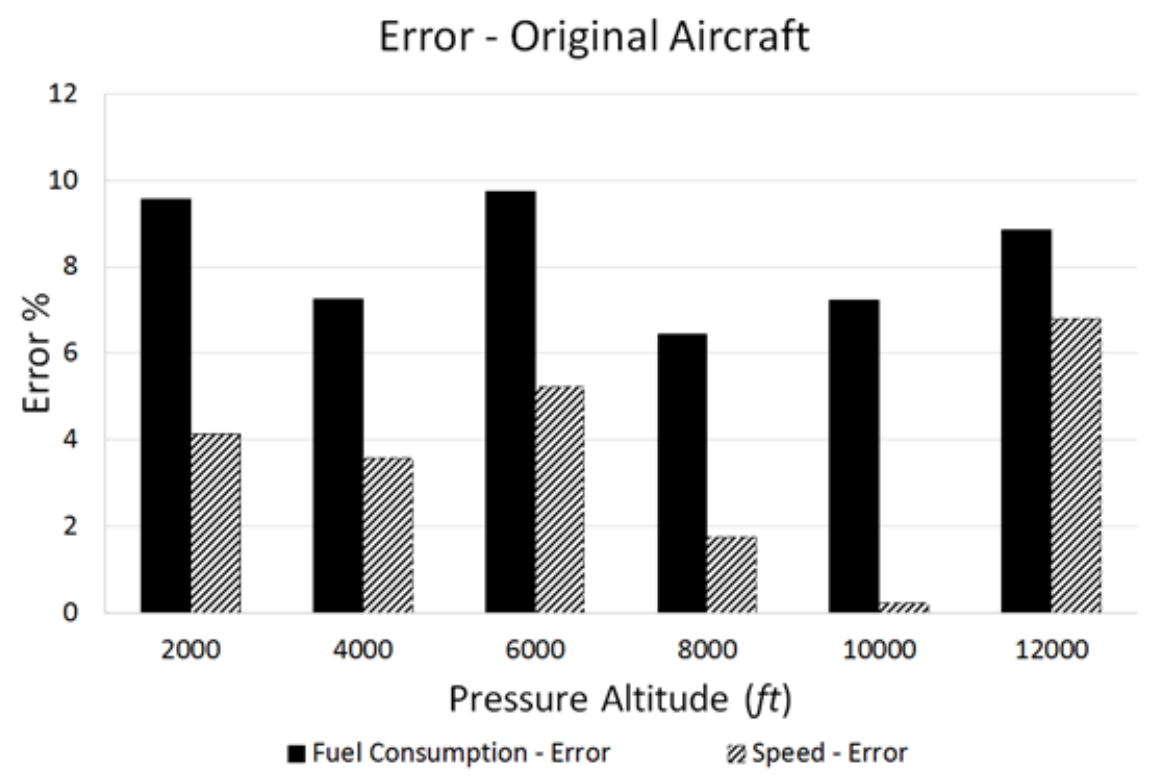

Figure 6.3 Fuel consumption and speed error - 'Original' vs POH

Figure 6.4 and Figure 6.5 showed the fuel consumption and cruise speed comparison respectively. The fuel consumption of the 'Optimized' model was slightly higher than that of the 'Initial' model. However, since the 'Optimized' model carries more fuel, it had extended range and endurance. This also affected the cruise speed of the 'Optimized' model. It had the slowest cruise speed until $10000 \mathrm{ft}$ because it was the heaviest of the three models. Both fuel consumption and cruise speed show similarity in trends. 


\section{Fuel Consumption}

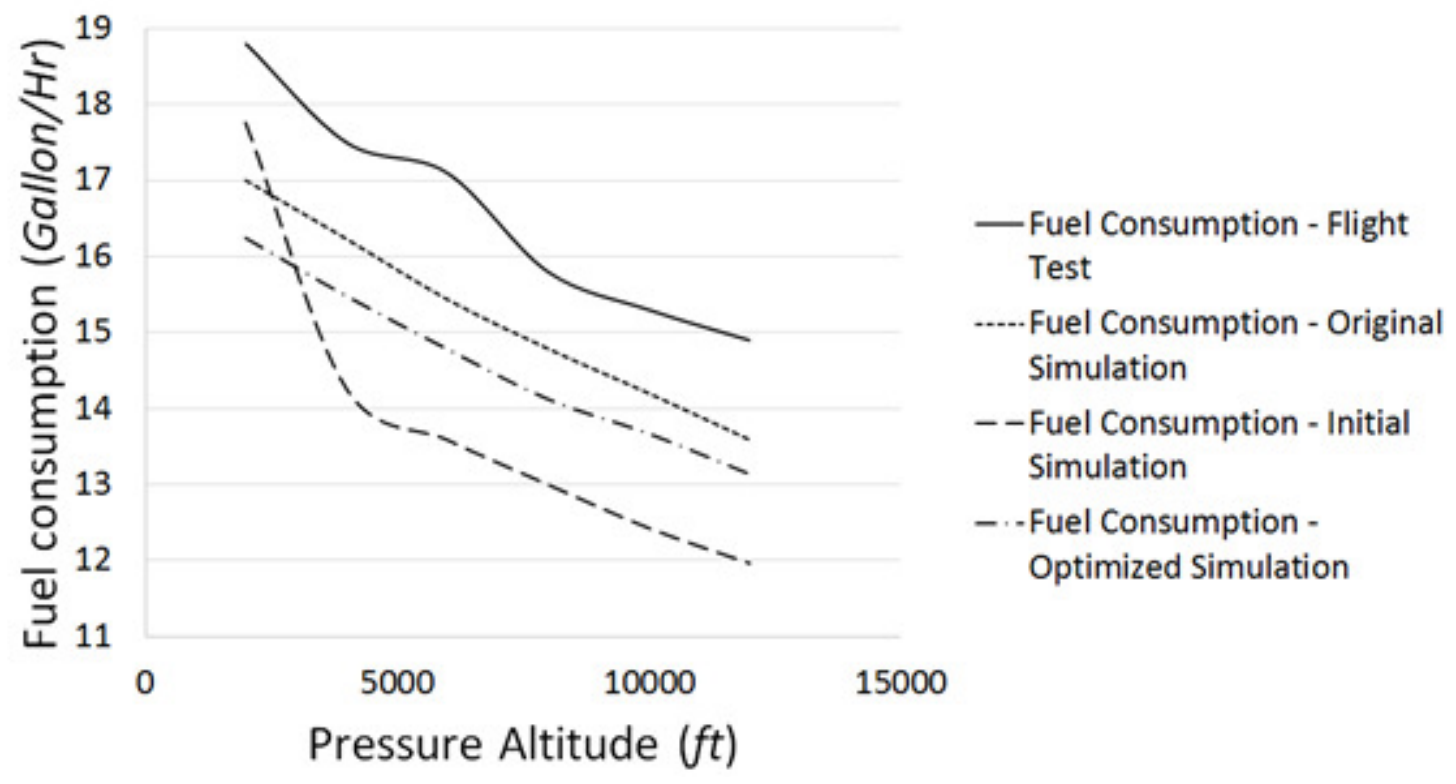

Figure 6.4 Fuel consumption comparison

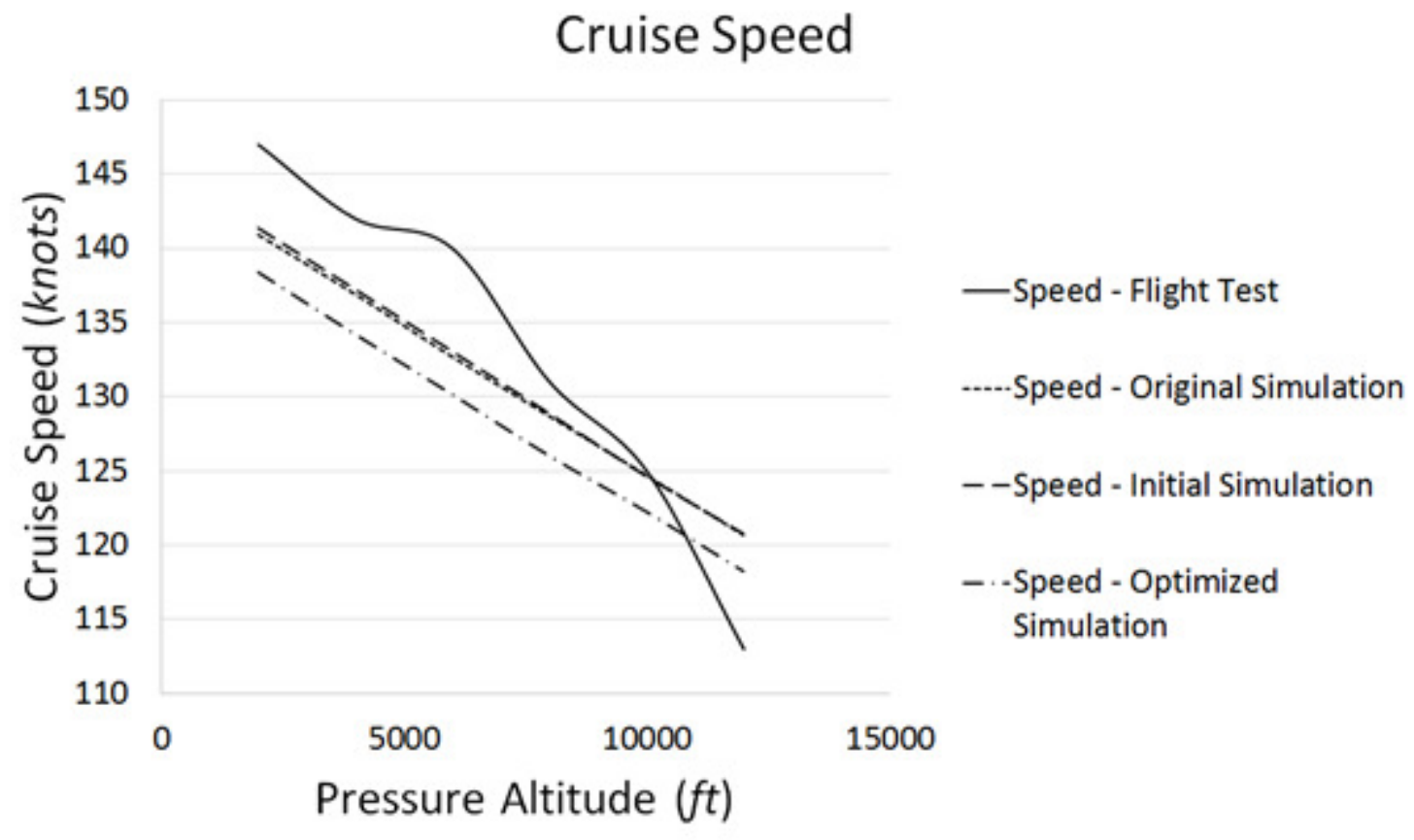

Figure 6.5 Cruise speed comparison 


\subsubsection{Test 2 Result}

The objective of this test was to verify the response of the aircraft after the disturbance, and calculate its $\omega_{n}, \zeta$ and $T_{1 / 2}$. Figure 6.6 represented each aircraft's sideslip angle respect to normalized time when $100 \%$ of the rudder was input. The 'Original' and 'Initial' sideslip angles coincided with each other. This showed that the simplified 'Initial' model's lateral stability characteristic was almost identical to that of the 'Original' model's whereas the 'Optimized' model showed a discrepancy. Table 6.3 showed the calculated $\omega_{n}, \zeta$ and $T_{1 / 2}$. Appendix E showed the data acquired to calculate these values.

\section{Sideslip vs Time}

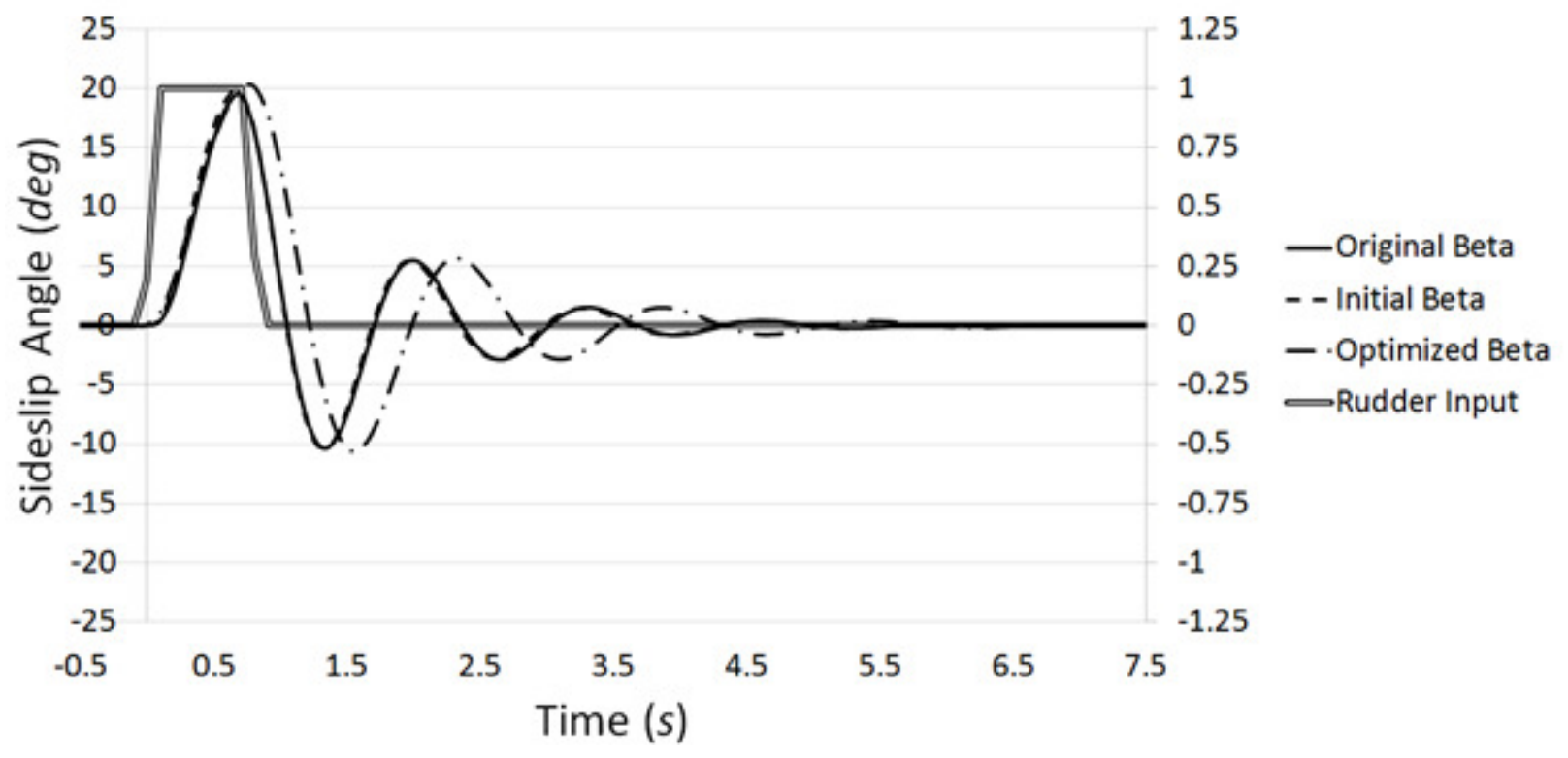

Figure 6.6 Sideslip vs. time graph

Table $6.3 \omega_{n}, \zeta$ and $T_{1 / 2}$ calculation results

\begin{tabular}{|c|c|c|c|}
\hline Model & $\begin{array}{c}\text { Natural } \\
\text { Frequency } \omega_{n},\end{array}$ & $\begin{array}{c}\text { Damping } \\
\text { Ratio } \zeta\end{array}$ & $\begin{array}{c}\text { Time to Half } \\
\text { Amplitude } T_{1 / 2}\end{array}$ \\
\hline Original Model & 4.9148 & 0.1994 & 0.7042 \\
\hline Initial Model & 4.9603 & 0.2047 & 0.6797 \\
\hline Optimized Model & 4.2165 & 0.2092 & 0.7822 \\
\hline
\end{tabular}




\subsubsection{Test 3 Result}

Each aircraft went through the scenario flight for four times. The averaged result were used for comparison. The purpose of this test was to show the virtual flight test capability using the methodology introduced in this thesis.

The comparison between the simulated result of the 'Original' aircraft was displayed with the POH result as seen on Table 6.4 and Figure 6.7. Every criteria except climb distance had error less than $10 \%$. The error spike for climb distance could be from human error in either flight phase or data analysis phase.

Table 6.4 Virtual flight test result comparison - POH \& 'Original'

\begin{tabular}{|c|c|c|c|c|}
\hline Criteria & Unit & POH result & $\begin{array}{c}\text { Simulated Average, } \\
\text { 'Original' }\end{array}$ & $\begin{array}{c}\text { Error } \\
(\%)\end{array}$ \\
\hline Ground Roll & $f t$ & 852.95 & 878.0093375 & 2.937961 \\
\hline TO Distance (50ft obst.) & $f t$ & 1428.35 & 1528.370058 & 7.002489 \\
\hline Liftoff Speed (KIAS - knots) & knots & 63 & 61.5876875 & 2.241766 \\
\hline Climb - Time & min & 3.35 & 3.416670667 & 1.990169 \\
\hline Climb - Fuel Consumed & gallon & 1.34 & 1.412983215 & 5.446509 \\
\hline Climb - Ground Distance & $n m$ & 5.35 & 6.916601539 & 29.28227 \\
\hline Cruise - Time & min & 0.242647059 & 0.229240233 & 5.525237 \\
\hline Cruise - Fuel Consumption & gallon/hr & 16 & 17.30405851 & 8.150366 \\
\hline $\begin{array}{c}\text { Fuel Consumed Until End of } \\
\text { Cruise }\end{array}$ & gallon & 5.222352941 & 5.439913039 & 4.16594 \\
\hline
\end{tabular}

Error - $\mathrm{POH}$ vs 'Original' results

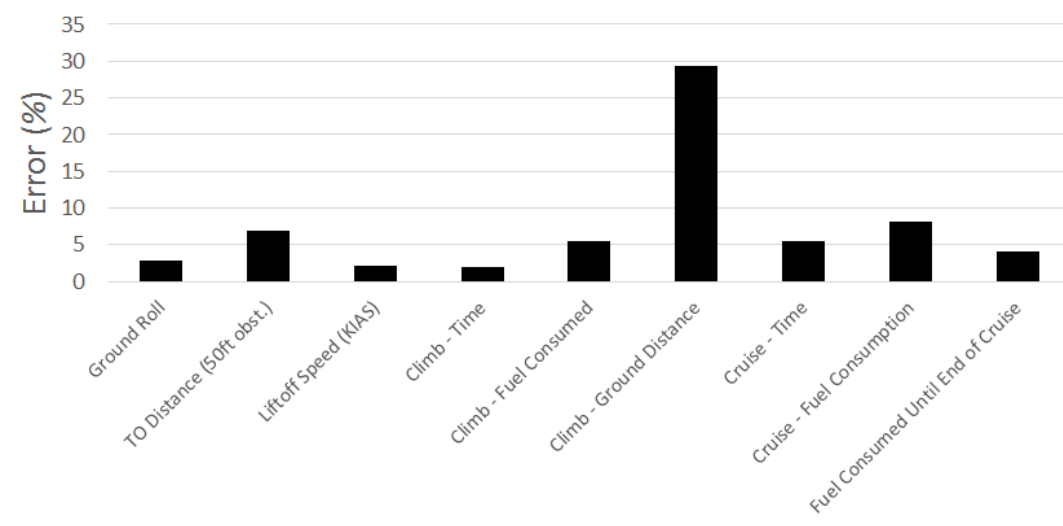

Criteria

Figure 6.7 Error between POH and 'Original' results 
The comparison between the 'Initial' model's results' average and 'Original' model's results' average could be seen on Table 6.5 and Figure 6.8. The error was slightly higher than the first case. Errors could arise from human factor and simplification.

Table 6.5 Virtual flight test result comparison - 'Original' \& 'Initial'

\begin{tabular}{|c|c|c|c|c|}
\hline Criteria & Unit & $\begin{array}{c}\text { Simulated } \\
\text { Average, } \\
\text { 'Original' }\end{array}$ & $\begin{array}{c}\text { Simulated } \\
\text { Average, } \\
\text { 'Initial' }\end{array}$ & $\begin{array}{c}\text { Error } \\
(\%)\end{array}$ \\
\hline Ground Roll & $f t$ & 878.0093375 & 1056.24286 & 20.29973 \\
\hline TO Distance (50ft obst.) & $f t$ & 1528.370058 & 1605.747925 & 5.06277 \\
\hline Liftoff Speed (KIAS) & knots & 61.5876875 & 67.0830075 & 8.922757 \\
\hline Climb - Time & min & 3.416670667 & 3.213397333 & 5.949456 \\
\hline Climb - Fuel Consumed & gallon & 1.412983215 & 1.154586305 & 18.28733 \\
\hline Climb - Ground Distance & $n m$ & 6.916601539 & 6.323743627 & 8.57152 \\
\hline Cruise - Time & min & 0.229240233 & 0.246084617 & 7.347918 \\
\hline Cruise - Fuel Consumption & gallon/hr & 17.30405851 & 12.19642062 & 29.51699 \\
\hline Fuel Consumed Until End of & gallon & 5.439913039 & 4.293240948 & 21.07887 \\
\hline Cruise & r & & &
\end{tabular}

\section{Error - 'Original' vs 'Initial'}

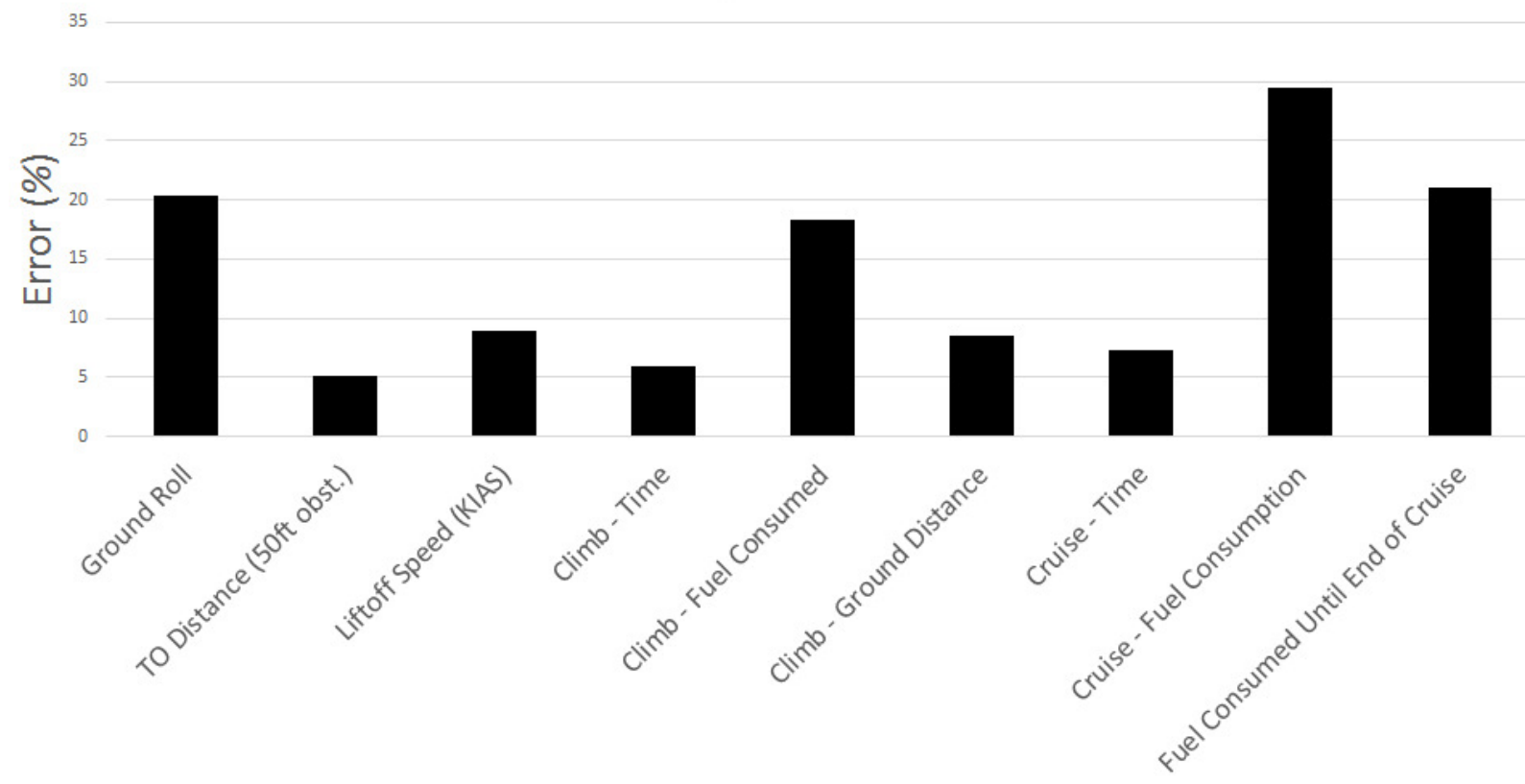

Criteria

Figure 6.8 Error between 'Original' and 'Initial' results 
The final comparison was between the simulated results and numerical results of the 'Optimized' model. As seen on Table 6.6 some of the criteria were not calculated numerically and were replaced with maximum endurance and maximum range. Figure 6.9 showed the error between the two results. The error of liftoff speed was highest. The liftoff speed was measured at the point where there was noticeable increase on the vertical speed. The actual liftoff could have happened after that point. Other errors were less than $10 \%$, which was fairly good.

Table 6.6 Virtual flight test result comparison - numerical \& simulated

\begin{tabular}{|c|c|c|c|c|}
\hline Criteria & Unit & Numerical & $\begin{array}{c}\text { Simulated Average, } \\
\text { 'Optimized' }\end{array}$ & $\begin{array}{c}\text { Error } \\
(\%)\end{array}$ \\
\hline Ground Roll & $f t$ & 932.4708 & 866.0282 & 7.125435 \\
\hline TO Distance (50ft obst.) & $f t$ & 1394.5 & 1394.72058 & 0.015818 \\
\hline Liftoff Speed (KIAS) & knots & 68.3 & 55.9910425 & 18.0219 \\
\hline Maximum Endurance & hour & 21.715 & 19.96068201 & 8.07883 \\
\hline Maximum Range & $n m$ & 3319.3 & 3051.209813 & 8.076709 \\
\hline
\end{tabular}

Error - Numerical vs Simulation - 'Original'

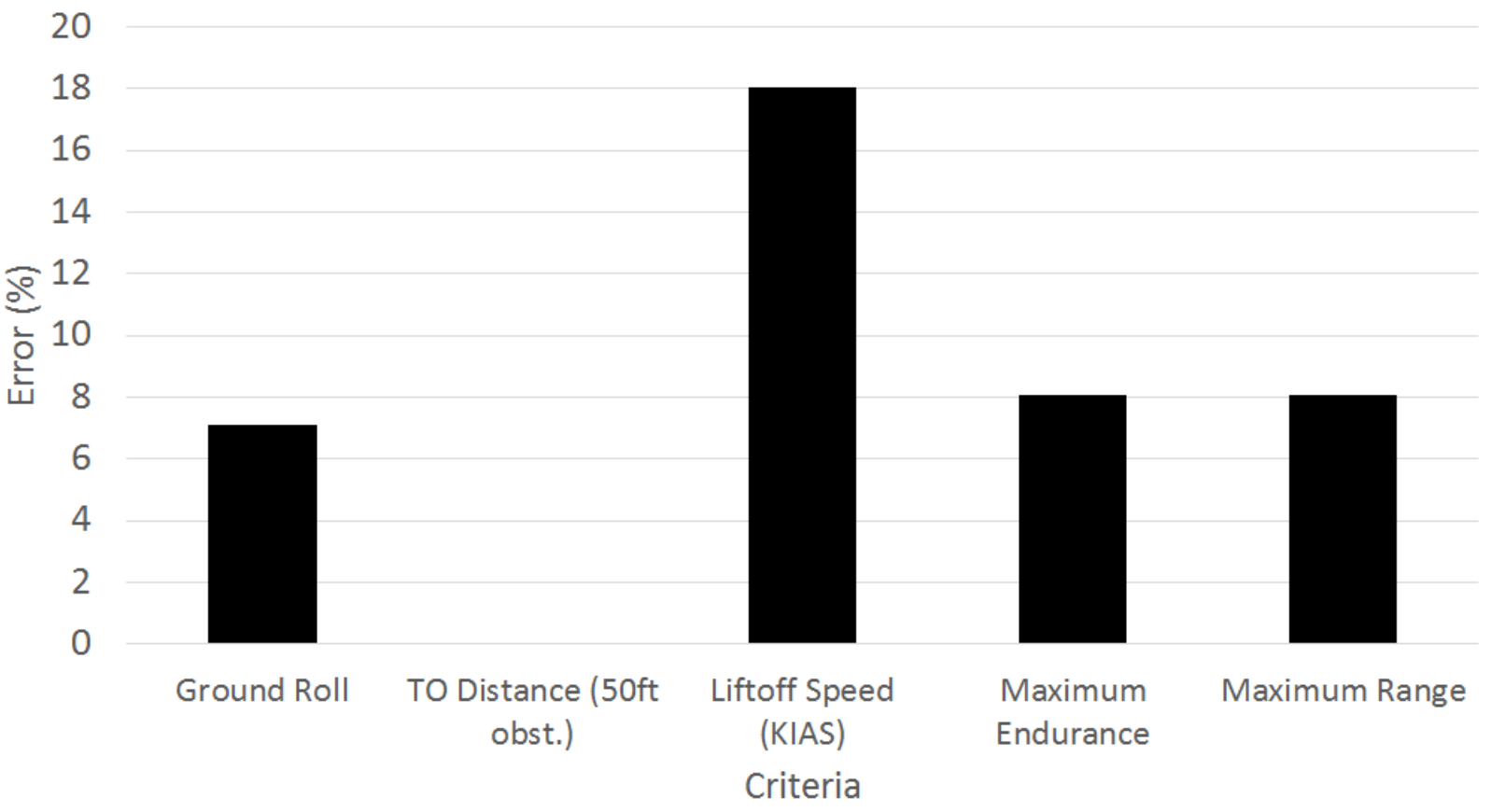

Figure 6.9 Error between numerical and simulated results 


\section{Chapter 7 Conclusion and Future Work}

\subsection{Conclusion}

This thesis introduced an integrated design method for UAV derivatives of a general aviation aircraft. The methodology included the optimization of UAV derivative utilizing MDO and virtual flight testing of the optimized result with a flight simulator. Found Aircraft Expedition E350 aircraft was selected as the baseline for the UAV derivative as it had advantages over other aircraft in the category including the maximum takeoff weight and takeoff distance. The MDF method with SQP algorithm was applied for the MDO formulation and endurance maximization was defined as the objective function. Aerodynamic, weight \& balance and performance were chosen disciplines. The optimization process delivered the UAV derivative of the Expedition E350. It met its goal with increased endurance up to 21.7 hours, while satisfying all of the constraints. The optimization result and additional parameters for the X-Plane implementation were shown as the final result of the optimization phase. In-house code was developed for optimization and data 
transition to and from the X-Plane. Configuration results from the optimization phase was transferred into X-Plane using PlaneMaker. Three aircraft models were created: 'Original', 'Initial' and 'Optimized'. The 'Original' model was created using the data provided by the $\mathrm{POH}$ and exhibited physical characteristic as similar as possible with the real aircraft. The 'Initial' model was created using the simplified data where wing and HS' physical characteristics were simplified to run MDO more efficiently. Finally, the 'Optimized' model was created with the results from the MDO. These aircraft conducted numerous virtual flight tests. The first test compared the simulated performance result of the 'Original' aircraft with the POH's reference values. The second test checked each model's yawing stability. The final test checked the takeoff and cruising performance of each aircraft. Landing performance was disregarded because it was done manually and showed discrepancy between the flights. Results from the virtual flight tests were converted and transferred to a flight-data analysis program. The flight-data analysis program was used to locate specific data from specific timeframe. The first test exhibited less than $10 \%$ error on cruise performance between the 'Original' and $\mathrm{POH}$. From the second test, the 'Original' and 'Initial' behaved similarly while 'Optimized' model had lower natural frequency and time to half amplitude but higher damping ratio. This was due to considerable changes made to the aerodynamic surfaces. The final test showed less discrepancy between the $\mathrm{POH}$ and 'Original' results and between the 'Optimized' and numerical results, with most criteria's error under 10\%. Throughout the above process, the use of MDO and flight simulation to create a UAV was demonstrated to be a viable method.

\subsection{Contributions}

The following contributions were made in this thesis: 
1. MDO method of UAV derivative had been developed. This method included four major phases: pre-MDO phase, MDO phase, flight simulation phase and flight data evaluation phase. This method was capable of optimizing an aircraft into a UAV then verify its performance by virtual flight tests.

2. Built the RFBS. This reconfigurable flight simulator was capable of generating valuable flight data effortlessly. It was also a great training tool for students to learn the basics of flight simulation, virtual flight testing, flight data generation and flight data analysis. Finally, it served as a platform for flight simulation phase and flight data evaluation phase of the optimization procedure.

3. Developed a flight data converter program that converts raw flight data to be used for a commercial flight-data analysis software. This enhanced the capabilities of the RFBS by connecting the off-the-shelf flight simulation software seamlessly with commercial flight-data analysis software. This was an important feature because it made flight-data generation relatively easy and cheap for academic purposes.

4. The X-plane was verified as a viable tool for flight data generation.

\subsection{Future Work}

Although the methodology of using MDO and flight simulation to design a UAV was validated, improvements were still necessary. First of all, the MDO process demonstrated in this thesis was low fidelity optimization relying only on empirical equations. Adapting high fidelity analysis software may improve the optimization results and provide values that are more realistic. Moreover, the aircraft design generally required more than three disciplines; however, the stability and control discipline was missing in this thesis. Hence, the addition of stability and control could 
improve the result of the MDO. Furthermore, the optimization only considered single object limiting the capability of the UAV as it compensated some of its performance characteristics. Multi-objective MDO process could improve the result without compromising on some performance characteristic. Moreover, the data transfer to the X-Plane was done manually and it could be improved by writing a separate code to reduce human effort leading to the reduction of human error. Finally, although X-Plane utilized unique methods to solve equations of motion, it had its limitations, as it was a simulation software developed for entertainment purposes. The MIMS facility acquired Flightgear [66] and a licensed version of PRESAGIS FlightSIM [67]. Flightgear is popular amongst researcher because of its connectivity with MATLAB. FlightSIM is a high fidelity flight simulator used by aircraft manufacturers and militaries around the world. Provided with adequate information, it will generate excellent virtual flight test results. Integration of these simulation software will improve the capability of the design methodology much further. 


\section{Appendix A - UAV: Civilian mission - technology allocation}

\section{table}

Table A.1 Civilian mission - technology allocation

\begin{tabular}{|c|c|c|c|c|c|c|c|c|c|c|c|c|c|c|c|c|c|c|c|c|c|c|}
\hline & & \multicolumn{15}{|c|}{ Capabilities } & \multicolumn{6}{|c|}{ Technologies } \\
\hline & & 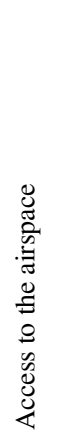 & 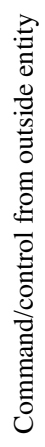 & 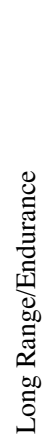 & 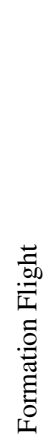 & 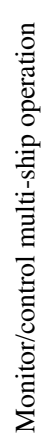 & 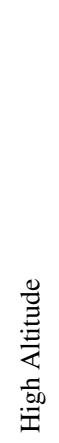 & 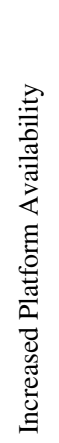 & 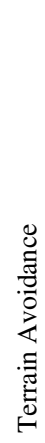 & 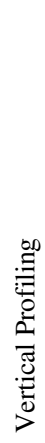 & 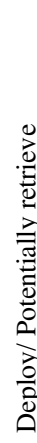 & 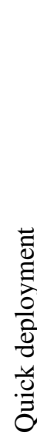 & 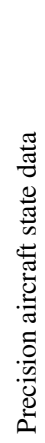 & 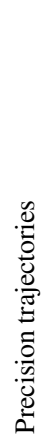 & 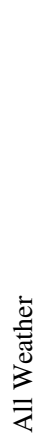 & 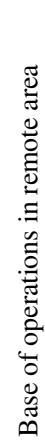 & 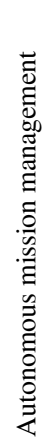 & 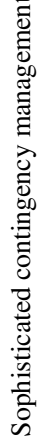 & 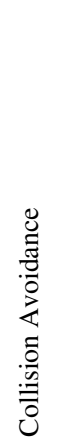 & 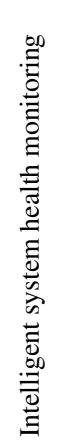 & 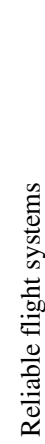 & 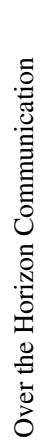 \\
\hline & & 1 & 2 & 3 & 4 & 5 & 6 & 7 & 8 & 9 & 1 & 1 & 12 & 13 & 14 & 15 & 1 & 2 & 3 & 4 & 5 & 6 \\
\hline 1 & $\begin{array}{l}\text { Repeat Pass Interferometry } \\
\text { for Surface } \\
\text { Deformation }\end{array}$ & $\mathbf{X}$ & & & & & $\mathbf{X}$ & $\mathbf{x}$ & & & & $\mathrm{X}$ & & $\mathbf{X}$ & & & $\mathbf{x}$ & $\mathbf{x}$ & $\mathbf{X}$ & $\mathbf{X}$ & $\mathrm{x}$ & $\mathbf{X}$ \\
\hline 2 & $\begin{array}{l}\text { Cloud and Aerosol } \\
\text { Measurements }\end{array}$ & $\mathbf{x}$ & $\mathbf{X}$ & $\mathbf{X}$ & $\mathbf{X}$ & $\mathbf{X}$ & & & $\mathbf{x}$ & $\mathbf{X}$ & & & & & $x$ & & $\mathbf{x}$ & $\mathbf{x}$ & $\mathbf{X}$ & $\mathbf{X}$ & $\mathrm{x}$ & $\mathbf{X}$ \\
\hline 3 & $\begin{array}{l}\text { Stratospheric Ozone } \\
\text { Chemistry }\end{array}$ & $\mathbf{x}$ & $\mathbf{X}$ & $\mathbf{X}$ & $\mathbf{X}$ & & $\mathbf{X}$ & $\mathbf{x}$ & & & & & & & & & $\mathbf{x}$ & $\mathbf{x}$ & $\mathbf{X}$ & $\mathbf{X}$ & $\mathrm{x}$ & $\mathbf{X}$ \\
\hline
\end{tabular}




\begin{tabular}{|c|c|c|c|c|c|c|c|c|c|c|c|c|c|c|c|c|c|c|c|c|}
\hline 4 & $\begin{array}{l}\text { Tropospheric Pollution and } \\
\text { Air Quality }\end{array}$ & $\mathbf{X}$ & $\mathbf{X}$ & $\mathbf{X}$ & $\mathbf{X}$ & $\mathbf{X}$ & $\mathbf{X}$ & $\mathbf{X}$ & & $\mathbf{X}$ & & $\mathbf{X}$ & & & $\mathbf{X}$ & $\mathbf{X}$ & $\mathbf{X}$ & $\mathbf{X}$ & $\mathbf{X}$ & $\mathbf{X}$ \\
\hline 5 & $\begin{array}{l}\text { Water Vapor and Total } \\
\text { Water Measurements }\end{array}$ & $\mathbf{X}$ & $\mathbf{X}$ & $\mathbf{X}$ & & $\mathbf{X}$ & $\mathbf{X}$ & $\mathbf{X}$ & & $\mathbf{X}$ & & & $\mathbf{X}$ & & $\mathbf{X}$ & $\mathbf{X}$ & $\mathbf{X}$ & $\mathbf{X}$ & $\mathbf{X}$ & $\mathbf{X}$ \\
\hline 6 & Coastal Ocean Observations & $\mathbf{X}$ & $\mathbf{X}$ & $\mathbf{X}$ & $\mathbf{X}$ & & & & & & & & & & $\mathbf{X}$ & $\mathbf{X}$ & $\mathbf{X}$ & $\mathbf{X}$ & $\mathbf{X}$ & $\mathbf{X}$ \\
\hline 7 & $\begin{array}{l}\text { Active Fire, Emissions, and } \\
\text { Plume } \\
\text { Assessment }\end{array}$ & $\mathbf{X}$ & $\mathbf{X}$ & $\mathbf{X}$ & $\mathbf{X}$ & $\mathbf{X}$ & & & & & $\mathbf{X}$ & & & $\mathbf{X}$ & $\mathbf{X}$ & $\mathbf{X}$ & $\mathbf{X}$ & $\mathbf{X}$ & $\mathbf{X}$ & $\mathbf{X}$ \\
\hline 8 & $\begin{array}{l}\mathrm{O} 2 \text { and } \mathrm{CO} 2 \text { Flux } \\
\text { Measurements }\end{array}$ & $\mathbf{X}$ & $\mathbf{X}$ & $\mathbf{X}$ & & $\mathbf{X}$ & & & $\mathbf{X}$ & $\mathbf{X}$ & & & & & $\mathbf{X}$ & $\mathbf{X}$ & $\mathbf{X}$ & $\mathbf{X}$ & $\mathbf{X}$ & $\mathbf{X}$ \\
\hline 9 & $\begin{array}{l}\text { Vegetation Structure, } \\
\text { Composition, and } \\
\text { Canopy Chemistry }\end{array}$ & $\mathbf{X}$ & & $\mathbf{X}$ & $\mathbf{X}$ & $\mathbf{X}$ & & & & & & & $\mathbf{X}$ & & $\mathbf{X}$ & $\mathbf{X}$ & $\mathbf{X}$ & $\mathbf{X}$ & $\mathbf{X}$ & $\mathbf{X}$ \\
\hline 10 & $\begin{array}{l}\text { Aerosol, Cloud, and } \\
\text { Precipitation Distribution }\end{array}$ & $\mathbf{X}$ & $\mathbf{X}$ & $\mathbf{X}$ & & $\mathbf{X}$ & $\mathbf{X}$ & $\mathbf{X}$ & & $\mathbf{X}$ & & & $\mathbf{X}$ & & $\mathbf{X}$ & $\mathbf{X}$ & $\mathbf{X}$ & $\mathbf{X}$ & $\mathbf{X}$ & $\mathbf{X}$ \\
\hline 11 & $\begin{array}{l}\text { Glacier and Ice Sheet } \\
\text { Dynamics }\end{array}$ & $\mathbf{X}$ & $\mathbf{X}$ & $\mathbf{X}$ & & & & $\mathbf{X}$ & & & $\mathbf{X}$ & $\mathbf{X}$ & & & $\mathbf{X}$ & $\mathbf{X}$ & $\mathbf{X}$ & $\mathbf{X}$ & $\mathbf{X}$ & $\mathbf{X}$ \\
\hline 12 & $\begin{array}{l}\text { Radiation - Vertical Profiles } \\
\text { of Shortwave } \\
\text { Atmospheric Heating Rates }\end{array}$ & $\mathbf{X}$ & $\mathbf{X}$ & & $\mathbf{X}$ & $\mathbf{X}$ & $\mathbf{X}$ & $\mathbf{X}$ & $\mathbf{X}$ & $\mathbf{X}$ & $\mathbf{X}$ & & & & $\mathbf{X}$ & $\mathbf{X}$ & $\mathbf{X}$ & $\mathbf{X}$ & $\mathbf{X}$ & $\mathbf{X}$ \\
\hline 13 & $\begin{array}{l}\text { Ice Sheet Thickness and } \\
\text { Surface Deformation }\end{array}$ & $\mathbf{X}$ & $\mathbf{X}$ & & $\mathbf{X}$ & $\mathbf{X}$ & & & $\mathbf{X}$ & & & & & & $\mathbf{X}$ & $\mathbf{X}$ & $\mathbf{X}$ & $\mathbf{X}$ & $\mathbf{X}$ & $\mathbf{X}$ \\
\hline 14 & Imaging Spectroscopy & $\mathbf{X}$ & & $\mathbf{X}$ & & & $\mathbf{X}$ & & & & & $\mathbf{X}$ & & & $\mathbf{X}$ & $\mathbf{X}$ & $\mathbf{X}$ & $\mathbf{X}$ & $\mathbf{X}$ & $\mathbf{X}$ \\
\hline
\end{tabular}




\begin{tabular}{|c|c|c|c|c|c|c|c|c|c|c|c|c|c|c|c|c|c|c|c|c|c|c|}
\hline 15 & $\begin{array}{l}\text { Topographic Mapping and } \\
\text { Topographic } \\
\text { Change with LIDAR }\end{array}$ & $\mathbf{X}$ & $\mathbf{X}$ & & & & $\mathbf{X}$ & & & & & & $\mathbf{X}$ & $\mathbf{X}$ & & & $\mathbf{X}$ & $\mathbf{X}$ & $\mathbf{X}$ & $\mathbf{X}$ & $\mathbf{X}$ & $\mathbf{X}$ \\
\hline 16 & $\begin{array}{l}\text { Gravitational Acceleration } \\
\text { Measurements }\end{array}$ & & & & & & & & & & & & $\mathbf{X}$ & $\mathbf{X}$ & & & & & & & & \\
\hline 17 & $\begin{array}{l}\text { Antarctic Exploration } \\
\text { Surveyor }\end{array}$ & & & $\mathbf{X}$ & & & & $\mathbf{X}$ & $\mathbf{X}$ & & & & & & & $\mathbf{X}$ & & & & & & $\mathbf{X}$ \\
\hline 18 & $\begin{array}{l}\text { Magnetic Fields } \\
\text { Measurements }\end{array}$ & & $\mathbf{X}$ & & $\mathbf{X}$ & $\mathbf{X}$ & $\mathbf{X}$ & & & & & & $\mathbf{X}$ & & & & & & & & & $\mathbf{X}$ \\
\hline 19 & Cloud Properties & $\mathbf{X}$ & $\mathbf{X}$ & $\mathbf{X}$ & $\mathbf{X}$ & $\mathbf{X}$ & $\mathbf{X}$ & & & $\mathbf{X}$ & $\mathbf{X}$ & $\mathbf{X}$ & $\mathbf{X}$ & & & & $\mathbf{X}$ & $\mathbf{X}$ & $\mathbf{X}$ & $\mathbf{X}$ & $\mathbf{X}$ & $\mathbf{X}$ \\
\hline 20 & River Discharge & $\mathbf{X}$ & $\mathbf{X}$ & & & & & & & & & & $\mathbf{X}$ & $\mathbf{X}$ & & & $\mathbf{X}$ & $\mathbf{X}$ & $\mathbf{X}$ & $\mathbf{X}$ & $\mathbf{X}$ & $\mathbf{X}$ \\
\hline 21 & $\begin{array}{l}\text { Snow - Liquid Water } \\
\text { Equivalents }\end{array}$ & $\mathbf{X}$ & $\mathbf{X}$ & $\mathbf{X}$ & & & & $\mathbf{X}$ & $\mathbf{X}$ & & $\mathbf{X}$ & & & $\mathbf{X}$ & & & $\mathbf{X}$ & $\mathbf{X}$ & $\mathbf{X}$ & $\mathbf{X}$ & $\mathbf{X}$ & $\mathbf{X}$ \\
\hline 22 & $\begin{array}{l}\text { Soil Moisture and } \\
\text { Freeze/Thaw States }\end{array}$ & $\mathbf{X}$ & $\mathbf{X}$ & $\mathbf{X}$ & & & & $\mathbf{X}$ & & $\mathbf{X}$ & & & $\mathbf{X}$ & $\mathbf{X}$ & & & $\mathbf{X}$ & $\mathbf{X}$ & $\mathbf{X}$ & $\mathbf{X}$ & $\mathbf{X}$ & $\mathbf{X}$ \\
\hline 23 & $\begin{array}{l}\text { Cloud } \\
\text { Microphysics/Properties }\end{array}$ & $\mathbf{X}$ & $\mathbf{X}$ & & $\mathbf{X}$ & & $\mathbf{X}$ & $\mathbf{X}$ & & $\mathbf{X}$ & $\mathbf{X}$ & $\mathbf{X}$ & & & $\mathbf{X}$ & & $\mathbf{X}$ & $\mathbf{X}$ & $\mathbf{X}$ & $\mathbf{X}$ & $\mathbf{X}$ & \\
\hline 24 & $\begin{array}{l}\text { Focused Observations - } \\
\text { Extreme Weather }\end{array}$ & $\mathbf{X}$ & $\mathbf{X}$ & $\mathbf{X}$ & & & $\mathbf{X}$ & & & & $\mathbf{X}$ & & & & & & $\mathbf{X}$ & $\mathbf{X}$ & $\mathbf{X}$ & $\mathbf{X}$ & $\mathbf{X}$ & $\mathbf{X}$ \\
\hline 25 & Forecast Initialization & $\mathbf{X}$ & $\mathbf{X}$ & $\mathbf{X}$ & $\mathbf{X}$ & $\mathbf{X}$ & $\mathbf{X}$ & & $\mathbf{X}$ & & $\mathbf{X}$ & $\mathbf{X}$ & & & $\mathbf{X}$ & & $\mathbf{X}$ & $\mathbf{X}$ & $\mathbf{X}$ & $\mathbf{X}$ & $\mathbf{X}$ & $\mathbf{X}$ \\
\hline 26 & $\begin{array}{l}\text { Hurricane Genesis, } \\
\text { Evolution, and Landfall }\end{array}$ & $\mathbf{X}$ & $\mathbf{X}$ & $\mathbf{X}$ & $\mathbf{X}$ & $\mathbf{X}$ & $\mathbf{X}$ & & $\mathbf{X}$ & & $\mathbf{X}$ & $\mathbf{X}$ & & & $\mathbf{X}$ & & $\mathbf{X}$ & $\mathbf{X}$ & $\mathbf{X}$ & $\mathbf{X}$ & $\mathbf{X}$ & $\mathbf{X}$ \\
\hline 27 & Coastal Patrol & $\mathbf{X}$ & $\mathbf{X}$ & $\mathbf{X}$ & $\mathbf{X}$ & $\mathbf{X}$ & $\mathbf{X}$ & & & $\mathbf{X}$ & $\mathbf{X}$ & & & & $\mathbf{X}$ & & $\mathbf{X}$ & $\mathbf{X}$ & $\mathbf{X}$ & $\mathbf{X}$ & $\mathbf{X}$ & $\mathbf{X}$ \\
\hline
\end{tabular}




\begin{tabular}{|c|c|c|c|c|c|c|c|c|c|c|c|c|c|c|c|c|c|c|c|c|c|}
\hline 28 & $\begin{array}{l}\text { Forest Fire Damage } \\
\text { Assessment }\end{array}$ & $\mathbf{X}$ & $\mathbf{X}$ & $\mathbf{X}$ & $\mathbf{X}$ & $\mathbf{X}$ & $\mathbf{X}$ & & & & & & & & & $\mathbf{X}$ & $\mathbf{X}$ & $\mathbf{X}$ & $\mathbf{X}$ & $\mathbf{X}$ & $\mathbf{X}$ \\
\hline 29 & Forest Fire Mapping & $\mathbf{X}$ & $\mathbf{X}$ & $\mathbf{X}$ & & & $\mathbf{X}$ & $\mathbf{X}$ & & & & $\mathbf{X}$ & & & & $\mathbf{X}$ & $\mathbf{X}$ & $\mathbf{X}$ & $\mathbf{X}$ & $\mathbf{X}$ & $\mathbf{X}$ \\
\hline 30 & $\begin{array}{l}\text { Physical Oceanography, } \\
\text { Meteorology, and } \\
\text { Atmospheric Chemistry }\end{array}$ & $\mathbf{X}$ & $\mathbf{X}$ & $\mathbf{X}$ & & $\mathbf{X}$ & & $\mathbf{X}$ & $\mathbf{X}$ & $\mathbf{X}$ & $\mathbf{X}$ & & & $\mathbf{X}$ & $\mathbf{X}$ & $\mathbf{X}$ & $\mathbf{X}$ & $\mathbf{X}$ & $\mathbf{X}$ & $\mathbf{X}$ & \\
\hline 31 & Forest Fire Communications & $\mathbf{X}$ & $\mathbf{X}$ & & $\mathbf{X}$ & $\mathbf{X}$ & & $\mathbf{X}$ & $\mathbf{X}$ & & & $\mathbf{X}$ & & & $\mathbf{X}$ & $\mathbf{X}$ & $\mathbf{X}$ & $\mathbf{X}$ & $\mathbf{X}$ & $\mathbf{X}$ & \\
\hline 32 & $\begin{array}{l}\text { Forest Fire Retardant } \\
\text { Application }\end{array}$ & $\mathbf{X}$ & $\mathbf{X}$ & & $\mathbf{X}$ & $\mathbf{X}$ & & $\mathbf{X}$ & $\mathbf{X}$ & $\mathbf{X}$ & & $\mathbf{X}$ & $\mathbf{X}$ & & & $\mathbf{X}$ & $\mathbf{X}$ & $\mathbf{X}$ & $\mathbf{X}$ & $\mathbf{X}$ & $\mathbf{X}$ \\
\hline 33 & Wild Life Census & & $\mathbf{X}$ & $\mathbf{X}$ & & & & & $\mathbf{X}$ & & & & & & & & & & & & $\mathbf{X}$ \\
\hline 34 & Animal Tracking & & & $\mathbf{X}$ & & & & & & & & & & & & & & & & & $\mathbf{X}$ \\
\hline 35 & Invasive Plant Assessment & & $\mathbf{X}$ & $\mathbf{X}$ & & & & & $\mathbf{X}$ & & & & & & & & & & & & $\mathbf{X}$ \\
\hline
\end{tabular}




\section{Appendix B - Sample Flight Data}

Note: this is just a small portion of flight data, adjusted to fit in this page.

Table B.1 Sample flight data

\begin{tabular}{|c|c|c|c|c|c|}
\hline missn,_time & _Vind,_kias & -VVI,_fpm & _alt,ftmsl & _dist,__ & rpm_1,engin \\
\hline 0 & -0.1098 & 0.00361 & 654.5652 & 0 & 300 \\
\hline 0.40159 & -0.0653 & 9.59923 & 654.8306 & 0.64076 & 305.8773 \\
\hline 0.9013 & -0.03956 & 6.33279 & 654.8509 & 0.83209 & 312.2419 \\
\hline 1.40353 & -0.02391 & 4.06111 & 654.8588 & 0.86748 & 318.2911 \\
\hline 1.90372 & -0.01448 & 2.52651 & 654.861 & 0.87421 & 324.3447 \\
\hline 2.40628 & -0.00876 & 1.5422 & 654.8615 & 0.8756 & 330.4751 \\
\hline 2.91015 & -0.00529 & 0.9344 & 654.8616 & 0.87588 & 336.6623 \\
\hline 3.41402 & -0.0032 & 0.56446 & 654.8616 & 0.87595 & 342.852 \\
\hline 3.90877 & -0.00195 & 0.34425 & 654.8616 & 0.87598 & 348.9509 \\
\hline 4.40561 & -0.00119 & 0.21064 & 654.8617 & 0.87602 & 355.057 \\
\hline 4.90194 & -0.00073 & 0.12797 & 654.8617 & 0.87605 & 361.1303 \\
\hline 5.39927 & -0.00046 & 0.07603 & 654.8616 & 0.87609 & 367.1696 \\
\hline 5.89874 & -0.00026 & 0.04597 & 654.8616 & 0.87612 & 373.1002 \\
\hline 6.40136 & -0.0002 & 0.02759 & 654.8616 & 0.87615 & 379.0082 \\
\hline 6.90589 & -0.0002 & 0.01418 & 654.8616 & 0.8762 & 384.8982 \\
\hline 7.41021 & -0.0002 & 0.00778 & 654.8616 & 0.87628 & 390.7131 \\
\hline 7.9059 & -0.0002 & 0.00405 & 654.8616 & 0.87634 & 396.2879 \\
\hline 8.40142 & -0.0002 & 0.00078 & 654.8615 & 0.87639 & 401.8031 \\
\hline 8.89513 & -0.00016 & 0.00059 & 654.8615 & 0.87643 & 407.1074 \\
\hline 9.39437 & -0.00016 & 0.00018 & 654.8615 & 0.87647 & 412.3942 \\
\hline 9.89696 & -0.00014 & -0.0003 & 654.8615 & 0.87652 & 417.5466 \\
\hline 10.38189 & -0.00014 & -0.00209 & 654.8615 & 0.87657 & 422.3414 \\
\hline 10.88884 & -0.00014 & -0.00144 & 654.8615 & 0.8766 & 427.2049 \\
\hline 11.39423 & -0.00014 & -0.00099 & 654.8615 & 0.87662 & 431.8706 \\
\hline 11.89434 & -0.00014 & -0.00058 & 654.8615 & 0.87664 & 436.3178 \\
\hline 12.37937 & -0.00014 & -0.00037 & 654.8615 & 0.87665 & 440.5191 \\
\hline 12.88552 & -0.00014 & -0.00027 & 654.8615 & 0.87666 & 444.6976 \\
\hline 13.38603 & -0.00014 & -0.00031 & 654.8615 & 0.87667 & 448.6565 \\
\hline 13.88946 & -0.00014 & -0.00009 & 654.8615 & 0.87668 & 452.477 \\
\hline 14.39126 & -0.00014 & -0.00018 & 654.8615 & 0.87672 & 456.1346 \\
\hline 14.8919 & -0.00014 & -0.0018 & 654.8615 & 0.87677 & 459.5572 \\
\hline
\end{tabular}




\section{Appendix C - Found Aircraft Expedition E350: Comparison with other aircraft [57]}

Table C.1 Price comparison table

\begin{tabular}{|l|l|}
\hline Aircraft & Price \\
\hline Cessna 350 Corvalis & US $\$ 558,200$ \\
\hline Cirrus SR22 GTS X & US \$551,890 \\
\hline Cessna 206H Stationair & US $\$ 533,400$ \\
\hline Mooney Ovation3 & US $\$ 520,000$ \\
\hline Expedition E350 & US $\$ 495,000$ \\
\hline Cessna 182T Skylane & US $\$ 390,300$ \\
\hline
\end{tabular}

Table C.2 Engine comparison table

\begin{tabular}{|l|l|l|l|}
\hline Aircraft & Engine & Horsepower & Fuel Flow @ Cruise \\
\hline Expedition E350 & Lycoming IO-580 & $315 \mathrm{hp}$ & $18.0 \mathrm{gph}$ \\
\hline Cirrus SR22 GTS & Continental IO-550 & $310 \mathrm{hp}$ & $16.4 \mathrm{gph}$ \\
\hline Mooney Ovation3 & Continental IO-550 & $310 \mathrm{hp}$ & $17.1 \mathrm{gph}$ \\
\hline Cessna 350 Corvalis & Continental IO-550 & $310 \mathrm{hp}$ & $19.3 \mathrm{gph}$ \\
\hline Cessna 206H Stationair & Lycoming IO-540 & $300 \mathrm{hp}$ & $16.5 \mathrm{gph}$ \\
\hline Cessna 182T Skylane & Lycoming IO-540 & $230 \mathrm{hp}$ & $14.5 \mathrm{gph}$ \\
\hline
\end{tabular}

Table C.3 Weight comparison table

\begin{tabular}{|l|l|l|l|}
\hline Aircraft & Empty Weight (lbs) & $\begin{array}{l}\text { Gross/ Takeoff } \\
\text { Weight (lbs) }\end{array}$ & Useful Load (lbs) \\
\hline Expedition E350 & 2280 & 3800 & 1520 \\
\hline Cirrus SR22 GTS X & 2352 & 3400 & 1048 \\
\hline Mooney Ovation3 & 2261 & 3368 & 1107 \\
\hline Cessna 350 Corvalis & 2450 & 3400 & 950 \\
\hline Cessna 206H Stationair & 2241 & 3600 & 1359 \\
\hline Cessna 182T Skylane & 1984 & 3100 & 1116 \\
\hline
\end{tabular}


Table C.4 Takeoff distance over a 50ft obstacle at gross weight @ sea level

\begin{tabular}{|l|l|l|}
\hline Aircraft & \multicolumn{1}{|c|}{$\begin{array}{c}\text { 50ft obstacle } \\
\text { clearance }\end{array}$} & $\begin{array}{l}\text { Gross/ Takeoff } \\
\text { Weight (lbs) }\end{array}$ \\
\hline Expedition E350 & 1286 & 3800 \\
\hline Cessna 182T Skylane & 1515 & 3100 \\
\hline Cirrus SR22 GTS X & 1594 & 3400 \\
\hline Cessna 206H Stationair & 1860 & 3600 \\
\hline Mooney Ovation3 & 2100 & 3368 \\
\hline Cessna 350 Corvalis & 2300 & 3400 \\
\hline
\end{tabular}




\title{
Appendix D - Cruise Performance at different altitudes, 2600RPM
}

\author{
D.1 POH Reference
}

Table D.1 Cruise performance at 2600RPM, POH

\begin{tabular}{|c|c|c|}
\hline Altitude & Airspeed (KTAS, knots) & Fuel consumption (Gallon/hr) \\
\hline 2000 & 147 & 18.8 \\
\hline 4000 & 142 & 17.5 \\
\hline 6000 & 140 & 17.1 \\
\hline 8000 & 131 & 15.8 \\
\hline 10000 & 125 & 15.3 \\
\hline 12000 & 113 & 14.9 \\
\hline
\end{tabular}

D.2 Simulation Results - 'Original'

Table D.2 Cruise performance at 2600RPM, 'Original' simulated

\begin{tabular}{|c|c|c|}
\hline Altitude & Airspeed (KTAS, knots) & Fuel consumption (Gallon/hr) \\
\hline 2000 & 140.9214 & 17.000 \\
\hline 4000 & 136.9135 & 16.228 \\
\hline 6000 & 132.6958 & 15.432 \\
\hline 8000 & 128.6971 & 14.781 \\
\hline 10000 & 124.7118 & 14.193 \\
\hline 12000 & 120.6759 & 13.582 \\
\hline
\end{tabular}

D.3 Simulation Results - 'Initial'

Table D.3 Cruise performance at 2600RPM, 'Initial' simulated

\begin{tabular}{|c|c|c|}
\hline Altitude & Airspeeed (KTAS, knots) & Fuel consumption (Gallon/hr) \\
\hline 2000 & 141.34 & 17.763 \\
\hline 4000 & 137.2165 & 14.258 \\
\hline 6000 & 133.053 & 13.587 \\
\hline 8000 & 128.8865 & 12.998 \\
\hline 10000 & 124.6669 & 12.424 \\
\hline 12000 & 120.8081 & 11.961 \\
\hline
\end{tabular}




\section{D.4 Simulation Results - 'Optimized'}

Table D.4 Cruise performance at 2600RPM, 'Optimized' simulated

\begin{tabular}{|c|c|c|}
\hline Altitude & Airspeeed (KTAS, knots) & Fuel consumption (Gallon/hr) \\
\hline 2000 & 141.34 & 17.763 \\
\hline 4000 & 137.2165 & 14.258 \\
\hline 6000 & 133.053 & 13.587 \\
\hline 8000 & 128.8865 & 12.998 \\
\hline 10000 & 124.6669 & 12.424 \\
\hline 12000 & 120.8081 & 11.961 \\
\hline
\end{tabular}




\title{
Appendix E - Yawing stability analysis
}

\author{
E.1 'Original' Model
}

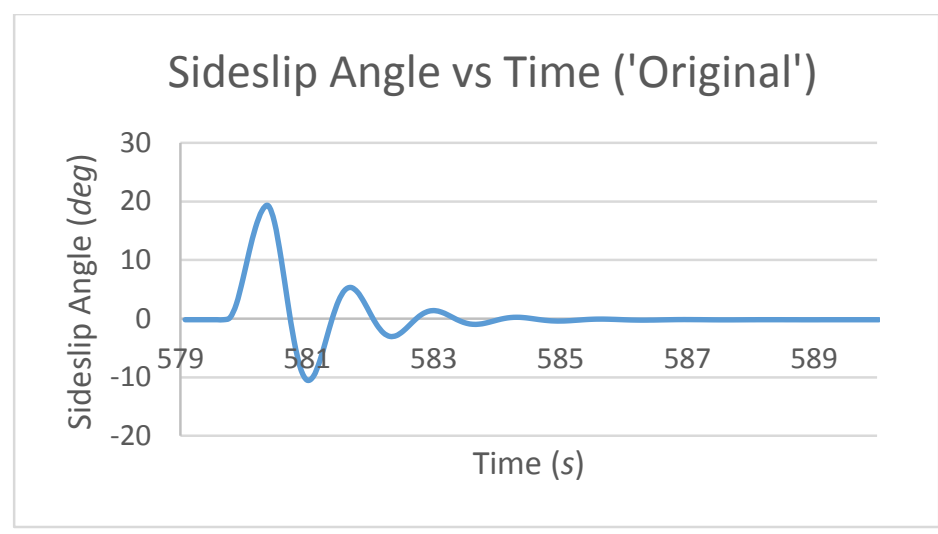

Figure E.1 Sideslip vs time graph of 'Original' model

Table E.1 Variables used for $\omega_{n}, \zeta$ and $T_{1 / 2}$ calculation - 'Original'

\begin{tabular}{|c|c|c|c|c|c|c|}
\hline $\mathrm{N}$ & $\mathrm{t}$ & $\mathrm{t}$ corr & $\mathrm{B}$ & $\mathrm{B}$ corr & $\mathrm{DA}$ & $\mathrm{DA} / \mathrm{DA}$ \\
\hline 1 & 580.3907 & 0.70417 & 19.2872 & 19.4375 & 29.74042 & 0.5313 \\
\hline 2 & 581.0017 & 1.31513 & -10.4532 & -10.3029 & 15.80109 & 0.528143 \\
\hline 3 & 581.6953 & 2.00879 & 5.34787 & 5.49817 & 8.34523 & 0.526305 \\
\hline 4 & 582.31 & 2.62348 & -2.99736 & -2.84706 & 4.39214 & 0.529154 \\
\hline 5 & 583.021 & 3.33448 & 1.39478 & 1.54508 & 2.32412 & 0.514492 \\
\hline 6 & 583.6185 & 3.93201 & -0.92934 & -0.77904 & 1.19574 & 0.536898 \\
\hline 7 & 584.313 & 4.62647 & 0.2664 & 0.4167 & 0.64199 & \\
\hline 8 & 585.0093 & 5.32282 & -0.37559 & -0.22529 & & \\
\hline
\end{tabular}

Table E.2 Calculated values - 'Original'

\begin{tabular}{|c|c|}
\hline TPR & 0.527715 \\
\hline $\ln$ TPR & -0.6392 \\
\hline damping & 0.199378 \\
\hline$\omega_{n}$ & 4.914779 \\
\hline$\zeta$ & -0.9799 \\
\hline$T_{1 / 2}$ & 0.704154 \\
\hline
\end{tabular}




\section{E.2 'Initial' Model}

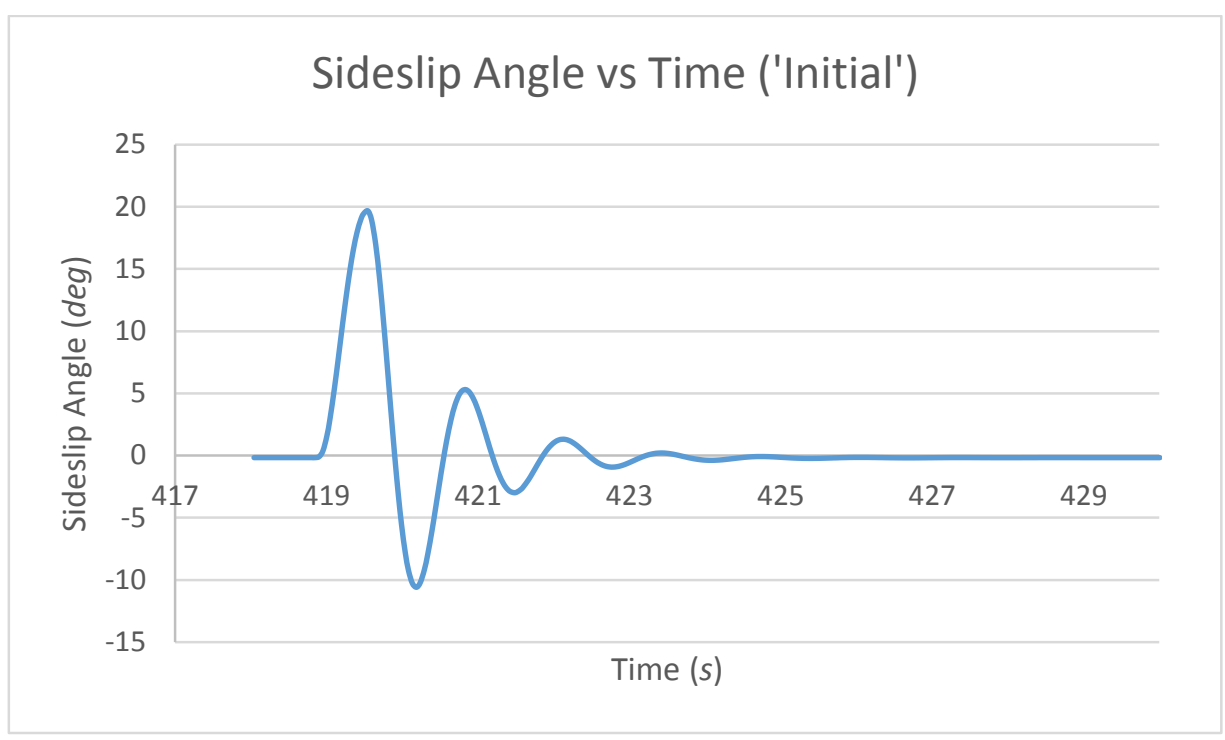

Figure E.2 Sideslip vs time graph of 'Initial' model

Table E.3 Variables used for $\omega_{n}, \zeta$ and $T_{1 / 2}$ calculation - 'Initial'

\begin{tabular}{|c|c|c|c|c|c|c|}
\hline $\mathrm{N}$ & $\mathrm{t}$ & $\mathrm{t}$ corr & $\mathrm{B}$ & $\mathrm{B}$ corr & $\mathrm{DA}$ & $\mathrm{DA} / \mathrm{DA}$ \\
\hline 1 & 419.5451 & 0.69476 & 19.67516 & 19.82976 & 30.24805 & 0.525015 \\
\hline 2 & 420.1867 & 1.33634 & -10.5729 & -10.4183 & 15.88068 & 0.521507 \\
\hline 3 & 420.8392 & 1.98886 & 5.30779 & 5.46239 & 8.28188 & 0.51858 \\
\hline 4 & 421.4771 & 2.62671 & -2.97409 & -2.81949 & 4.29482 & 0.52093 \\
\hline 5 & 422.1102 & 3.25986 & 1.32073 & 1.47533 & 2.2373 & 0.50611 \\
\hline 6 & 422.7848 & 3.93448 & -0.91657 & -0.76197 & 1.13232 & 0.51859 \\
\hline 7 & 423.4325 & 4.58219 & 0.21575 & 0.37035 & 0.58721 & \\
\hline 8 & 424.0729 & 5.22257 & -0.37146 & -0.21686 & & \\
\hline
\end{tabular}

Table E.4 Calculated values - 'Initial'

\begin{tabular}{|c|c|}
\hline TPR & 0.518455 \\
\hline $\ln$ TPR & -0.6569 \\
\hline damping & 0.204672 \\
\hline$\omega_{n}$ & 4.960259 \\
\hline$\zeta$ & -1.01523 \\
\hline$T_{1 / 2}$ & 0.679652 \\
\hline
\end{tabular}




\section{E.3 'Optimized’ Model}

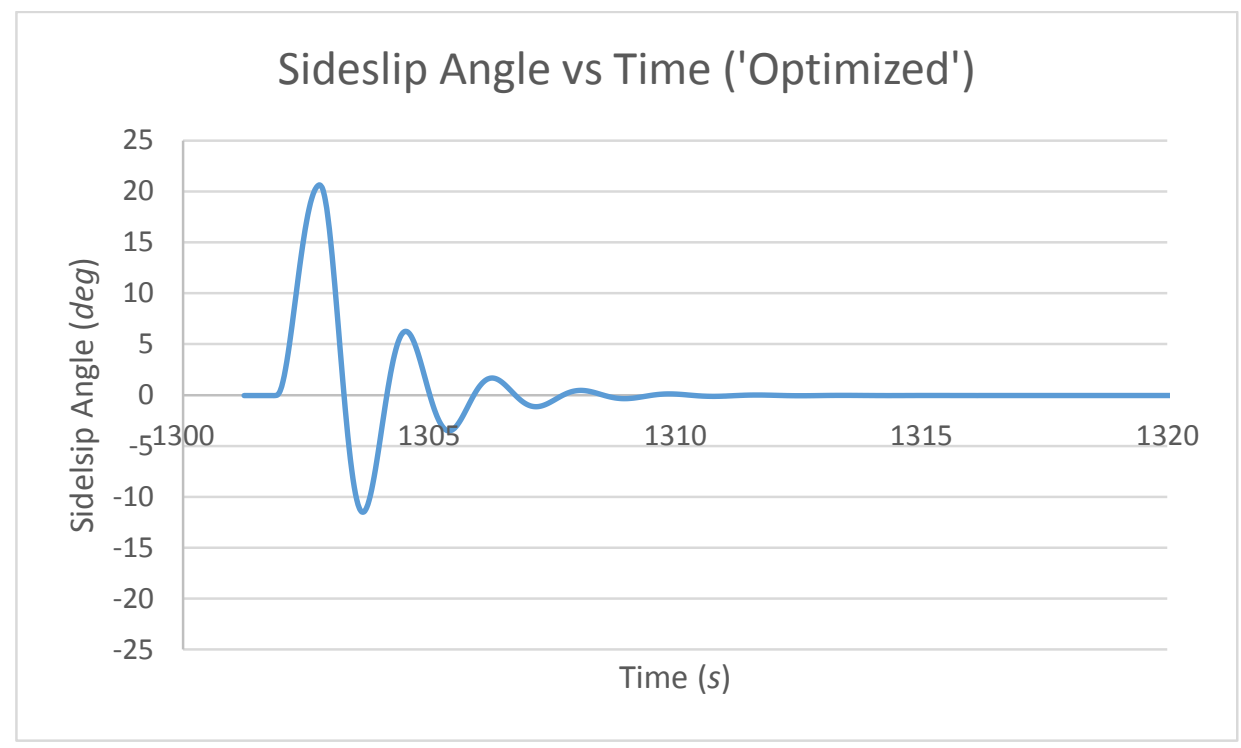

Figure E.3 Sideslip vs time graph of 'Optimized' model

Table E.5 Variables used for $\omega_{n}, \zeta$ and $T_{1 / 2}$ calculation - 'Optimized'

$\begin{array}{ccccccc}\mathrm{N} & \mathrm{t} & \mathrm{t} \text { corr } & \mathrm{B} & \mathrm{B} \text { corr } & \mathrm{DA} & \mathrm{DA} / \mathrm{DA} \\ 1 & 1302.728 & 0.854 & 20.50039 & 20.54139 & 31.96481 & 0.554095 \\ 2 & 1303.633 & 1.75903 & -11.4644 & -11.4234 & 17.71155 & 0.550523 \\ 3 & 1304.507 & 2.63342 & 6.24713 & 6.28813 & 9.75062 & 0.531201 \\ 4 & 1305.386 & 3.51281 & -3.50349 & -3.46249 & 5.17954 & 0.542293 \\ 5 & 1306.266 & 4.39221 & 1.67605 & 1.71705 & 2.80883 & 0.568689 \\ 6 & 1307.148 & 5.27392 & -1.13278 & -1.09178 & 1.59735 & 0.504279 \\ 7 & 1308.079 & 6.2052 & 0.46457 & 0.50557 & 0.80551 & \\ 8 & 1309.013 & 7.13977 & -0.34094 & -0.29994 & & \end{array}$

Table E.6 Calculated values - 'Optimized'

\begin{tabular}{|l|l|}
\hline TPR & 0.541847 \\
\hline $\ln$ TPR & -0.61277 \\
\hline damping & 0.191444 \\
\hline$\omega_{n}$ & 3.597571 \\
\hline$\zeta$ & -0.68873 \\
\hline$T_{1 / 2}$ & 1.001841 \\
\hline
\end{tabular}




\section{Appendix F - Sample calculation}

\section{F.1 Linear interpolation}

The takeoff distance required for an airfield at $650 f t$ pressure altitude was found by linearly interpolating the data from the POH shown on Table F.1.

Table F.1 Section of takeoff distance chart from POH

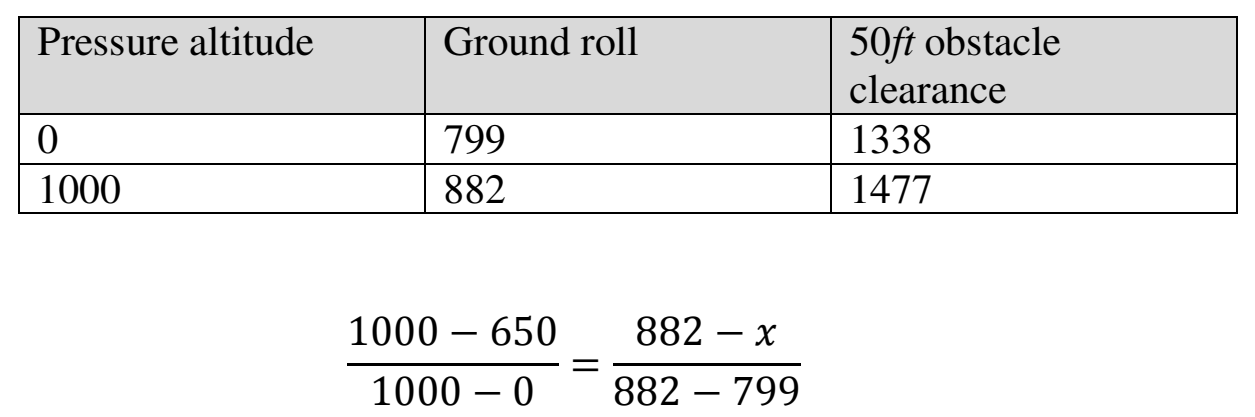

Where $x$ represented the desired ground roll distance. Solving the above equation, $x=$ 852.95ft. Similarly, 50ft obstacle clearance distance was $1428.35 f t$. 


\section{Appendix $\mathrm{G}$ - Scenario test results}

\section{G.1 'Original’ Model}

Table G.1 Scenario test result - 'Original' - Flight 1

\begin{tabular}{|c|c|c|c|}
\hline Flight 1 & Variable & Unit & Value \\
\hline \multirow[t]{3}{*}{ Takeoff } & Ground Roll & $f t$ & 864.1137 \\
\hline & TO Distance (50ft obst.) & $f t$ & 1372.81226 \\
\hline & Liftoff Speed (KIAS) & knots & 61.53776 \\
\hline \multirow{13}{*}{ Climb } & Time Start & $\sec$ & 69.54008 \\
\hline & Time End & $\sec$ & 295.32718 \\
\hline & Total Time & $\min$ & 3.763118333 \\
\hline & Fuel Start & $l b$ & 542.88544 \\
\hline & Fuel End & $l b$ & 533.3338 \\
\hline & Total Fuel & gallons & 1.589355587 \\
\hline & Altitude Start & $f t$ & 706.72046 \\
\hline & Altitude End & $f t$ & 3931.76514 \\
\hline & Total Altitude & $f t$ & 3225.04468 \\
\hline & Distance Start & $f t$ & 1430.51831 \\
\hline & Distance End & $f t$ & 50764.09766 \\
\hline & Total Distance & $f t$ & 49333.57935 \\
\hline & Total Distance (ground) & $n m$ & 8.101903628 \\
\hline \multirow[t]{12}{*}{ Cruise } & Time Start & sec & 295.83142 \\
\hline & Time End & $\mathrm{sec}$ & 1008.02094 \\
\hline & Total Time & $h r$ & 0.197830422 \\
\hline & Fuel Start & $l b$ & 533.2894 \\
\hline & Fuel End & $l b$ & 499.45524 \\
\hline & Fuel Consumption & gallons $/ \mathrm{hr}$ & 28.45807032 \\
\hline & Distance Start & $f t$ & 50886.82031 \\
\hline & Distance End & $f t$ & 248962.75 \\
\hline & Total Distance & $f t$ & 198075.9297 \\
\hline & Total Distance (ground) & $n m$ & 32.5991381 \\
\hline & Fuel Consumed Until End of Cruise & $l b$ & 44.50512 \\
\hline & Fuel Consumed Until End of Cruise & gallons & 7.405478131 \\
\hline \multirow[t]{2}{*}{ After Flight } & Total Fuel Consumed & $l b$ & 51.17906 \\
\hline & Total Fuel Consumed & gallons & 8.515995679 \\
\hline
\end{tabular}


Table G.2 Scenario test result - 'Original' - Flight 2

\begin{tabular}{|c|c|c|c|}
\hline Flight 2 & Variable & Unit & Value \\
\hline \multirow[t]{3}{*}{ Takeoff } & Ground Roll & $f t$ & 764.09845 \\
\hline & TO Distance (50ft obst.) & $f t$ & 1317.40698 \\
\hline & Liftoff Speed (KIAS) & knots & 58.49428 \\
\hline \multirow[t]{13}{*}{ Climb } & Time Start & sec & 43.38045 \\
\hline & Time End & sec & 236.81844 \\
\hline & Total Time & $\min$ & 3.2239665 \\
\hline & Fuel Start & $l b$ & 543.07736 \\
\hline & Fuel End & $l b$ & 535.42606 \\
\hline & Total Fuel & gallons & 1.273146434 \\
\hline & Altitude Start & $f t$ & 702.1286 \\
\hline & Altitude End & $f t$ & 3929.76733 \\
\hline & Total Altitude & $f t$ & 3227.63873 \\
\hline & Distance Start & $f t$ & 1374.6886 \\
\hline & Distance End & $f t$ & 36805.55469 \\
\hline & Total Distance & $f t$ & 35430.86609 \\
\hline & Total Distance (ground) & $n m$ & 5.806930721 \\
\hline \multirow[t]{12}{*}{ Cruise } & Time Start & sec & 237.31836 \\
\hline & Time End & sec & 1111.64734 \\
\hline & Total Time & $h r$ & 0.242869161 \\
\hline & Fuel Start & $l b$ & 535.38178 \\
\hline & Fuel End & $l b$ & 515.04986 \\
\hline & Fuel Consumption & gallons/hr & 13.92993683 \\
\hline & Distance Start & $f t$ & 36926.08594 \\
\hline & Distance End & $f t$ & 241349.6094 \\
\hline & Total Distance & $f t$ & 204423.5234 \\
\hline & Total Distance (ground) & $n m$ & 33.64381899 \\
\hline & Fuel Consumed Until End of Cruise & $l b$ & 28.89335 \\
\hline & Fuel Consumed Until End of Cruise & gallons & 4.807740583 \\
\hline \multirow[t]{2}{*}{ After Flight } & Total Fuel Consumed & $l b$ & 34.59616 \\
\hline & Total Fuel Consumed & gallons & 5.756665891 \\
\hline
\end{tabular}


Table G.3 Scenario test result - 'Original' - Flight 3

\begin{tabular}{|c|c|c|c|}
\hline Flight 3 & Variable & Unit & Value \\
\hline \multirow[t]{3}{*}{ Takeoff } & Ground Roll & $f t$ & 884.47742 \\
\hline & TO Distance (50ft obst.) & $f t$ & 1397.12793 \\
\hline & Liftoff Speed (KIAS) & knots & 61.96416 \\
\hline \multirow[t]{13}{*}{ Climb } & Time Start & sec & 73.48409 \\
\hline & Time End & sec & 270.90781 \\
\hline & Total Time & $\min$ & 3.290395333 \\
\hline & Fuel Start & $l b$ & 542.82898 \\
\hline & Fuel End & $l b$ & 534.75265 \\
\hline & Total Fuel & gallons & 1.343869766 \\
\hline & Altitude Start & $f t$ & 701.58789 \\
\hline & Altitude End & $f t$ & 3932.37549 \\
\hline & Total Altitude & $f t$ & 3230.7876 \\
\hline & Distance Start & $f t$ & 1455.979 \\
\hline & Distance End & $f t$ & 40945.30078 \\
\hline & Total Distance & $f t$ & 39489.32178 \\
\hline & Total Distance (ground) & $n m$ & 6.477325452 \\
\hline \multirow[t]{12}{*}{ Cruise } & Time Start & sec & 271.40994 \\
\hline & Time End & sec & 1141.24219 \\
\hline & Total Time & $h r$ & 0.241620069 \\
\hline & Fuel Start & $l b$ & 534.75265 \\
\hline & Fuel End & $l b$ & 514.7395 \\
\hline & Fuel Consumption & gallons/hr & 13.78242294 \\
\hline & Distance Start & $f t$ & 41067.1875 \\
\hline & Distance End & $f t$ & 243925.2656 \\
\hline & Total Distance & $f t$ & 202858.0781 \\
\hline & Total Distance (ground) & $n m$ & 33.38617956 \\
\hline & Fuel Consumed Until End of Cruise & $l b$ & 29.21192 \\
\hline & Fuel Consumed Until End of Cruise & gallons & 4.860749386 \\
\hline \multirow[t]{2}{*}{ After Flight } & Total Fuel Consumed & $l b$ & 33.31788 \\
\hline & Total Fuel Consumed & gallons & 5.543965092 \\
\hline
\end{tabular}


Table G.4 Scenario test result - 'Original' - Flight 4

\begin{tabular}{|c|c|c|c|}
\hline Flight 4 & Variable & Unit & Value \\
\hline \multirow[t]{3}{*}{ Takeoff } & Ground Roll & $f t$ & 999.34778 \\
\hline & TO Distance (50ft obst.) & $f t$ & 2026.13306 \\
\hline & Liftoff Speed (KIAS) & knots & 64.35455 \\
\hline \multirow[t]{13}{*}{ Climb } & Time Start & sec & 50.89315 \\
\hline & Time End & $\mathrm{sec}$ & 254.2453 \\
\hline & Total Time & $\min$ & 3.3892025 \\
\hline & Fuel Start & $l b$ & 542.93119 \\
\hline & Fuel End & $l b$ & 534.24372 \\
\hline & Total Fuel & gallons & 1.445561075 \\
\hline & Altitude Start & $f t$ & 701.47357 \\
\hline & Altitude End & $f t$ & 3931.73657 \\
\hline & Total Altitude & $f t$ & 3230.263 \\
\hline & Distance Start & $f t$ & 2095.32397 \\
\hline & Distance End & $f t$ & 46448.68359 \\
\hline & Total Distance & $f t$ & 44353.35962 \\
\hline & Total Distance (ground) & $n m$ & 7.280246354 \\
\hline \multirow[t]{12}{*}{ Cruise } & Time Start & $\sec$ & 254.74477 \\
\hline & Time End & $\sec$ & 1099.45337 \\
\hline & Total Time & $h r$ & 0.234641278 \\
\hline & Fuel Start & $l b$ & 534.19819 \\
\hline & Fuel End & $l b$ & 515.80182 \\
\hline & Fuel Consumption & gallons/hr & 13.04580396 \\
\hline & Distance Start & $f t$ & 46573.27734 \\
\hline & Distance End & $f t$ & 243174.9531 \\
\hline & Total Distance & $f t$ & 196601.6758 \\
\hline & Total Distance (ground) & $n m$ & 32.35650713 \\
\hline & Fuel Consumed Until End of Cruise & $l b$ & 28.15982 \\
\hline & Fuel Consumed Until End of Cruise & gallons & 4.685684056 \\
\hline \multirow[t]{2}{*}{ After Flight } & Total Fuel Consumed & $l b$ & 32.09025 \\
\hline & Total Fuel Consumed & gallons & 5.339692255 \\
\hline
\end{tabular}




\section{G.2 'Initial' Model}

Table G.5 Scenario test result - 'Initial' - Flight 1

\begin{tabular}{|c|c|c|c|}
\hline Flight 1 & Variable & Unit & Value \\
\hline \multirow[t]{3}{*}{ Takeoff } & Ground Roll & $f t$ & 1073.74573 \\
\hline & TO Distance (50ft obst.) & $f t$ & 1692.84937 \\
\hline & Liftoff Speed (KIAS) & knots & 67.89368 \\
\hline \multirow{13}{*}{ Climb } & Time Start & $\sec$ & 31.02304 \\
\hline & Time End & sec & 225.54182 \\
\hline & Total Time & $\min$ & 3.241979667 \\
\hline & Fuel Start & $l b$ & 543.23141 \\
\hline & Fuel End & $l b$ & 536.1723 \\
\hline & Total Fuel & gallons & 1.174608331 \\
\hline & Altitude Start & $f t$ & 707.06879 \\
\hline & Altitude End & $f t$ & 3930.39185 \\
\hline & Total Altitude & $f t$ & 3223.32306 \\
\hline & Distance Start & $f t$ & 1757.35852 \\
\hline & Distance End & $f t$ & 41732.03516 \\
\hline & Total Distance & $f t$ & 39974.67664 \\
\hline & Total Distance (ground) & $n m$ & 6.557569578 \\
\hline \multirow[t]{12}{*}{ Cruise } & Time Start & $\mathrm{sec}$ & 226.03954 \\
\hline & Time End & $\mathrm{sec}$ & 1150.16919 \\
\hline & Total Time & $h r$ & 0.256702681 \\
\hline & Fuel Start & $l b$ & 536.13308 \\
\hline & Fuel End & $l b$ & 517.23881 \\
\hline & Fuel Consumption & gallons $/ \mathrm{hr}$ & 12.24737007 \\
\hline & Distance Start & $f t$ & 41853.57031 \\
\hline & Distance End & $f t$ & 258667.8594 \\
\hline & Total Distance & $f t$ & 216814.2891 \\
\hline & Total Distance (ground) & $n m$ & 35.68307882 \\
\hline & Fuel Consumed Until End of Cruise & $l b$ & 26.72551 \\
\hline & Fuel Consumed Until End of Cruise & gallons & 4.447020474 \\
\hline \multirow[t]{2}{*}{ After Flight } & Total Fuel Consumed & $l b$ & 28.8482 \\
\hline & Total Fuel Consumed & gallons & 4.800227799 \\
\hline
\end{tabular}


Table G.6 Scenario test result - 'Initial' - Flight 2

\begin{tabular}{|c|c|c|c|}
\hline Flight 2 & Variable & Unit & Value \\
\hline \multirow[t]{3}{*}{ Takeoff } & Ground Roll & $f t$ & 1040.43262 \\
\hline & TO Distance (50ft obst.) & $f t$ & 1659.95776 \\
\hline & Liftoff Speed (KIAS) & knots & 66.72371 \\
\hline \multirow[t]{13}{*}{ Climb } & Time Start & sec & 49.97619 \\
\hline & Time End & sec & 245.32425 \\
\hline & Total Time & $\min$ & 3.255801 \\
\hline & Fuel Start & $l b$ & 543.12339 \\
\hline & Fuel End & $l b$ & 536.02762 \\
\hline & Total Fuel & gallons & 1.180708412 \\
\hline & Altitude Start & $f t$ & 705.10632 \\
\hline & Altitude End & $f t$ & 3932.27417 \\
\hline & Total Altitude & $f t$ & 3227.16785 \\
\hline & Distance Start & $f t$ & 1724.3623 \\
\hline & Distance End & $f t$ & 41894.86328 \\
\hline & Total Distance & $f t$ & 40170.50098 \\
\hline & Total Distance (ground) & $n m$ & 6.589851954 \\
\hline \multirow[t]{12}{*}{ Cruise } & Time Start & sec & 245.8241 \\
\hline & Time End & sec & 1107.87866 \\
\hline & Total Time & $h r$ & 0.2394596 \\
\hline & Fuel Start & $l b$ & 535.98834 \\
\hline & Fuel End & $l b$ & 518.59823 \\
\hline & Fuel Consumption & gallons/hr & 12.08406921 \\
\hline & Distance Start & $f t$ & 42017.05469 \\
\hline & Distance End & $f t$ & 243544.5156 \\
\hline & Total Distance & $f t$ & 201527.4609 \\
\hline & Total Distance (ground) & $n m$ & 33.16718793 \\
\hline & Fuel Consumed Until End of Cruise & $l b$ & 25.36619 \\
\hline & Fuel Consumed Until End of Cruise & gallons & 4.220834936 \\
\hline \multirow[t]{2}{*}{ After Flight } & Total Fuel Consumed & $l b$ & 29.04764 \\
\hline & Total Fuel Consumed & gallons & 4.833413836 \\
\hline
\end{tabular}


Table G.7 Scenario test result - 'Initial' - Flight 3

\begin{tabular}{|c|c|c|c|}
\hline Flight 3 & Variable & Unit & Value \\
\hline \multirow[t]{3}{*}{ Takeoff } & Ground Roll & $f t$ & 1049.30273 \\
\hline & TO Distance (50ft obst.) & $f t$ & 1592.9425 \\
\hline & Liftoff Speed (KIAS) & knots & 66.99284 \\
\hline \multirow[t]{13}{*}{ Climb } & Time Start & sec & 53.44193 \\
\hline & Time End & sec & 240.33253 \\
\hline & Total Time & $\min$ & 3.114843333 \\
\hline & Fuel Start & $l b$ & 543.09668 \\
\hline & Fuel End & $l b$ & 536.53192 \\
\hline & Total Fuel & gallons & 1.092350422 \\
\hline & Altitude Start & $f t$ & 708.25873 \\
\hline & Altitude End & $f t$ & 3933.37915 \\
\hline & Total Altitude & $f t$ & 3225.12042 \\
\hline & Distance Start & $f t$ & 1663.90283 \\
\hline & Distance End & $f t$ & 36230.01172 \\
\hline & Total Distance & $f t$ & 34566.10889 \\
\hline & Total Distance (ground) & $n m$ & 5.664039504 \\
\hline \multirow[t]{12}{*}{ Cruise } & Time Start & sec & 240.83261 \\
\hline & Time End & $\mathrm{sec}$ & 1128.64636 \\
\hline & Total Time & $h r$ & 0.246614931 \\
\hline & Fuel Start & $l b$ & 536.53192 \\
\hline & Fuel End & $l b$ & 518.16928 \\
\hline & Fuel Consumption & gallons/hr & 12.38964553 \\
\hline & Distance Start & $f t$ & 36351.40234 \\
\hline & Distance End & $f t$ & 245068.8281 \\
\hline & Total Distance & $f t$ & 208717.4258 \\
\hline & Total Distance (ground) & $n m$ & 34.35050516 \\
\hline & Fuel Consumed Until End of Cruise & $l b$ & 25.79514 \\
\hline & Fuel Consumed Until End of Cruise & gallons & 4.29221054 \\
\hline \multirow[t]{2}{*}{ After Flight } & Total Fuel Consumed & $l b$ & 29.0503 \\
\hline & Total Fuel Consumed & gallons & 4.83385645 \\
\hline
\end{tabular}


Table G.8 Scenario test result - 'Initial' - Flight 4

\begin{tabular}{|c|c|c|c|}
\hline Flight 4 & Variable & Unit & Value \\
\hline \multirow[t]{3}{*}{ Takeoff } & Ground Roll & $f t$ & 1061.49036 \\
\hline & TO Distance (50ft obst.) & $f t$ & 1477.24207 \\
\hline & Liftoff Speed (KIAS) & knots & 66.7218 \\
\hline \multirow[t]{13}{*}{ Climb } & Time Start & sec & 41.37239 \\
\hline & Time End & sec & 235.83031 \\
\hline & Total Time & $\min$ & 3.240965333 \\
\hline & Fuel Start & $l b$ & 543.16708 \\
\hline & Fuel End & $l b$ & 536.13159 \\
\hline & Total Fuel & gallons & 1.170678055 \\
\hline & Altitude Start & $f t$ & 702.00232 \\
\hline & Altitude End & $f t$ & 3930.39014 \\
\hline & Total Altitude & $f t$ & 3228.38782 \\
\hline & Distance Start & $f t$ & 1537.29175 \\
\hline & Distance End & $f t$ & 41063.89062 \\
\hline & Total Distance & $f t$ & 39526.59887 \\
\hline & Total Distance (ground) & $n m$ & 6.483513473 \\
\hline \multirow[t]{12}{*}{ Cruise } & Time Start & sec & 236.33333 \\
\hline & Time End & sec & 1105.95386 \\
\hline & Total Time & $h r$ & 0.241561258 \\
\hline & Fuel Start & $l b$ & 536.13159 \\
\hline & Fuel End & $l b$ & 518.61712 \\
\hline & Fuel Consumption & gallons/hr & 12.06459768 \\
\hline & Distance Start & $f t$ & 41186.66406 \\
\hline & Distance End & $f t$ & 244339.9063 \\
\hline & Total Distance & $f t$ & 203153.2422 \\
\hline & Total Distance (ground) & $n m$ & 33.43475739 \\
\hline & Fuel Consumed Until End of Cruise & $l b$ & 25.31849 \\
\hline & Fuel Consumed Until End of Cruise & gallons & 4.212897842 \\
\hline \multirow[t]{2}{*}{ After Flight } & Total Fuel Consumed & $l b$ & 28.74152 \\
\hline & Total Fuel Consumed & gallons & 4.782476664 \\
\hline
\end{tabular}




\section{G.3 'Optimized’ Model}

Table G.9 Scenario test result - 'Optimized' - Flight 1

\begin{tabular}{|c|c|c|c|}
\hline Flight 1 & Variable & Unit & Value \\
\hline \multirow[t]{3}{*}{ Takeoff } & Ground Roll & $f t$ & 846.50043 \\
\hline & TO Distance (50ft obst.) & $f t$ & 1359.38074 \\
\hline & Liftoff Speed (KIAS) & knots & 55.63376 \\
\hline \multirow[t]{13}{*}{ Climb } & Time Start & sec & 54.32627 \\
\hline & Time End & $\mathrm{sec}$ & 274.99939 \\
\hline & Total Time & $\min$ & 3.677885333 \\
\hline & Fuel Start & $l b$ & 777.29877 \\
\hline & Fuel End & $l b$ & 769.64506 \\
\hline & Total Fuel & gallons & 1.273547449 \\
\hline & Altitude Start & $f t$ & 702.76898 \\
\hline & Altitude End & $f t$ & 3925.14014 \\
\hline & Total Altitude & $f t$ & 3222.37116 \\
\hline & Distance Start & $f t$ & 1410.50122 \\
\hline & Distance End & $f t$ & 41730.23438 \\
\hline & Total Distance & $f t$ & 40319.73316 \\
\hline & Total Distance (ground) & $n m$ & 6.614555124 \\
\hline \multirow[t]{12}{*}{ Cruise } & Time Start & sec & 275.50067 \\
\hline & Time End & sec & 1164.22803 \\
\hline & Total Time & $h r$ & 0.246868711 \\
\hline & Fuel Start & $l b$ & 769.64506 \\
\hline & Fuel End & $l b$ & 750.36878 \\
\hline & Fuel Consumption & gallons/hr & 12.99272672 \\
\hline & Distance Start & $f t$ & 41834.16406 \\
\hline & Distance End & $f t$ & 243233.5 \\
\hline & Total Distance & $f t$ & 201399.3359 \\
\hline & Total Distance (ground) & $n m$ & 33.14610124 \\
\hline & Fuel Consumed Until End of Cruise & $l b$ & 27.79566 \\
\hline & Fuel Consumed Until End of Cruise & gallons & 4.625089254 \\
\hline \multirow[t]{2}{*}{ After Flight } & Total Fuel Consumed & $l b$ & 31.4155 \\
\hline & Total Fuel Consumed & gallons & 5.227416491 \\
\hline
\end{tabular}


Table G.10 Scenario test result - 'Optimized' - Flight 2

\begin{tabular}{|c|c|c|c|}
\hline Flight 2 & Variable & Unit & Value \\
\hline \multirow[t]{3}{*}{ Takeoff } & Ground Roll & $f t$ & 941.30182 \\
\hline & TO Distance (50ft obst.) & $f t$ & 1357.20251 \\
\hline & Liftoff Speed (KIAS) & knots & 58.0737 \\
\hline \multirow[t]{13}{*}{ Climb } & Time Start & sec & 46.43431 \\
\hline & Time End & sec & 267.96997 \\
\hline & Total Time & $\min$ & 3.692261 \\
\hline & Fuel Start & $l b$ & 777.3332 \\
\hline & Fuel End & $l b$ & 769.66575 \\
\hline & Total Fuel & gallons & 1.275833731 \\
\hline & Altitude Start & $f t$ & 703.84247 \\
\hline & Altitude End & $f t$ & 3937.89062 \\
\hline & Total Altitude & $f t$ & 3234.04815 \\
\hline & Distance Start & $f t$ & 1408.81335 \\
\hline & Distance End & $f t$ & 41336.65234 \\
\hline & Total Distance & $f t$ & 39927.83899 \\
\hline & Total Distance (ground) & $n m$ & 6.54969267 \\
\hline \multirow[t]{12}{*}{ Cruise } & Time Start & sec & 268.47159 \\
\hline & Time End & $\mathrm{sec}$ & 1149.45166 \\
\hline & Total Time & $h r$ & 0.244716686 \\
\hline & Fuel Start & $l b$ & 769.66575 \\
\hline & Fuel End & $l b$ & 750.52515 \\
\hline & Fuel Consumption & gallons/hr & 13.01472788 \\
\hline & Distance Start & $f t$ & 41443.77344 \\
\hline & Distance End & $f t$ & 241581.7031 \\
\hline & Total Distance & $f t$ & 200137.9297 \\
\hline & Total Distance (ground) & $n m$ & 32.93850026 \\
\hline & Fuel Consumed Until End of Cruise & $l b$ & 27.63938 \\
\hline & Fuel Consumed Until End of Cruise & gallons & 4.599084873 \\
\hline \multirow[t]{2}{*}{ After Flight } & Total Fuel Consumed & $l b$ & 31.36533 \\
\hline & Total Fuel Consumed & gallons & 5.219068399 \\
\hline
\end{tabular}


Table G.11 Scenario test result - 'Optimized' - Flight 3

\begin{tabular}{|c|c|c|c|}
\hline Flight 3 & Variable & Unit & Value \\
\hline \multirow[t]{3}{*}{ Takeoff } & Ground Roll & $f t$ & 812.52472 \\
\hline & TO Distance (50ft obst.) & $f t$ & 1427.70984 \\
\hline & Liftoff Speed (KIAS) & knots & 54.71446 \\
\hline \multirow[t]{13}{*}{ Climb } & Time Start & sec & 54.43839 \\
\hline & Time End & $\mathrm{sec}$ & 274.23978 \\
\hline & Total Time & $\min$ & 3.6633565 \\
\hline & Fuel Start & $l b$ & 777.26087 \\
\hline & Fuel End & $l b$ & 769.71656 \\
\hline & Total Fuel & gallons & 1.255343716 \\
\hline & Altitude Start & $f t$ & 706.21881 \\
\hline & Altitude End & $f t$ & 3935.87012 \\
\hline & Total Altitude & $f t$ & 3229.65131 \\
\hline & Distance Start & $f t$ & 1480.474 \\
\hline & Distance End & $f t$ & 40240.28516 \\
\hline & Total Distance & $f t$ & 38759.81116 \\
\hline & Total Distance (ground) & $n m$ & 6.356867472 \\
\hline \multirow[t]{12}{*}{ Cruise } & Time Start & sec & 274.7417 \\
\hline & Time End & $\mathrm{sec}$ & 1163.39465 \\
\hline & Total Time & $h r$ & 0.246848042 \\
\hline & Fuel Start & $l b$ & 769.67957 \\
\hline & Fuel End & $l b$ & 750.18525 \\
\hline & Fuel Consumption & gallons/hr & 13.14079172 \\
\hline & Distance Start & $f t$ & 40347.07422 \\
\hline & Distance End & $f t$ & 243114.1563 \\
\hline & Total Distance & $f t$ & 202767.082 \\
\hline & Total Distance (ground) & $n m$ & 33.37120352 \\
\hline & Fuel Consumed Until End of Cruise & $l b$ & 27.97208 \\
\hline & Fuel Consumed Until End of Cruise & gallons & 4.654444853 \\
\hline \multirow[t]{2}{*}{ After Flight } & Total Fuel Consumed & $l b$ & 31.64927 \\
\hline & Total Fuel Consumed & gallons & 5.266314906 \\
\hline
\end{tabular}


Table G.12 Scenario test result - 'Optimized' - Flight 4

\begin{tabular}{|c|c|c|c|}
\hline Flight 4 & Variable & Unit & Value \\
\hline \multirow[t]{3}{*}{ Takeoff } & Ground Roll & $f t$ & 863.78583 \\
\hline & TO Distance (50ft obst.) & $f t$ & 1434.58923 \\
\hline & Liftoff Speed (KIAS) & knots & 55.54225 \\
\hline \multirow[t]{13}{*}{ Climb } & Time Start & sec & 40.25197 \\
\hline & Time End & $\mathrm{sec}$ & 258.27258 \\
\hline & Total Time & $\min$ & 3.633676833 \\
\hline & Fuel Start & $l b$ & 777.39744 \\
\hline & Fuel End & $l b$ & 769.68363 \\
\hline & Total Fuel & gallons & 1.283547854 \\
\hline & Altitude Start & $f t$ & 704.64124 \\
\hline & Altitude End & $f t$ & 3935.26416 \\
\hline & Total Altitude & $f t$ & 3230.62292 \\
\hline & Distance Start & $f t$ & 1487.66602 \\
\hline & Distance End & $f t$ & 42276.30859 \\
\hline & Total Distance & $f t$ & 40788.64257 \\
\hline & Total Distance (ground) & $n m$ & 6.69186479 \\
\hline \multirow[t]{12}{*}{ Cruise } & Time Start & sec & 258.77103 \\
\hline & Time End & $\mathrm{sec}$ & 1141.73657 \\
\hline & Total Time & $h r$ & 0.245268206 \\
\hline & Fuel Start & $l b$ & 769.64558 \\
\hline & Fuel End & $l b$ & 751.14185 \\
\hline & Fuel Consumption & gallons/hr & 12.5533939 \\
\hline & Distance Start & $f t$ & 42386.27344 \\
\hline & Distance End & $f t$ & 243652.75 \\
\hline & Total Distance & $f t$ & 201266.4766 \\
\hline & Total Distance (ground) & $n m$ & 33.12423538 \\
\hline & Fuel Consumed Until End of Cruise & $l b$ & 27.05817 \\
\hline & Fuel Consumed Until End of Cruise & gallons & 4.502373799 \\
\hline \multirow[t]{2}{*}{ After Flight } & Total Fuel Consumed & $l b$ & 30.60034 \\
\hline & Total Fuel Consumed & gallons & 5.091777051 \\
\hline
\end{tabular}




\section{References}

[1] D. J. Neufeld, J. Chung, Unmanned Aerial Vehicle Conceptual Design Using a Genetic Algorithm and Data Mining, Infotech@Aerospace, Arlington, Virginia, 26-29 September 2005 .

[2] J. Hannavy, Encyclopedia of Nineteenth-Century Photography: Taylor \& Francis, 2013

[3] ICAO, Unmanned Aircraft Systems (UAS), ed. Montreal: International Civil Aviation Organization, 2011.

[4] D. T. Parker, Building Victory: Aircraft Manufacturing in the Los Angeles Area in World War II, Cypress, CA, 2013.

[5] Radioplane OQ-2 - Aerial Target Drone - History, Specs and Pictures, http://www.militaryfactory.com/aircraft/detail.asp?aircraft_id=331.

[6] P. G. Fahlstrom, T. J. Gleason, Introduction to UAV Systems Fourth Edition, John Wiley \& Sons, 2012.

[7] W. Wagner, Fireflies and Other UAVs (Unmanned Aerial Vehicles), Tulsa: Aerofax Inc, 1992.

[8] J. R. Wilson, UAV Roundup 2013, Aerospace America, Vol. 51, No. 7, 2013, pp. 26-36.

[9] S. Tsach, A. Peled, D. Penn, D. H. Touitou, The CAPECON Program: Civil Applications and Economical Effectivity of Potential UAV Configuration, AIAA $3^{\text {rd }}$ "Unmanned Unlimited" Technical Conference, Workshop and Exhibit, Chicago, Illinois, 20-23 September 2004. 

Assessment, December 2004.

[11] Maria de Fatima Bento, Unmanned Aerial Vehicles: An Overview, InsideGNSS, January 2008, pp. 54-61.

[12] J. Reagan, Drone Company Investments Take the VC World by Storm, dronelife.com, May 2015.

[13] Civil \& Unmanned Aerial Systems Symposium 2015, http://www.uaseast.com/, Washington DC, 27-28 October 2015.

[14] D. L. Robinson, M. F. Melary, Large Airplane Derivative Development Methodology, AIAA/AHS/ASEE Aircraft Design Systems and Operations Meeting, Colorado Springs, Colorado, 14-16 October 1985.

[15] Diamond Aircraft Industries, http://www.diamond-air.at/special-missionaircraft.html.

[16] S. S. Rao, Engineering Optimization: Theory and Practice, Third edition, John Wiley \& Sons, 1996.

[17] H. U. Park, J. Chung, J. W. Lee, K. Behdinan, Uncertainty Based MDO for Aircraft Conceptual Design, Aircraft Engineering and Aerospace Technology, Vol. 87, Issue 4, 2015, pp. 345-356.

[18] H. U. Park, J. Chung, K. Behdinan, J. W. Lee, Multidisciplinary Wing Design Optimization Considering Global Sensitivity and Uncertainty of Approximation Models, Journal of Mechanical Science and Technology, Vol. 28, Issue 6, 2014, pp. 2231-2242. 
Uncertainty in Surrogate Models, Structural and Multidisciplinary Optimization, Vol. 42, Issue 5, 2010, pp. 745-753.

[20] X. Chen, L. Yan, W. Luo, L. Xu, Y. Zhao, Z. Wang, Research on Theory and Application of Multidisciplinary Design Optimization of Flight Vehicles, $47^{\text {th }}$ AIAA/ASME/ASCE/AHS/ASC Structures, Structural Dynamics and Materials Conference, Newport, Rhode Island, 1-4 May 2006.

[21] E. J. Cramer, J. E. Dennis Jr., P. D. Frank, R. M. Lewis, G. R. Shubin, Problem Formulation for Multidisciplinary Optimization, SIAM Journal of Optimization, No. 4, November 1994, pp. 754-776.

E. J. Cramer, P. D. Frank, G. R. Shubin, J. E. Dennis Jr., R. M. Lewis, On Alternative Problem Formulations for Multidisciplinary Design Optimization, Fourth AIAA/NASA/ISSMO Symposium on Multidisciplinary Analysis and Optimization, Cleveland, Ohio, September 1992, pp. 518-530.

[23] J. E. Dennis, R. M. Lewis, Problem Formulations and Other Optimization Issues in Multidisciplinary Optimization, AIAA Symposium on Fluid Dynamics, Colorado Springs, Colorado, June 1994.

[24] S. Kodiyalam, J. Sobieszczanski-Sobieski, Multidisciplinary Design Optimization - Some Formal Methods, Framework Requirements, and Application to Vehicle Design, International Journal of Vehicle Design, Vol. 25, Issue 1-2, 2001, pp. 3-22.

[25] N. P. Tedford, J. R. R. A. Martins, Benchmarking Multidisciplinary Design Optimization Algorithms, Optimization and Engineering, Vol. 11, Issue 1, February 2010, pp. $159-183$. 
[26] S. I. Yi, J. K. Shin, G. J. Park, Comparison of MDO Methods With Mathematical Examples, Structural Multidisciplinary Optimization, Vol. 35, Issue 5, 2008, pp. 391-402.

[27] K. Behdinan, R. E. Perez, H. T. Liu, Multidisciplinary Design Optimization of Aerospace Systems, Canadian Design Engineering Network Conference, Kaninaskis, Alberta, 18-20 July 2005.

[28] R. S. Sellar, S. M. Batill, J. E. Renaud, Response Surface Based, Concurrent Subspace Optimization for Multidisciplinary System Design, AIAA $34^{\text {th }}$ Aerospace Sciences Meeting and Exhibit, Reno, Nevada, 15-18 January 1996.

[29] J. Sobieszczanski-Sobieski, J. S. Agte, R. R. Sandusky Jr., Bi-Level Integrated System Synthesis (BLISS), National Aeronautics and Space Administration Technical Manual NASA/TM-1998-208715, August 1998.

[30] G. N. Vanderplaats, Numerical Optimization Techniques for Engineering Design Third Edition, Vanderplaats Research \& Development Inc. 2005.

[31] A. J. Keane, P. B. Nair, Computational approaches for aerospace design: the pursuit of excellence, John Wiley \& Sons, July 2005.

[32] R. J. Balling, D. T. Clark, A Flexible Approximation Model for Use With Optimization, $4^{\text {th }}$ Symposium on Multidisciplinary Analysis and Optimization, 1992.

[33] L. A. Schmit, Structural synthesis - Its genesis and development, AIAA Journal, Vol. 19, Issue 10, October 1981.

[34] M. R. Betker, J.S. Fernando, S.P. Whalen, The History of the Microprocessor, Bell Labs Technical Journal, Vol. 2, Issue 4, 1997, pp. 29-56. D. Allerton, Principles of Flight Simulation, Chichester: John Wiley \& Sons, 2009 
Source System Architecture for the Fast Designing and Prototyping of Autonomous MultiUAV Systems: Simulation and Experimentation, Journal of Intelligent and Robotic Systems: Theory and Applications, 2015

J. B. Chaudron, D. Saussie, P. Siron, M. Adelantado, Real-time Distributed Simulations in an HLA Framework: Application to Aircraft Simulation, Simulation: Transactions of the Society for Modeling and Simulation International, Vol. 90, Issue 6, 2014, pp. 627-634. using 6DOF Simulation, Proceedings of Institution of Mechanical Engineering Part G: Journal of Aerospace Engineering, Vol. 228, Issue 1, 2013, pp. 7-19.

[39] R. A. Morris, K. B. Venable, J. Lindsey, Simulation to Support Local Search in Trajectory Optimization Planning, 2012 IEEE Aerospace Conference, Big Sky, MT, USA, 3-10 March 2012.

[40] G. G. Gutierrez, J. Alvarez, M. Bandinelli, R. Guidi, V. Martorelli, M. F. Pantoja, M. R. Cabello, S. G. Garcia, HIRF Virtual Testing on the C-295 Aircraft: On the Application of a Pass/Fail Criterion and the FSV Method, IEEE TRANSACTIONS ON ELECTROMAGNETIC COMPATIBILITY, 562014 pp. 854-863.

[41] M. Baarspul, A Review of Flight Simulation Techniques, Progress in Aerospace Sciences, Vol. 27, 1990, pp. 1-120.

[42] S. Jennings, L. D. Reid, R. V. Kruk, Time Delays in Visually Coupled Systems During Flight Test and Simulation, Journal of Aircraft, Vol. 41, No. 6, November 2004 
Flight Simulator, AIAA Modeling and Simulation Technologies Conference and Exhibit, Denver, Colorado, 14-17 August 2000

[44] L. N. Wu and Y. P. Sun, Development of a Low-Cost Flight Simulation Training Device for Research and Education, $2^{\text {nd }}$ International Conference on Intelligent Technologies and Engineering Systems, Kaohsiung, Taiwan, 12-14 December 2013

[45] F. Holzapfel, I. Sturhan, G. Sachs, Low-Cost PC Based Flight Simulator for Education and Research Proc. AIAA Modeling and Simulation Technologies Conference and Exhibit, Monterey, California, 5-8 August 2002

[46] R. W. Deters, G. A. Dimock, M. S. Selig, Icing Encounter Flight Simulator, Journal of Aircraft, Vol. 43, No. 5, September 2006

[47] R. S. Burns, M. M. Duquette, J. B. Howerton, R. J. Simko, Development of a Lowcost Simulator for Demonstration and Engineer Training, AIAA Modeling and Simulation Technologies Conference and Exhibit, Austin, Texas, 11-14 August 2003

[48] G. Williams, K. Lawrence R. Weeks, Modeling and Simulation Technologies: Reconfigurable Flight Simulators in Modeling and Simulation, AIAA Modeling and Simulation Technologies Conference and Exhibit, Providence, 16-19 August 2004 O. Kwon, J. Chung, H. U. Park, Development and Application of a Reconfigurable Engineering Flight Simulator at Ryerson University, The Journal of Instrumentation, Automation and Systems, Vol. 2, No. 1, 2015, pp. 22-30

[50] L. C. Boyer, Introducing Parks College Reconfigurable Engineering Simulator, AIAA Flight Simulation Technologies Conference, San Diego, 29-31 July 1996, pp. 565572. 

Intelligent and Robotic Systems: Theory and Applications, Vol. 57, 2010, pp. 393-406. of Aircraft Parameters Using Fourier Transform Regression, Proceedings of 2014 IEEE Chinese Guidance, Navigation and Control Conference, Yantai, China, Aug. 8-10, 2014.

A. Bittar, N. M. F. de Oliveria, H.V. de Figueiredo, Hardware-In-the-Loop Simulation with X-Plane of Attitude Control of a SUAV Exploring Atmosheric Conditions, Journal of Intelligent and Robotic Systems: Theory and Applications, Vol. 73, 2014, pp. 271-287.

Forced Landing of a UAS, Journal of Intelligent and Robotic Systems: Theory and Applications, Vol. 73, 2014, pp. 635-653.

A. Bittar, N. M. F. de Oliveira, Central Processing Unit for an Autopilot: Description and Hardware-In-the-Loop Simulation, Journal of Intelligent and Robotic Systems: Theory and Applications, Vol. 70, 2013, pp. 557-574.

[56] MATLAB, http://www.mathworks.com.

[57] Understanding the Expedition E350, http://www.northwestbackcountryaircraft.com/pdf/e350specs.pdf.

[58] J. D. Anderson, Aircraft performance and design, McGraw-Hill, 1999.

[59] J. D. Anderson, Fundamentals of aerodynamics, Fifth edition, McGraw-Hill, 2009.

[60] B. Etkin, L. D. Reid, Dynamics of flight: Stability and control, Third edition, John Wiley \& Sons, 1995. 
[61] D. P. Raymer, Aircraft Design: a Conceptual Approach, Fifth edition, American Institute of Aeronautics and Astronautics Inc., 2012.

[62] R. C. Nelson, Flight stability and automatic control, Second edition, McGrawHill, 1998.

[63] M. Hepperle, JavaFoil User's Guide (http://www.mh-aerotools.de), Mar. 2014.

[64] Found Aircraft Canada Inc, Pilot's Operating Handbook FBA-2C3 Expedition E350, April 2012.

[65] M. G. Perhinschi, M. R. Napolitano, Using Flight Simulation for Flight Dynamics and Control Education Enhancement, AIAA Atmospheric Flight Mechanics Conference and Exhibit, Hilton Head, South Carolina, 20-23 August 2007.

[66] Flightgear Flight Simulator | sophisticated, professional, open-source, www.flightgear.org.

[67] FlightSIM | Fixed Wing Flight Simulation Software | PRESAGIS, http://www.presagis.com/products_services/products/modelingsimulation/simulation/flightsim/. 